\title{
LOS EFECTOS GEOECOLÓGICOS DEL CAMBIO GLOBAL EN EL PIRINEO CENTRAL ESPAÑOL: UNA REVISIÓN A DISTINTAS ESCALAS ESPACIALES Y TEMPORALES
}

\section{Geo-ecological effects of Global Change in the Central Spanish Pyrenees: A review at different spatial and temporal scales}

\author{
José M. García-Ruiz ${ }^{*}$, Juan I. López-Morenoํㅜㄹ Teodoro Lasanta ${ }^{1}$, Sergio M. Vicente-Serrano ${ }^{1}$, Penélope \\ González-Sampériz ${ }^{1}$, Blas L. Valero-Garcés ${ }^{1}$, Yasmina Sanjuán ${ }^{1}$, Santiago Beguería² ${ }^{2}$ Estela Nadal-Romero³ \\ Noemí Lana-Renault ${ }^{4}$ y Amelia Gómez-Villar ${ }^{5}$ \\ 'Instituto Pirenaico de Ecología, CSIC, Campus de Aula Dei, Apartado 13.034, 50.080-Zaragoza, España. humberto@ipe.csic.es \\ ${ }^{2}$ Estación Experimental de Aula Dei, CSIC, Campus de Aula Dei, Apartado 13.034, 50.080-Zaragoza, España. \\ ${ }^{3}$ Institute for Biodiversity and Ecosystem Dynamics. Earth Surface Science Research Group, University of Amsterdam, 1098XH-Amsterdam,The Netherlands. \\ ${ }^{4}$ Área de Geografía Física, Departamento de Ciencias Humanas y Sociales, Universidad de La Rioja, 26.004-Logroño, España. \\ ${ }^{5}$ Departamento de Geografía y Geología, Facultad de Filosofía y Letras, Universidad de León, Campus de Vegazana, 24.071-León, España. \\ *Autor corresponsal
}

Recibido: 03-03-2015. Aceptado: 08-04-2015. Fecha de publicación on-line: 09-10-2015.

Citation / Cómo citar este artículo: García-Ruiz, J. M., López-Moreno, J. I., Lasanta, T., Vicente-Serrano, S. M., González-Sampériz, P., Valero-Garcés, B. L., Sanjuán, Y., Beguería, S., Nadal-Romero, E., Lana-Renault, N. y Gómez-Villar, A. (2015). Los efectos geoecológicos del cambio global en el Pirineo Central español: una revisión a distintas escalas espaciales y temporales. Pirineos, 170, e012. doi: http://dx.doi.org/10.3989/Pirineos.2015.170005

RESUMEN: Se revisan los efectos de la evolución del clima y los cambios de uso del suelo / cubierta vegetal en el Pirineo Central español a diferentes escalas espaciales y temporales. Los estudios paleoclimáticos, basados en análisis multiproxy de sedimentos lacustres, glaciares, espeleotémicos y registros dendrológicos, entre otros, han demostrado la ocurrencia de importantes fluctuaciones climáticas durante la deglaciación de finales del Pleistoceno Superior y durante el Holoceno, afectando a la distribución de la vegetación, la generación de escorrentía, la frecuencia de avenidas y las formas de organización del espacio por parte de las sociedades humanas, en particular durante el evento 8.2, la Edad del Bronce, la Anomalía Climática Medieval y la Pequeña Edad del Hielo. El estudio del impacto de las actividades humanas sobre la dinámica del paisaje en el último siglo y medio ha revelado cambios espectaculares en la estructura y distribución de la vegetación, tanto en el piso montano como en el subalpino y, consecuentemente, cambios en la generación de escorrentía, la intensidad de la erosión del suelo y las fuentes de sedimento, cualquiera que sea la escala espacial a la que se contempla el problema. De forma general puede afirmarse que a mediados del siglo XIX se alcanza la máxima presión sobre el territorio, cultivándose todas las laderas posibles hasta una altitud aproximada de 1650 m s.n.m. y empleando frecuentemente el fuego para limitar la expansión de matorrales en zonas de pastos, lo que dio lugar a intensos procesos de erosión y degradación del suelo, y al desarrollo de ríos trenzados con una elevada torrencialidad. Posteriormente, el abandono de tierras de cultivo desde comienzos del siglo xx (y, en especial, desde la década de 1960) y el descenso de la presión ganadera han favorecido la revegetación de las antiguas áreas de cultivo y pastos bien por avance de formaciones naturales de matorral y bosque, bien por la reforestación artificial de extensas laderas, ascendiendo el treeline en el piso subalpino, en este último caso 
ayudado además por el incremento de la temperatura. Las consecuencias más destacadas de esta evolución han sido: (i) el descenso sostenido del caudal de los ríos pirenaicos desde la década de 1970 debido al aumento de la evapotranspiración; (ii) la contracción espacial de las áreas fuente de sedimento; (iii) la creciente desconexión entre laderas y cauces; (iv) el peso decreciente de la nieve en el régimen de los ríos pirenaicos, con un adelanto en la ocurrencia del momento de aguas altas primaverales; (v) los cambios en la dinámica de llenado de los embalses que han obligado a introducir nuevos patrones de gestión de los embalses; y (vi) la incisión de los cauces fluviales en su propia llanura aluvial. Los estudios llevados a cabo en el Pirineo Central durante las tres últimas décadas sobre el Cambio Global y sus consecuencias confirman la complejidad de las interacciones que se producen en los sistemas naturales y la rápida respuesta de la vegetación, la generación de escorrentía y la erosión frente a variaciones del clima y las actividades humanas.

PALABRAS CLAVE: Cambio Global; Paleogeografía; generación de escorrentía; erosión; morfología fluvial; abandono de tierras; colonización vegetal.

\begin{abstract}
We review the effects of climate variability and land use / land cover changes in the Central Spanish Pyrenees at different spatial and temporal scales. Paleoclimatic studies based upon multi-proxy analyses of lacustrine, glacial and speleothematic deposits, among others, have demonstrated the occurrence of intense climatic fluctuations not only during the Late Upper Pleistocene associated to deglaciation, but also during the Holocene, affecting plant cover distribution, runoff generation, flood frequency, and the spatial organization of human activities, particularly during the 8.2 event, the Bronze Age, the Medieval Climatic Anomaly and the Little Ice Age. The study of the impact of human activity on landscape dynamics during the last 150 years has revealed dramatic changes in plant cover structure and distribution, in both the montane and the sub-alpine belts and, consequently, changes in runoff generation, soil erosion intensity, and sediment sources, whatever the spatial scale used. In general, the maximum human pressure on the territory was reached during the middle of the 19th century, with the cultivation of most of the south-facing slopes up to approximately $1650 \mathrm{~m}$ a.s.l., and the frequent use of fire to control shrub colonization, resulting in intense soil erosion and degradation processes, as well as the development of braided rivers with a high torrentiality. Farmland abandonment since the beginning of the 20th century (and, particularly, since the 1960s) and the declining livestock pressure have favoured plant recolonization, with the expansion of shrubs and forests in the old cultivated and grazing areas, the human-induced reforestation of large hillslopes, and the treeline upward in the subalpine belt, in this latter case with the contribution of climate warming. The most outstanding consequences of such an evolution have been: (i) the sustained decline of discharge in the Pyrenean rivers since the 1970s because of increasing actual evapotranspiration; (ii) the spatial shrinkage of sediment source areas; (iii) the increasing uncoupled geomorphic dynamics between hillslopes and channels; (iv) the decreasing importance of snow accumulation and snowmelt processes in the fluvial regime of the Pyrenean rivers, with earlier onset of the high spring discharges; (v) the changes in reservoir hydrological dynamics and the need for new management policies; and (vi) the increasing scouring processes that affect most of the Pyrenean rivers. The studies carried out on Global Change and its consequences in the Central Pyrenees confirm the extreme complexity of interactions occurring in the natural systems, and the quick response of plant cover, runoff generation and soil erosion as a consequence of climatic and land use changes.
\end{abstract}

KEYWORDS: Global Change; Paleogeography; runoff generation; erosion; fluvial morphology; land abandonment; plant colonization.

\section{Introducción}

La ocurrencia de grandes cambios ambientales relacionados con las fluctuaciones climáticas y con la actividad humana se conoce como Cambio Global (Vitousek et al., 1997; Steffen et al., 2004; Dearing et al., 2006) y representa un nuevo escenario en las relaciones entre las sociedades humanas y el medio ambiente. Antes de que la presencia humana en la Tierra iniciase una transformación profunda del paisaje mediante la deforestación, la agricultura y las actividades ganaderas, la organización espacial de los paisajes y su funcionalidad estaba controlada por factores ambientales que interactuaban de manera más o menos compleja (Goudie, 1981), siendo el clima y los procesos geomorfológicos los dos fac- tores de control principales. Dado que el relieve varía muy lentamente en el tiempo, los cambios en la vegetación, la generación de escorrentía y la erosión estaban esencialmente condicionados por sus mutuas interacciones y la variabilidad climática. Es evidente que los primeros pobladores tuvieron una escasa capacidad para intervenir el paisaje, tanto por su bajo número como por sus limitaciones tecnológicas, aunque no deben excluirse transformaciones notables a escala local por la utilización intencionada del fuego (por ej., Vannière et al., 2001; Galop et al., 2002; Miras et al., 2007). Hoy se conoce relativamente bien la evolución experimentada por muchas regiones del planeta. Así, en las zonas de montaña mediterránea (como es el caso del Pirineo Central español) el incremento demográfico desde el Neolítico 
produjo una creciente presión sobre los recursos naturales, lo que ha dado lugar a una progresiva expansión de las áreas cultivadas (Lasanta, 1989) y a un aumento del pastoreo (García Ruiz \& Balcells, 1978), causando deforestaciones en los diferentes pisos altitudinales y provocando cambios importantes en la generación de escorrentía y los procesos de erosión (Montserrat, 1992; García-Ruiz \& Valero-Garcés, 1998). Este aumento demográfico en el Pirineo fue constante hasta mediados del siglo XIX y ocurrió acompañado de fluctuaciones climáticas de cierta envergadura (Morellón et al., 2012; Moreno et al., 2012), que han podido influir sobre las actividades humanas $\mathrm{y}$, sobre todo, en la dinámica de procesos hidromorfológicos. Es seguro que en algunas montañas mediterráneas, si no en todas, ha habido avances y retrocesos en la ocupación del territorio, tanto a escala local como regional, debido a la inestabilidad política y a eventos naturales de gran magnitud. La actual, desde hace aproximadamente un siglo, es una etapa caracterizada por un notable abandono en la mayor parte de esas montañas (García-Ruiz \& Lana-Renault, 2011; Lasanta, 2014), coincidiendo con un aumento de la temperatura y con cambios paisajísticos (Gottfried et al., 2012), hidrológicos y geomorfológicos de notable envergadura.

Los cambios observados han producido consecuencias muy importantes desde una perspectiva hidrológica y geomorfológica (Catalán et al., 2013; García-Ruiz et al., 2013a; Valero-Garcés et al., 2013). Debe tenerse en cuenta, por ejemplo, que el caudal de los ríos mediterráneos se genera fundamentalmente en las áreas de montaña, que tienden a comportarse como islas de humedad rodeadas de ambientes sub-húmedos o semiáridos. Esto convierte a las regiones de montaña en espacios críticos desde un punto de vista hidrológico, de manera que los cambios que se producen en ellas afectan a la cantidad y calidad del agua que llevan los ríos (Viviroli et al., 2003, 2011). Esto es particularmente importante porque, al margen de las montañas, las cuencas hidrográficas del entorno mediterráneo apenas tienen capacidad para producir escorrentía, excepto (y aún así, limitadamente) en periodos de lluvias prolongadas y de cierta intensidad. Se da asimismo la paradoja de que, en contraste con las cabeceras montañosas productoras de agua, las tierras bajas son consumidoras de abundantes recursos hídricos en centros urbanos, complejos industriales y, especialmente, grandes perímetros regados. Algunos de estos últimos ocupan decenas de miles de hectáreas, como es el caso de Bardenas, Monegros o los Llanos de Urgel en España, y contienen algunos de los cultivos con los consumos de agua más elevados por unidad de superficie en el mundo (García-Ruiz et al., 2003a). Debemos considerar, pues, que la forma de explotación y gestión de las áreas de montaña y la manera en que se organiza su espacio puede afectar a territorios mucho más extensos, que incluyen la montañas y las tierras bajas, y pueden condicionar la calidad de vida y la capacidad para generar riqueza más allá de los límites de las montañas.

Desde hace más de 30 años el Instituto Pirenaico de Ecología trabaja para interpretar la evolución de los paisajes y su dinámica con una perspectiva lo más integrado- ra posible. Numerosas investigaciones se han enfocado a conocer el impacto de las actividades humanas sobre la vegetación e indirectamente sobre los recursos hídricos y la erosión del suelo. Esta última, en particular, se consideró entonces un tema clave por su dependencia de numerosos factores, entre ellos y muy especialmente los humanos, permitiendo una aproximación global al estudio de procesos geomorfológicos (García-Ruiz, 2015). También era clave como indicador del estado de conservación de los sistemas naturales, por su implicación en otros aspectos geomorfológicos e hidrológicos y por su importancia general para la conservación a largo plazo de los recursos en montaña. Después, se iniciaron estudios en profundidad que complementaban a otros anteriores sobre la evolución paleoambiental de los paisajes pirenaicos y la gran influencia ejercida por los cambios climáticos de finales del Pleistoceno y del Holoceno, para finalizar en los numerosos trabajos que se han llevado a cabo sobre las tendencias climáticas e hidrológicas más recientes, la ocurrencia de eventos extremos y los cambios de uso y cubiertas del suelo. Este trabajo es una revisión de los conocimientos más destacados acerca de la influencia de las fluctuaciones climáticas y las actividades humanas sobre la dinámica geomorfológica e hidrológica a distintas escalas espaciales y temporales, como ejemplo de la complejidad de las interacciones que ocurren en los sistemas naturales de un área de montaña mediterránea como el Pirineo Central español.

\section{El área de estudio}

Los Pirineos son una gran cadena montañosa alargada de oeste a este, con más de 450 kilómetros de longitud y más de $100 \mathrm{~km}$ de anchura en su sector central, en el que son muy frecuentes altitudes por encima de $2500 \mathrm{~m}$ s.n.m. La cordillera culmina en el Pico de Aneto (3404 m), en la cabecera del valle del Ésera, y cuenta con dos núcleos más elevados en torno a los macizos de Monte Perdido y de Posets, con numerosos picos por encima de $3000 \mathrm{~m}$ (Figura 1). Básicamente la cordillera se ha formado en dos grandes periodos tectónicos, la orogenia varisca, a finales de la era Primaria, y la orogenia alpina, durante gran parte de la era Terciaria. Entre ambas predominó un largo periodo de relativa calma, con sedimentación marina durante la era Secundaria y comienzos de la Terciaria (Eoceno). La tectónica alpina ocurrió en varias fases que permitieron la sedimentación de materiales continentales en grandes surcos y depresiones internas, fundamentalmente de edad oligocena. Posteriormente, la erosión hídrica, los deslizamientos profundos y superficiales y el modelado glaciar a lo largo de millones de años desde mediados del Mioceno han configurado la cordillera tal como la conocemos en la actualidad, pudiendo distinguirse en su sector central, entre los ríos Aragón y Noguera Ribagorzana, grandes complejos morfoestructurales. Estos últimos se identifican por los estilos tectónicos dominantes, la litología y el modelado y se organizan de norte a sur de la siguiente manera: 


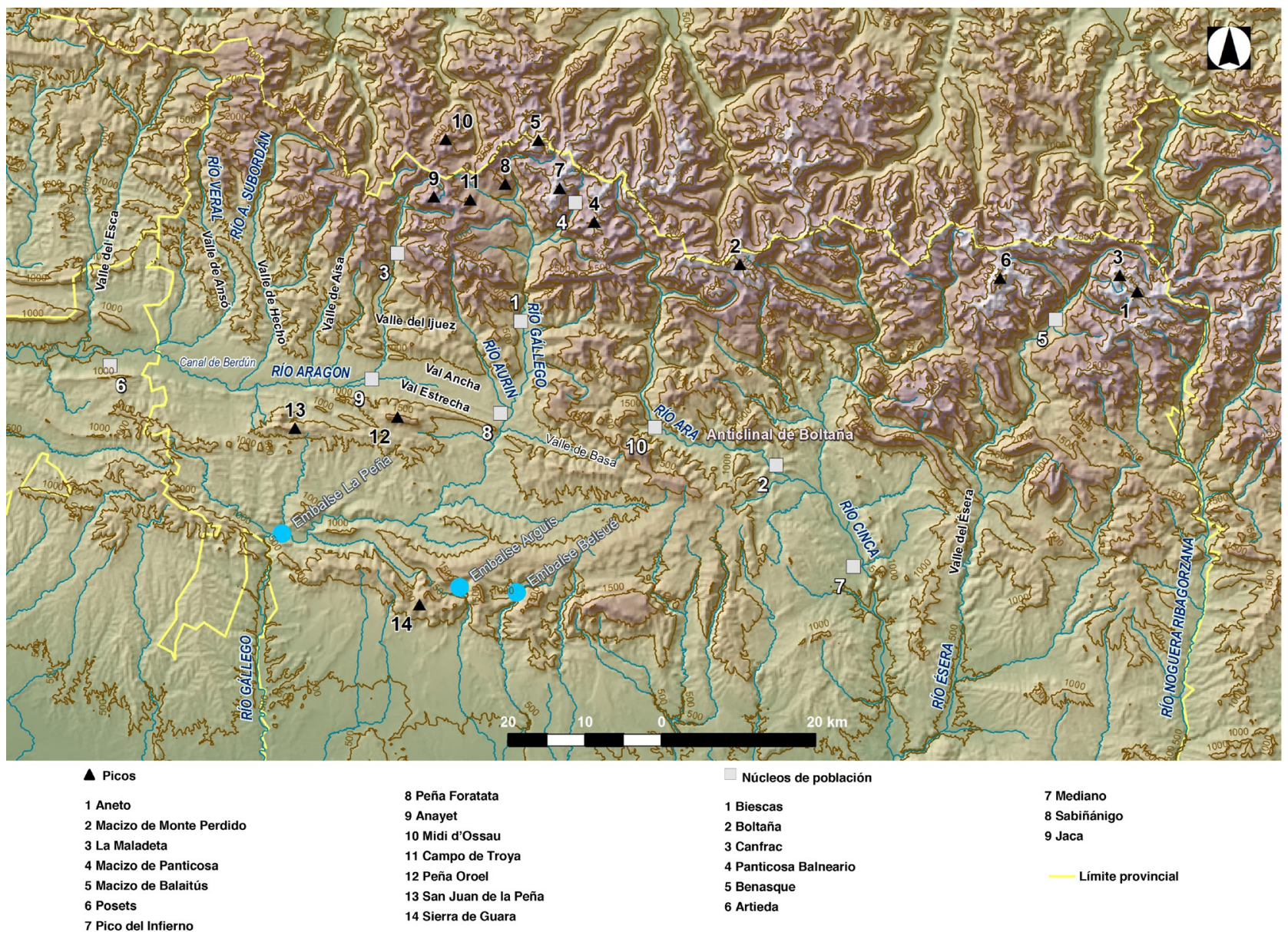

Figura 1: El área de estudio. Se indica la localización de los principales macizos, picos, ríos y localidades citados en el texto dentro de los límites del Pirineo aragonés.

Figure 1: Study area. The location of the main mountain massifs and peaks, rivers and sites cited in the text is shown.

(i) El Pirineo Axial se formó durante la orogenia varisca, aunque fue posteriormente deformado por el plegamiento alpino. Ocupa el eje de la cordillera y está formado por materiales paleozoicos, fundamentalmente pizarras, esquistos, cuarcitas y, en menor medida, calizas. Estos materiales fueron atravesados por batolitos graníticos, como los de Panticosa, Balaitus, Posets y Maladeta, dando lugar a una aureola de metamorfismo de contacto (Marmolera del Infierno, en el Macizo de Panticosa, por ejemplo). Los batolitos graníticos, de edad carbonífera, forman macizos de formas alomadas muy afectados por el glaciarismo cuaternario. En general las pizarras dan lugar a relieves suaves que evolucionan por deslizamientos profundos, mientras las calizas han evolucionado hacia pequeños macizos aislados que destacan por su resistencia a la erosión (Peña Foratata, en Sallent de Gállego). Quedan algunos restos de volcanismo paleozoico que también destacan en el relieve, como Anayet y Campo de Troya en la cabecera del valle del Gállego. De edad similar es la gran caldera volcánica del Midi d'Ossau, ya en la vertiente francesa.

El Pirineo Axial muestra una cierta discontinuidad, apareciendo en las cabeceras de los ríos Aragón, Gállego y Ara, se interrumpe en el Macizo de Monte Perdido y vuelve a aparecer en la cabecera de los ríos Cinca, Ésera y Noguera Ribagorzana.

(ii) Las Sierras Interiores son una banda estrecha y alargada en sentido W-E o WNW-ESE. Están formadas por materiales continentales del Trías (lutitas y conglomerados) y marinos del Cretácico (calizas, calizas margosas y areniscas) y el Eoceno (calizas) desplazados hacia el sur en forma de cabalgamientos o mantos de corrimiento durante el plegamiento alpino. En general las Sierras Interiores, vistas desde el sur, se manifiestan como una gran muralla abrupta, intensamente deformada en varios anticlinales tumbados, vergentes hacia el sur, con complejos escarpes verticales (Figura 2). A veces los anticlinales aparecen apilados unos sobre otros hasta formar una gran acumulación de materiales calizos, como sucede en el Macizo de Monte Perdido (3355 m). En su vertiente norte son aún más abruptas, dominadas por la presencia de grandes circos glaciares y canales de aludes activos. Las Sierras son muy estrechas en su sector más occidental (valles de Ansó, Hecho, Aragüés, Aísa, Aragón y Gállego), alcanzan una notable anchura en su sector central 


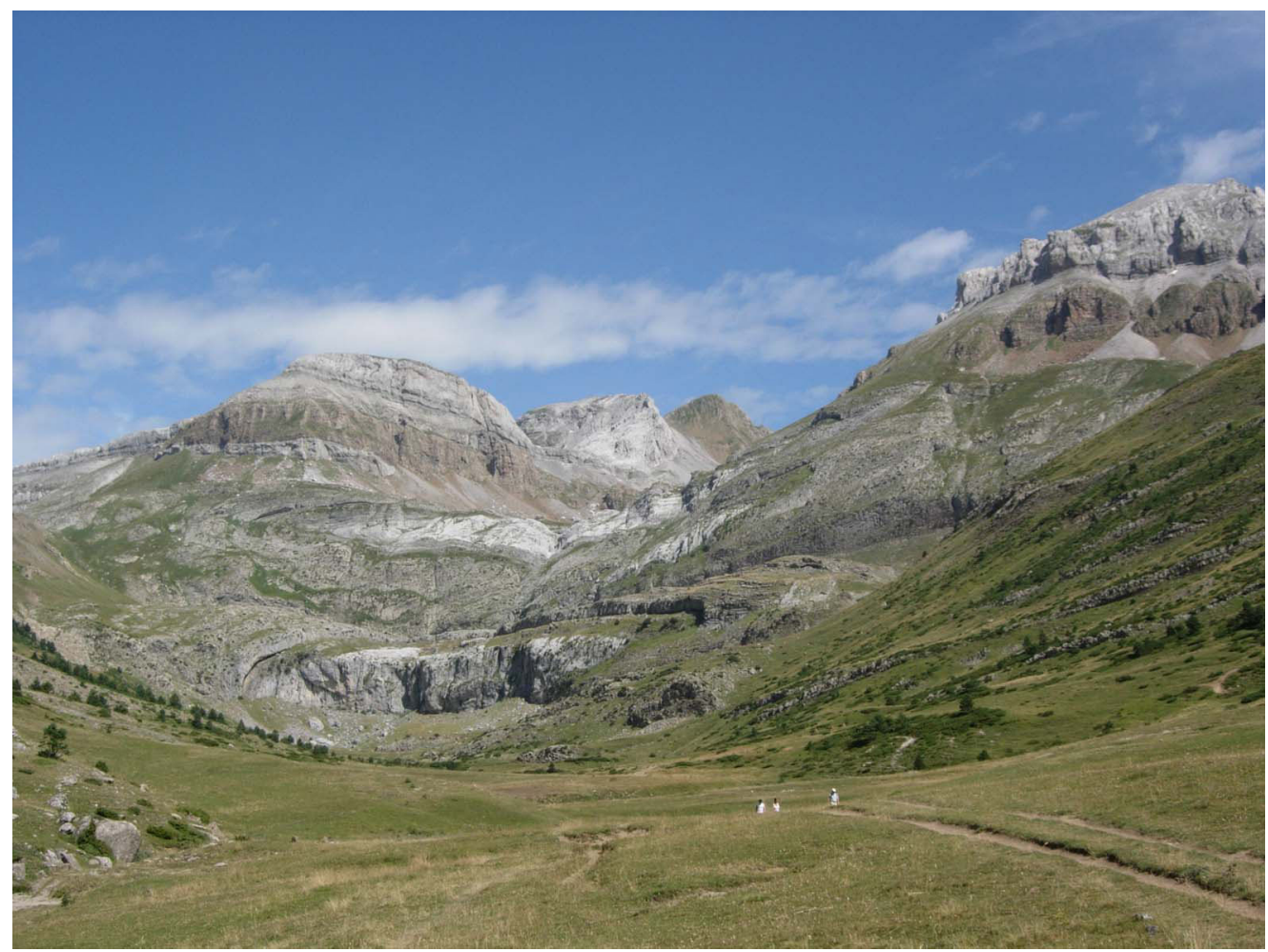

Figura 2: Cabecera del Valle de Aísa (cuenca del río Estarrún), mostrando el frente abrupto de dos anticlinales tumbados correspondientes a las Sierras Interiores.

Figure 2: The Aisa Valley headwaters (Estarrún River basin) in the Inner Ranges. Note the presence of two recumbent anticlines in the forefront.

(valles del Ara y del Cinca) y adelgazan de nuevo hacia el valle del Noguera Ribagorzana.

(iii) El Sector del Flysch está formado masivamente por la alternancia de areniscas y margas en estratos de escala centimétrica, dando lugar a una estructura hojaldrada que alcanza unos $5000 \mathrm{~m}$ de potencia. La delgadez de los estratos explica la facilidad con que se deforman, dando lugar a estructuras plegadas extraordinariamente complejas que, sin embargo, pocas veces se expresan en el relieve. Este último se caracteriza por el predominio de divisorias alomadas que descienden hacia el sur y que corresponden a antiguos niveles de erosión pre-cuaternarios, mientras las laderas muestran rasgos de una regularización quizás periglaciar, con un coluvión pedregoso que las recubre insistentemente. Sólo cuando aparecen unos estratos calizos intercalados dentro del flysch se muestra la estructura de pliegues sinuosos, con estratos levantados en vertical para dar lugar a las únicas formas abruptas dentro del flysch (Soler \& Puigdefábregas, 1972). En las cumbres apenas hay rasgos de glaciarismo, pero los glaciares cuaternarios desarrollaron en el Sector del Flysch sus cubetas terminales, como la de Hecho (García-Ruiz \& Martí-Bono, 2011), Aragón (García-Ruiz et al., 2013b), Gállego (Lewis et al., 2009) y Ara.

(iv) La Depresión Interior Altoaragonesa está formada por las margas grises o azules del Eoceno (fm. Pamplona), entre las que aparecen algunos estratos de areniscas que pueden tener un notable significado en el relieve. En general, la Depresión Interior Altoaragonesa es una sucesión de valles alineados de oeste a este e interrumpidos ocasionalmente por otros materiales plegados (el anticlinal de Boltaña, por ejemplo). Destaca, sobre todo la Canal de Berdún, que continúa hasta Pamplona y es drenada por el valle del río Aragón, la Val Ancha y la Val Estrecha, entre Jaca y Sabiñánigo, prolongándose hacia el este por el más estrecho valle del Basa, la Ribera de Fiscal en el valle del Ara, los llanos de Aínsa y Tierrantona (valle del Cinca) y la Depresión de Campo (valle del Ésera). En todos los valles y depresiones, el relieve se caracteriza por la presencia de espacios abiertos debido a la facilidad de la erosión en las rocas margosas, con una serie de glacis y terrazas escalonados. La erosión actual se manifiesta por la presencia de áreas dominadas por cárcavas muy activas.

(v) Las Sierras Exteriores son la avanzadilla del Pirineo hacia la Depresión del Ebro. Pueden definirse como un anticlinal (o mejor, anticlinorio) desplazado hacia el sur, intensamente deformado y con frecuencia fallado en su frente meridional, dando lugar a un pliegue cabalgante que a veces se superpone o afecta a los conglomerados terciarios de la Depresión del Ebro. Forman una banda muy estrecha en su sector occidental (Sierra de Santo Domingo) y se ensanchan hacia el este, alcanzando su máxima anchura en la Sierra de Guara, donde se registra la 
mayor altitud $(2077 \mathrm{~m})$. No es infrecuente la presencia de pliegues en sentido norte-sur que desdibujan la continuidad del anticlinorio y que son anteriores al pliegue oesteeste. Calizas y areniscas de origen marino constituyen la base litológica de las Sierras Interiores, con una franja muy estrecha de margas eocenas de presencia irregular en el borde norte, donde se asientan algunos embalses de pequeñas dimensiones (Arguís, La Peña, Belsué).

(vi) Las molasas prepirenaicas son sedimentos continentales depositados entre las margas de la Depresión Interior Altoaragonesa y las Sierras Exteriores. Por lo tanto, son posteriores al momento álgido de la tectónica alpina e inmediatamente anteriores a los últimos empujes de esa tectónica. Las molasas, de edad oligocena, tienen origen fluvial y deltaico, formadas por areniscas, arcillas y conglomerados, estos últimos en su borde norte, donde dan lugar a relieves resaltados a modo de sinclinales colgados muy resistentes a la erosión (macizos de Oroel y San Juan de la Peña). Hacia el este los conglomerados ocupan mayor extensión (valle del Ésera). En general las molasas están deformadas en sinclinorio, destacando el valle del Guarga, donde el relieve tiene un marcado carácter estructural en cuestas con amplios reversos y abruptos frentes.

En el Pirineo Central español la distribución de temperaturas y precipitaciones está condicionada por la altitud y la mayor o menor proximidad al océano atlántico y al mar mediterráneo. El descenso progresivo de altitud hacia el sur explica la existencia de un gradiente muy marcado en sentido norte-sur, al que se suma otro gradiente en sentido oeste-este debido a la progresiva pérdida de influencia atlántica y la mayor presencia de factores mediterráneos o mediterráneo-continentales. La temperatura media anual desciende hacia el norte, con un gradiente térmico medio en torno a $0,6^{\circ} \mathrm{C}$ cada 100 metros. En Biescas ( 875 m s.n.m.) la temperatura media anual es $11^{\circ} \mathrm{C}$, y en Sallent de Gállego (1305 m s.n.m.) de $8,2^{\circ} \mathrm{C}$. Hacia el sur, en la Depresión Interior la temperatura asciende ligeramente hacia el oeste debido al descenso de la altitud (Artieda, $12^{\circ} \mathrm{C}$, Jaca, $11,4^{\circ} \mathrm{C}$, Sabiñánigo, $11^{\circ} \mathrm{C}$ ), aunque los inviernos se caracterizan por frecuentes inversiones térmicas (Puigdefábregas, 1970). Más al norte los valores térmicos medios descienden rápidamente, más en el sector occidental que en el oriental: Canfranc, $8,7^{\circ} \mathrm{C}$, Panticosa-Balneario, $6,2^{\circ} \mathrm{C}$, Benasque, $10^{\circ} \mathrm{C}$. Temperaturas medias anuales inferiores a $0^{\circ} \mathrm{C}$ son esperables en los macizos más elevados, como estimó Rijckborst (1967) en el alto valle del río Ésera. La isoterma anual de $0{ }^{\circ} \mathrm{C}$ fue situada en 2726 m s.n.m. por del Barrio et al. (1990).

Las precipitaciones siguen un gradiente inverso, aunque su distribución espacial es más compleja que la de las temperaturas debido a su relación con la rugosidad orográfica y con la exposición frente a los vientos portadores de humedad. Aunque es difícil cuantificar la precipitación en las áreas más elevadas de la cordillera, éstas podrían recibir más de $2500 \mathrm{~mm}$ anuales (Rijckborst, 1967). Sin embargo, la mayor parte de las estaciones meteorológicas se refieren generalmente a localidades situadas en fondos de valle. Así, en Benasque
(1138 m s.n.m.) el total estimado anualmente es de 1182 mm; en Canfranc (1260 m s.n.m.), 1858 mm, y en Panticosa-Balneario (1650 m s.n.m.), 1576 mm. En la Depresión Interior el brusco descenso del relieve se manifiesta en unos valores de precipitación sensiblemente más bajos: $717 \mathrm{~mm}$ en Artieda (620 m s.n.m.); $873 \mathrm{~mm}$ en Jaca (820 m s.n.m.); 986 mm en Boltaña (634 m s.n.m.); y 864 mm en Mediano (504 m s.n.m.).

La distribución estacional de las precipitaciones muestra notables diferencias espaciales. (i) En las localidades más occidentales (valles del Esca, Veral y Aragón Subordán) el máximo se produce en otoño, con un máximo secundario muy próximo en invierno, mientras el verano registra los valores más bajos. Sin embargo, no puede hablarse de aridez, excepto en el sector más occidental de la Depresión Interior. (ii) En la Depresión Interior, valle del Gállego y cabecera del valle del Ara los máximos son equinocciales, casi siempre otoñales, presentando la primavera un máximo secundario. (iii) Más al este, en la cuenca inferior del Ara y las cuencas del Cinca, Ésera y Noguera Ribagorzana, la primavera cobra una creciente importancia, registrando el máximo principal, mientras el otoño recoge el máximo secundario. El invierno pasa a ser la estación más seca, en un ambiente afectado por cierta continentalidad.

La distribución espacial de las precipitaciones está muy afectada por la existencia de barreras orográficas de importancia regional. Así, las Sierras Interiores se comportan como una frontera relativamente nítida entre los ambientes claramente marcados por la influencia oceánica al norte y la penetración de influencias mediterráneas por el sur. Además, la existencia de macizos muy elevados respecto al entorno produce un brusco aumento de la precipitación, definiéndose islotes de humedad que tienden a reproducir la organización del relieve.

La consecuencia más evidente de la existencia de gradientes climáticos y topográficos es la riqueza y variedad biogeográfica de los Pirineos. Simplificando mucho, la distribución de la vegetación desde el frente meridional de las Sierras Exteriores hasta los $2200 \mathrm{~m}$ de los altos valles pirenaicos muestra una sucesión de bosques de carrasca, pino laricio, quejigos, pino silvestre, abetos, hayas y pino negro, cuyos límites entre sí están relacionados tanto con factores topográficos (altitud y umbría/solana, sobre todo) como con la proximidad o alejamiento de la influencia oceánica. Así, las hayas predominan más hacia el oeste y descienden mucho más en altitud en las vertientes umbrías. De igual forma, la presencia de suelos poco potentes puede favorecer localmente la expansión de la carrasca fuera de su ámbito teórico de localización. Por encima de 2000 o $2200 \mathrm{~m}$ los pastos alpinos encuentran su mejor ubicación, mientras que a partir de $2600 \mathrm{~m}$ la vegetación se hace cada vez más escasa debido a la ausencia de suelo, la brevedad del periodo vegetativo y las bajas temperaturas.

La distribución natural de la vegetación ha sido profundamente alterada por las actividades agropecuarias, que han producido un descenso altitudinal generalizado del límite superior del bosque, de manera que antiguas forma- 
ciones forestales han sido sustituidas por pastos subalpinos. En la actualidad se observa una lenta recuperación del bosque hacia sectores más elevados, debido probablemente al descenso de la presión ganadera y eventualmente al aumento de la temperatura en las últimas décadas. Los cambios de paisaje también han sido muy notables por debajo de $1600 \mathrm{~m}$, especialmente en las laderas solanas del Sector del Flysch. Las estimaciones de Lasanta (1989) permiten concluir que en la mayor parte de los valles pirenaicos, por debajo de ese umbral altitudinal se llegó a cultivar al menos entre el 25 y el 30\% de la superficie total. En las áreas más humanizadas del Sector del Flysch y en las molasas prepirenaicas, el paisaje se organizó en un mosaico complejo donde las solanas mostraban una alternancia de campos de cereal, barbechos, laderas de matorral frecuentemente incendiadas y pequeños rodales de quejigos y pino laricio, mientras que las umbrías solían estar ocupadas por bosques de pino silvestre sometidos a talas ocasionales. A lo largo del siglo xx el uso del territorio cambió radicalmente. La mayor parte de las tierras de cultivo se han abandonado en los altos valles pirenaicos, excepto en los fondos de valle, mientras en la Depresión Interior Altoaragonesa y en el Prepirineo los espacios llanos se mantienen en cultivo con cereales y forrajes. Los cultivos cerealistas han sido sustituidos en una proporción elevada por prados de siega, que contribuyen a alimentar al ganado en invierno al haber desaparecido casi por completo la trashumancia descendente (Pascua, 2012). La recolonización vegetal de los antiguos campos de cultivo ha permitido la expansión de formaciones de bosque y matorral, algunas de los cuales han sido favorecidas por plantaciones artificiales, especialmente extensas en los valles de Ijuez y Aurín y en las molasas prepirenaicas.

\section{Métodos}

Para conocer los cambios que han ocurrido en el Pirineo Central español a distintas escalas espaciales y temporales se han empleado métodos muy diversos, que aquí serán expuestos muy sucintamente.

El estudio de cambios ambientales en el pasado, en un rango de miles a decenas de miles de años, se ha basado principalmente en el análisis de sedimentos depositados en lagos glaciares y kársticos, algunos de los cuales se han colmatado recientemente. La extracción de muestras de sedimento de esos lagos ha requerido la utilización de una plataforma flotante con un equipo de perforación, empleando diversos tipos de sondeadores según el sitio y características del material a recuperar: sondeadores de gravedad, de tipo Livingstone, Kullenberg, UWITEC, con camiones de geotecnia, etc. Se ha contado también con perfiladores sísmicos para reconstruir la estructura interna del relleno sedimentario de las cuencas lacustres.

Tras la extracción de los sondeos, el equipo del IPECSIC ha seguido una metodología de análisis multi-proxy (Morellón et al., 2009) que incluye fotografiado del sedimento en alta resolución para ayudar a la caracterización de las facies sedimentarias según protocolos de Schnu- rrenberger et al. (2003); escaneado mediante fluorescencia de rayos X para obtener datos sobre la composición geoquímica; análisis elemental de carbono, nitrógeno y azufre; mineralogía y análisis palinológico. En este último caso, se ha seguido el método químico clásico modificado (Moore et al., 1991; Dupré, 1988), incluyendo concentración en líquido denso y añadiendo Lycopodium clayatum para calcular la concentración polínica. Recientemente, se han utilizado otros indicadores biológicos (quironómidos, diatomeas, ostrácodos) y/o recuento de micro y macro-carbones para reconstruir la dinámica del fuego y la ocurrencia de incendios en el pasado, a escala local y regional (Higuera et al., 2010).

El tratamiento de datos climáticos ha necesitado de la elaboración de una base de datos de precipitaciones y temperaturas a escala diaria a partir de los registros completos mantenidos por la Agencia Estatal de Meteorología. La metodología consiste en un proceso de reconstrucción de series a partir de estaciones vecinas, con la finalidad de agrupar segmentos correspondientes a periodos diferentes; posteriormente las series son sometidas a un control de calidad con la finalidad de identificar registros anómalos, y finalmente se prueba la homogeneidad temporal de las series para eliminar cualquier posible señal no climática en las series. El procedimiento completo puede consultarse en Vicente-Serrano et al. (2010) y El Kenawy et al. (2013).

El estudio de la evolución de los recursos hídricos y su influencia en la gestión de embalses se ha basado en información proporcionada por la Confederación Hidrográfica del Ebro (CHE) del caudal en diversas estaciones de aforo y de volúmenes embalsados, salidas a pie de presa y canales derivados hacia canales de riego (López-Moreno et al., 2004). Dicha información se ha utilizado para realizar análisis de tendencia y comparar el régimen fluvial y la ocurrencia de eventos extremos aguas arriba y aguas abajo de los principales embalses pirenaicos. El estudio del manto nival y su evolución reciente se ha basado en la información disponible por el programa ERHIN (http://www.magrama.gob.es) sobre el espesor y densidad de nieve en 106 balizas colocadas en distintos sectores del Pirineo Central, que se miden habitualmente tres veces al año (enero, marzo y principios de mayo) desde 1986. Esta información se ha relacionado con la temperatura y precipitación de los meses precedentes, lo que ha permitido reconstruir series de las fluctuaciones del manto nival desde el año 1950 (López-Moreno, 2005).

Los estudios sobre la dinámica hidrológica y geomorfológica de laderas y cauces se han apoyado en la experimentación de campo a dos escalas espaciales. Por un lado, en 1991 se procedió a la instalación de la Estación Experimental Valle de Aísa, a 1150 m s.n.m., muy cerca de la localidad de Aísa, en una ladera solana que fue cultivada hasta los años cincuenta del pasado siglo. La estación ha obtenido información sobre la producción de agua y sedimento en diferentes usos del suelo, utilizando para ello parcelas experimentales cerradas con una dimensión de 10x3 m. Los usos del suelo que se tuvieron en cuenta fueron matorral denso, prado de diente, parcela de 
matorral quemado (dos, una quemada en 1992 y otra en 1993 y 2001), campo de cereal con abonado químico, barbecho, campo abandonado tras haber estado cultivado como cereal durante tres años, parcela de cereal bajo sistema nómada (artica, shifting agriculture field) y otra parcela similar que fue abandonada después de dos años de cultivo (artica abandonada, abandoned shifting agriculture field). En la base de cada parcela había un canal que permitía recoger el agua y el sedimento producido durante cada evento de lluvia. El agua se medía automáticamente en un sistema de canjilones conectados a un data logger. Parte de la escorrentía, con su correspondiente sedimento, se almacenaba en unos depósitos que permitían obtener el contenido en sedimento en suspensión y solutos (García-Ruiz et al., 1995; Cerdà \& Lasanta, 2005; Lasanta et al., 2010; Nadal-Romero et al., 2013). La esta- ción se abandonó en 2012 por el progresivo agotamiento del sedimento en algunas parcelas y por el deterioro de sus límites.

Por otro lado, se han instalado cinco cuencas experimentales en diferentes ambientes, con el fin de obtener información lo más natural posible acerca de la producción de agua y sedimento en un gradiente de cubiertas vegetales (Figura 3): (i) En 1996 se monitorizó la cuenca de Arnás (289 ha), en el valle de Borau, que fue cultivada de manera general (umbría y solana) hasta la primera mitad del siglo xx y después abandonada. Desde entonces entró en un proceso de recolonización vegetal. Se asienta sobre sustrato de flysch, entre 900 y $1340 \mathrm{~m}$ s.n.m. (ii) En 1998 se equipó la cuenca de San Salvador, en el Valle de Aísa, con 92 ha cubiertas al completo por un bosque denso de pino silvestre (Pinus sylvestris) y ha-
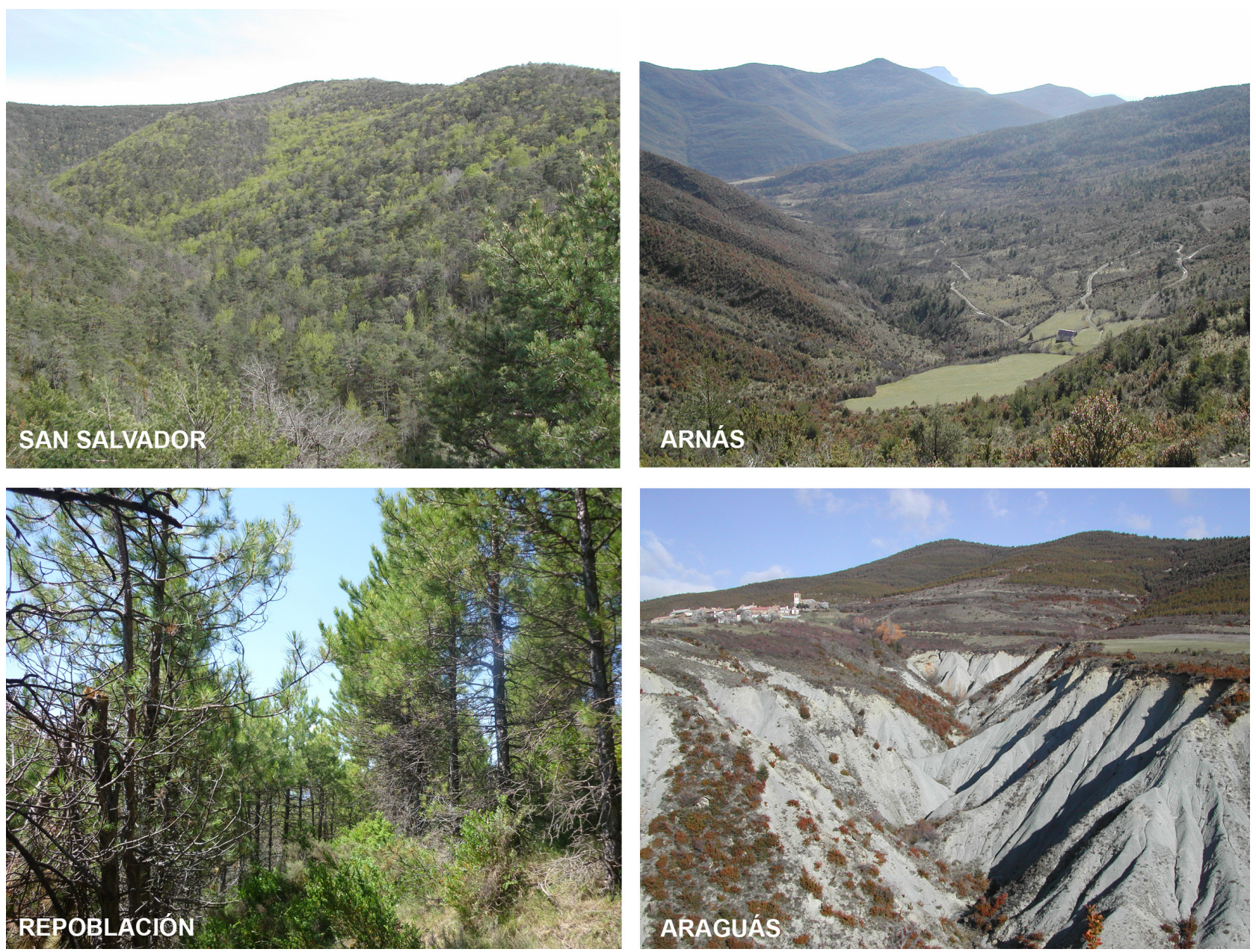

Figura 3: Las cuatro cuencas experimentales del Instituto Pirenaico de Ecología en montaña media: cuenca forestal (San Salvador), cuenca de campos abandonados en fase avanzada de recolonización vegetal (Arnás), cuenca de repoblación forestal (Repoblación) y cuenca de cárcavas (Araguás). Además, el Instituto dispone de otra cuenca experimental en alta montaña, dominada por la presencia de pastos subalpinos (Izas).

Figure 3: The four middle mountain experimental catchments managed by the Pyrenean Institute of Ecology (IPE-CSIC): 1. Forest catchment (San Salvador), 2. Abandoned field catchment, showing the progressive plant recolonization (Arnás), 3. Reforestation catchment (Afforestation) and 4. Badland catchment (Araguás). Besides, the Institute manages another experimental catchment (Izas) located in a high mountain environment, with dominant subalpine grasslands. 
yas (Fagus sylvatica) en la umbría, y un quejigal de Quercus faginea en la solana. Representa lo que podría ser una montaña forestal no perturbada por actividades humanas. El sustrato rocoso es flysch, entre 880 y $1325 \mathrm{~m}$. (iii) En 2004 se inició la toma de datos en la cuenca de Aragüás (45 ha), en el borde septentrional de la Depresión Interior Altoaragonesa, en el tramo final del Valle de Borau, entre 780 y $1105 \mathrm{~m}$. En su mitad septentrional se asienta sobre sustrato flysch con una repoblación de pino laricio (P. nigra) y pino silvestre ( $P$. Sylvestris) sobre antiguos campos de cultivo, mientras en su mitad meridional dominan las margas del Eoceno que se presentan intensamente erosionadas por cárcavas o badlands. (iv) En 2007 se inició la monitorización de la cuenca Repoblación (12,4 ha), entre 1000 y 1105 m s.n.m., que coincide precisamente con la parte superior de la cuenca de Araguás. Representa un ambiente de repoblación forestal sobre suelos relativamente degradados por haber sido cultivados con anterioridad en laderas pendientes. (v) En 1986 se equipó la cuenca de Izas (36 ha), en el alto valle del Gállego, sobre sustrato de pizarras carboníferas afectadas por intensa erosión en cabecera. Se localiza en el piso subalpino superior, entre 2060 y $2280 \mathrm{~m}$. y está colonizada por pastos de aprovechamiento estival, aunque la presión ganadera se ha reducido notablemente. Las cuatro primeras cuencas están muy próximas unas de otras en el piso montano y soportan condiciones climáticas similares. La cuenca de Izas, en cambio, puede considerarse una cuenca de alta montaña con una gran importancia de la innivación y una enorme estacionalidad de la escorrentía. Todas las cuencas disponen de estación meteorológica, sensor óptico y de presión para medir la altura del agua en un flume (y así estimar el caudal), tomamuestras automático de agua y turbidímetro para estimar la concentración de sedimento en suspensión. Además, en algunas cuencas se ha instalado un conductivímetro para calcular la conductividad eléctrica del agua y piezómetros para disponer de información continua sobre la altura de la capa freática. En la cuenca de San Salvador se instalaron tres parcelas de interceptación bajo hayedo, pinar y robledal con el fin de estudiar el efecto de la cubierta vegetal sobre la cantidad de agua que llega directamente al suelo.

En el piso subalpino se han tomado muestras de suelo para estudiar las relaciones entre las características de los suelos y los procesos geomórficos dominantes. En algunos de estos suelos y en paleolagos han aparecido restos de carbones correspondientes a incendios acaecidos en el piso superior del bosque. Su datación mediante ${ }^{14} \mathrm{C}$ ha permitido situar cronológicamente la deforestación intencionada de buena parte del piso subalpino. Por último, en conos de deyección y cauces fluviales se ha medido el tamaño del sedimento grueso siguiendo el método de Wolman (1954) con el fin de relacionar la evolución del tamaño del sedimento a lo largo del curso con los aportes de sedimento desde las laderas (Martínez-Castroviejo \& García-Ruiz, 1990; Gómez-Villar et al., 2014). En el caso de los conos de deyección de la Ribera de Biescas (Valle del Gállego) los resultados de estas mediciones se han utilizado como indicadores de la variabilidad espacial de la sedimentación y de la actividad torrencial (Gómez-Villar \& García-Ruiz, 2000).

\section{Fluctuaciones climáticas durante el Pleistoceno Superior}

El clima de la Tierra cambia a diferentes escalas temporales (Bradley, 1985; Lockwood, 1985), caracterizadas en el Cuaternario (últimos 2,1 millones de años) por la alternancia de periodos glaciares e interglaciares. Durante el Pleistoceno Superior importantes anomalías térmicas y pluviométricas dentro de un dominio general de las bajas temperaturas dieron lugar a la última gran expansión de los inlandsis (ice-sheets) escandinavo y lauréntide, y de los glaciares de valle o alpinos (Dawson, 1992; Marshall et al., 2000; Hughes et al., 2013; Rasmussen et al., 2014). En el Pirineo meridional algunos de los glaciares de valle alcanzaron en su momento de máxima extensión más de $30 \mathrm{~km}$ de longitud y más de $400 \mathrm{~m}$ de espesor (GarcíaRuiz \& Martí-Bono, 2011; García-Ruiz et al., 2013b). Los largos periodos glaciares fueron interrumpidos por periodos interglaciares como el MIS 5 y por fluctuaciones más templadas pero de relativa corta duración (por ejemplo durante el MIS 5 y el MIS 3) (Por ej., Andersen \& Borns, 1994). La intensidad de estas fluctuaciones glaciales/interglaciales ha diferido entre áreas, debido a la distinta influencia de la dinámica atmosférica y oceánica y de las peculiares condiciones geográficas y eso explica que el momento de máxima extensión de los glaciares varíe de unas regiones a otras, aunque periodos fríos y cálidos deben considerarse fenómenos planetarios sincrónicos. Así, existe un acuerdo creciente en el hecho de que la máxima extensión de los glaciares pirenaicos muestra una notable asincronía en relación con otros glaciares centroeuropeos y, especialmente, con el inlandsis escandinavo. De hecho, se ha comprobado en los valles del Aragón (García-Ruiz et al., 2013b), Gállego (García-Ruiz et al., 2003b; González-Sampériz et al., 2006; Lewis et al., 2009) y Cinca (Lewis et al., 2009), y en el Pirineo oriental, tanto en Francia como en España (Andrieu et al., 1988; Pallàs et al., 2010; Delmas et al., 2011). Dataciones mediante OSL han permitido situar el máximo glacial en el Gállego y en el Cinca durante el MIS 4, es decir, hace unos 60.000 años, si bien hay indicios de pulsaciones más externas en el mismo valle del Gállego (Peña et al., 2003). A conclusiones similares se ha llegado en otras montañas mediterráneas (por ej., Hughes et al., 2006). Durante el máximo periodo de frío, en torno a $20.000 \mathrm{cal}$. BP, cuando el inlandsis escandinavo alcanzó su máxima expansión, los glaciares pirenaicos también crecieron pero lo hicieron con menor intensidad, debido probablemente al predominio de condiciones secas. En el Pirineo se ha detectado por el desarrollo de derrubios estratificados que, en el valle del Cinca (Desfiladero de las Devotas), se han datado en $22.800 \pm 200$ años cal. BP (GarcíaRuiz et al., 2001a). También se ha podido identificar en la turbera de El Portalet un avance glaciar entre 22.500 y 
18.000 cal años BP (González-Sampériz et al., 2006). Evidencias indirectas de un periodo frío alrededor del Último Máximo Global se han encontrado también en las terrazas fluviales del río Alcanadre (Prepirineo y Depresión del Ebro), en el que la terraza Qt6 dio una edad OSL de $19.000 \pm 2000$ años (Calle et al., 2013).

El proceso de deglaciación desde el Último Máximo Global (ca. 20.000 años BP) está empezando a ser bien conocido (Delmas, 2015). La cartografía geomorfológica indica la presencia de numerosos depósitos morrénicos frontales y laterales correspondientes a reavances posteriores al máximo (Serrano-Cañadas, 1991; Martínez de Pisón \& Serrano, 1997; García-Ruiz et al., 2001b, 2011a). El empleo reciente de métodos de datación basados en edades de exposición cosmogénica (Palacios et al., 2015) ha permitido distinguir un complejo proceso de avances y retrocesos glaciares que tienden a confirmar las dataciones en los Alpes y en otras montañas del mundo. Así, se distingue un rápido retroceso inmediatamente posterior al último Máximo Global y una expansión menor durante el Oldest Dryas (aproximadamente ca. 17.000 años BP), durante la cual los glaciares de valle se disociaron en lenguas individuales, como por ejemplo los glaciares de Aguas Limpias y Caldarés en el Alto Gállego (Palacios et al., 2015). Un nuevo retroceso durante el periodo cálido denominado Bolling/Allerod fue seguido por un reavance breve y de escasa extensión, en unas condiciones de clima extremo con muy bajas temperaturas y escasas precipitaciones, conocido como Younger Dryas (12.90011.700 años cal. BP), que produjo pequeños glaciares de circo. El análisis polínico de la turbera del Portalet, en la cabecera del Valle del Gállego, también ha revelado en detalle la ocurrencia de estas oscilaciones (GonzálezSampériz et al., 2006).

La acción glaciar en la vertiente meridional del Pirineo Central ha tenido importantes repercusiones paisajísticas e, indirectamente, geomorfológicas, y en los usos del suelo y en la cubierta vegetal. La forma de artesa o en U está presente en frecuentes tramos, dando lugar a una ampliación entre paredes que ha favorecido no sólo las comunicaciones siguiendo el trazado de los valles, sino sobre todo los asentamientos y la posibilidad de crear excelentes áreas de cultivo que hoy son la base de los mejores prados, destacando la presencia de cubetas terminales en el Sector del Flysch, particularmente en los valles del Aragón Subordán, Aragón y Gállego. También explica el desarrollo de rellanos colgados lateralmente, que son antiguos lagos represados por morrenas laterales y posteriormente colmatados con sedimentos, como es el caso, por ejemplo, del valle del Hospital (cuenca del río Aragón Subordán), Villanúa (Cuenca del río Aragón), Barranco del Puerto, Yosa, Aso de Sobremonte, Betés y Escuer (cuenca del río Gállego), Diazas y Frajén (cuenca del río Ara), o Cerler (cuenca del río Ésera), entre otros muchos. La erosión de la morrena lateral en los valles principales por parte de los afluentes ha sido responsable del desarrollo de extensos y muy activos conos de deyección, particularmente en la Ribera de Biescas (Valle del río Gállego) (Gómez-Villar, 1996; Gómez-Villar \& García-Ruiz, 2000), y en el valle del Ésera (Barranco de Remáscaro). La erosión glaciar en los valles principales dejó numerosos valles laterales colgados entre 200 y $400 \mathrm{~m}$ por encima del fondo del valle, condicionando el último tramo de los perfiles longitudinales de los afluentes, que ocasionan importantes problemas de seguridad en periodo de lluvias intensas, como fue el caso de la gran avenida del Barranco de Arás o de Biescas en agosto de 1996 (White et al., 1997). Es probable, además, que algunos deslizamientos profundos en zonas de cabecera, que afectan a pizarras paleozoicas (Guerrero et al., 2012), tengan su origen en el relajamiento que se atribuye a muchas laderas como consecuencia de la deglaciación. Aunque disponemos de muy pocas dataciones en este sentido, dos pequeños paleolagos represados por deslizamientos en la zona de El Formigal y junto al Lago de Tramacastilla, ambos en la cabecera del valle del Gállego, han sido datados en $20.150 \pm$ 150 años cal. BP y $20.600 \pm 170$ años cal. BP, respectivamente (García-Ruiz et al., 2003b). La presencia continua de depósitos morrénicos tapizando las laderas tiene también notables consecuencias biogeográficas, entre las que destaca su colonización por extensos bosques de abedules (Betula alba) que son capaces de competir con ventaja en un ambiente oligotrófico como el que producen los sedimentos de origen glaciar (Puigdefábregas, 1978).

\section{Clima e impacto humano durante el Holoceno}

Durante el Holoceno también se han producido importantes oscilaciones climáticas de menor duración (secular o decadal) e intensidad que en épocas previas (Clague et al., 2009). En la cordillera pirenaica quedaron registradas en numerosos depósitos glaciares, fluviales y de ladera, lacustres (incluyendo el estudio de la vegetación) y espeleotemas, reflejando todos ellos la ocurrencia de frecuentes cambios en las características climáticas (temperaturas y precipitaciones), en la erosión del suelo y generación de avenidas fluviales (Morellón et al., 2009, 2012; Pérez-Sanz et al., 2013; Valero-Garcés et al., 2014) (Figura 4). Tal como sucedió en otras muchas áreas de montaña, probablemente la mayoría de los glaciares pirenaicos debieron retraerse en el Holoceno temprano y desaparecer entre 7000 y 5500 años cal. BP durante el Óptimo Térmico Holoceno (Davis et al., 2009).

Sorprendentemente, no hay muchas evidencias definitivas del impacto del evento 8.2 en el Pirineo. En la alta montaña no se observa un cambio sedimentario evidente (Lago de Marboré, Oliva-Urcia et al., 2013), pese a que, sin embargo, sí se ha detectado cierto descenso en la proporción de caducifolios (más sensibles que las coníferas a un incremento de aridez y descenso de temperaturas) en los registros palinológicos de Basa de la Mora (Pérez-Sanz et al., 2013), El Portalet (González-Sampériz et al., 2006) y Estaña, así como un claro descenso de la isoterma de $0^{\circ} \mathrm{C}$, según el registro de crisofíceas del Lago Redó (Pla \& Catalán, 2005), tal como se observa en la Figura 4 B, D, E y F. En otras regiones de la cuenca del Ebro se ha constata- 


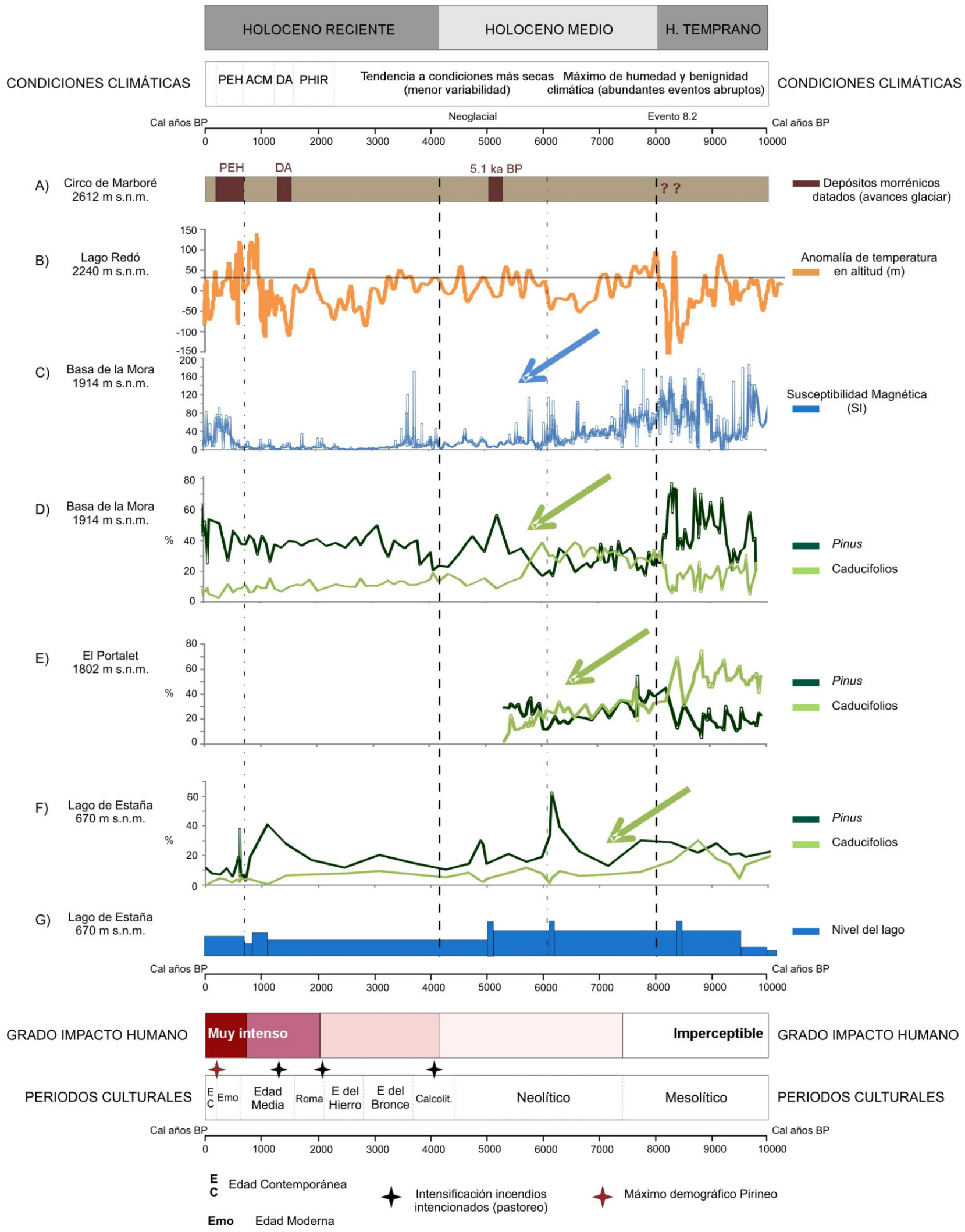


Figura 4: Cronología de la evolución paleoambiental del Pirineo central durante el Holoceno y selección de registros representativos. Se indica, en primer lugar, la organización tripartita clásica del Holoceno, junto a una reseña de las principales condiciones climáticas y periodos más significativos (Evento 8.2, Neoglacial, PHIR o Periodo Húmedo Ibero Romano, DA o Dark Ages, ACM o Anomalía Climática Medieval y PEH y Pequeña Edad del Hielo). La escala cronológica está representada en años calibrados antes del presente (cal años BP). A) Dataciones obtenidas en depósitos morrénicos en torno al circo de Marboré, que indican avances glaciares (a partir de García-Ruiz et al., 2014). B) Reconstrucción de la anomalía de temperatura en altitud a partir de crisofíceas del Lago Redó (Pla \& Catalán, 2005). C) Curva de Susceptibilidad Magnética procedente del registro de la Basa de la Mora (Pérez-Sanz et al., 2013), en la que se observan valores más altos durante la primera mitad del Holoceno, reflejo de unas condiciones más húmedas y una mayor cantidad de aportes al lago procedentes de arroyadas. D) Proporciones de polen de pino y árboles caducifolios del registro palinológico de la Basa de la Mora (a partir de Pérez-Sanz et al., 2013). E) Proporciones de polen de pino y árboles caducifolios del registro palinológico de El Portalet (a partir de González-Sampériz et al., 2006 y Gil-Romera et al., 2014). F) Proporciones de polen de pino y árboles caducifolios (exceptuando Quercus tipo faginea por su carácter semicaduco) del registro palinológico del Lago de Estaña (a partir de Pérez-Sanz, 2014). En los tres registros polínicos (D, E y F), los valores más elevados de caducifolios se corresponden con los momentos de mayor humedad y benignidad de temperaturas. G) Reconstrucción de la variabilidad del nivel del Lago de Estaña (a partir de Morellón et al., 2009). Se indican los grados de impacto humano en el paisaje vegetal a lo largo del Holoceno, correspondiendo los colores claros (a la derecha), a los menores impactos, y los oscuros (a la izquierda), a los de mayor intensidad. Se indican también periodos de intensificación de incendios en el piso subalpino, interpretados habitualmente como aperturas intencionadas del paisaje por parte de pastores trashumantes (símbolos negros), así como el momento de mayor presión demográfica en el Pirineo (s. XIX) (símbolo rojo). Por último, aparecen representados los diferentes periodos culturales y la cronología que se les atribuye para el Pirineo central.

Figure 4: Chronology of the main Holocene paleoenvironmental events in the Central Pyrenees and selection of most representative records. The classical organization in three sub-periods within the Holocene is indicated, as well as the main climatic intervals and the most significant events (8.2 event) and phases (Neoglacial, Humid Ibero-Roman Period, Dark Ages, Medieval Climatic Anomaly and Little Ice Age). Age scale in calibrated years before present (cal yr BP). A) Glacial advances from morainic deposits in the Marboré

Cirque (García-Ruiz et al., 2014). B) Reconstruction of temperature anomalies from crysophites in Redó Lake (Pla \& Catalán, 2005). C) Magnetic susceptibility from Basa de la Mora (Pérez-Sanz et al., 2013), with higher values during the first half of the Holocene, as a consequence of wetter conditions and higher runoff. D) Pine and deciduous trees percentages in the palinological record of Basa de la Mora (Pérez-Sanz et al., 2013). E) Pine and deciduous trees percentages in the palinological record of El Portalet (González-Sampériz et al., 2006; Gil-Romera et al., 2014). F) Pine and deciduous trees percentages (except for

Quercus faginea due to its semi-deciduous character) in the palinological record of the Estaña Lake (Pérez-Sanz et al., 2014). In the three pollen records (D, E and F), higher values of deciduous trees correspond to wetter periods and milder temperatures. G) Reconstruction of the variability in the Estaña Lake level (Morellón et al., 2009). The relative human impact on the landscape is indicated by clear colors (lower impact) and darker colors (strong impact). Historical periods of more intense fires in the subalpine belt are also indicated as a result of human-induced opening of the landscape by transhumant shepherds (black symbols), and the greatest demographic pressure (19th century) in the Pyrenees (red symbol). Main cultural periods are also indicated. 
do un efecto en la actividad humana y localización de asentamientos (González-Sampériz et al., 2009).

Muchos de estos glaciares debieron de reactivarse durante el Neoglacial, aunque estos depósitos pueden haber quedado enmascarados por el impulso posterior de tales glaciares durante la Pequeña Edad del Hielo (PEH) (Deline \& Orombelli, 2005). En el Pirineo se dispone de una datación en la morrena más externa del circo de Marboré, en la cara norte del Macizo de Monte Perdido, con una edad de $5100 \pm 0.1$ años cal. (Figura 4 A), coincidiendo con una reactivación del glaciarismo en el Circo de Troumouse, localizado a $9 \mathrm{~km}$ de distancia de Marboré, en el Pirineo francés, donde Gellatly et al. (1992) dataron las morrenas entre $5190 \pm 90$ y $4654 \pm 60$ años cal. BP. Este periodo coincide a su vez con el fin de condiciones más húmedas y cálidas durante el Holoceno temprano, y el inicio de una tendencia hacia condiciones más secas (Figura 4) y probablemente más frescas alrededor de 50004000 años cal. BP, tal como se ha detectado en los sedimentos del Lago de Marboré (Oliva-Urcia et al., 2013) y en un significativo descenso de nivel en otros lagos pirenaicos, como en Basa de La Mora (Pérez-Sanz et al., 2013), Estaña (Morellón et al., 2009) (Figura 4 G) y Montcortés (Corella et al., 2011), donde además se sugiere que el impacto humano era todavía muy bajo. En Sierra Nevada, sur de España, este periodo fresco de mediados del Holoceno coincidió con una de las varias etapas de desarrollo de formas de solifluxión (Oliva \& Gómez Ortiz, 2011) y en la Cordillera Cantábrica con la formación de glaciares rocosos (Redondo Vega et al., 2010; Pellitero et al., 2011).

Los depósitos y umbrales glaciares del Circo de Marboré proporcionan también información de otras fluctuaciones climáticas de menor entidad, como el retroceso glaciar durante la Edad del Bronce, el periodo húmedo romano y una corta expansión glaciar durante el Dark Ages Cold Period (entre 1400 y 1200 años cal. BP) (García-Ruiz et al., 2014) (Figura 4 A). A escala regional los aportes sedimentarios fluviales hacia el mar experimentaron un notable aumento durante el periodo romano en el Mediterráneo occidental, muy probablemente debido a una mayor actividad agrícola y minera (Nieto-Moreno et al., 2011). Sin embargo, la variabilidad climática durante el periodo Dark Ages Cold Period es aún poco conocida, ya que se trata de un periodo de transición entre el Periodo Húmedo Ibero-Romano y la Anomalía Climática Medieval, con importantes diferencias regionales a lo largo de Iberia (Moreno et al., 2012).

La ocurrencia de incendios muestra una notable variabilidad espacial y temporal durante el Holoceno. Así, en la cabecera del río Noguera Pallaresa, Cunill et al. (2012) identificaron una elevada frecuencia entre 10.500 y 9500 cal años BP a partir de restos de cenizas y restos vegetales quemados entre las cotas 1996 y 2200 m s.n.m., confirmando la presencia pionera de masas arbóreas a una altitud mínima de $2200 \mathrm{~m}$. En la turbera de El Portalet (Alto Valle del Gállego) se observó un aumento de la frecuencia de incendios entre 9000 y 7700 cal años BP, y un marcado descenso entre 7700 y 6000 cal años BP (Gil-Rome- ra et al., 2014). Estos autores concluyeron que la máxima insolación estival durante el Holoceno temprano y la expansión del bosque mesofítico pudieran ser los factores que explican la ocurrencia de incendios en el treeline del Pirineo Central. En todo caso, en ese periodo los incendios debieron tener predominantemente un origen natural, dado que no aparece ningún indicador antropogénico en el espectro polínico, ni hay yacimientos arqueológicos de esa época presentes en la zona. En la cuenca superior del río Cinca, en el entorno de lago de la Basa de la Mora, se ha identificado una mayor actividad del fuego entre 8100 y 4000 cal años BP, y un abrupto descenso entre 3200 y 1700 cal años BP hasta casi su desaparición (Lasheras et al., 2013). Estos autores sugieren que los contrastes temporales en la ocurrencia de incendios se podrían deber a dos razones: (i) la cantidad de biomasa disponible y en disposición de ser quemada, y (ii) la existencia de un clima más cálido, favorable al fuego. En otros lugares, sin embargo, se han detectado incendios en torno a 2500 años BP, por ejemplo en las cabeceras de los ríos Aragón Subordán, Osia y Estarrún (datos aún no publicados por los autores de este trabajo), probablemente ligados localmente a una mayor presencia humana y a la necesidad de abrir espacios no forestados en el piso subalpino para el pastoreo con rebaños trashumantes (Figura 5). Montserrat (1992), en el Lago de Tramacastilla, también detectó la ocurrencia de un periodo breve de incendios hace unos 4000 años, aunque la recuperación de la vegetación forestal fue bastante rápida, apuntando a una presión humana moderada pero no prolongada en el tiempo. Por otra parte, en la cabecera del río Noguera Pallaresa, desde el final de la Edad del Bronce y durante la Edad de Hierro y el Periodo romano (esencialmente entre 2500-1800 cal BP) se registra una creciente presencia humana en la montaña (Cunill et al., 2012), al igual que ocurre en la Basa de la Mora y en Estaña (Pérez-Sanz, 2014) extendiéndose un proceso de humanización del paisaje, que se ha ido intensificando en el tiempo (Figura 4). En el Estany de Burg, Pirineo catalán, el análisis de sedimentos, carbones, materia orgánica y polen (Bal et al., 2011) sugiere que los incendios de origen humano aparecieron sobre todo a partir de la Edad del Bronce, correlacionándose con cultivos nómadas, la metalurgia y el pastoreo, especialmente entre 2900 y 2650 cal años BP y entre 1850-1550 cal años BP. En fechas posteriores el impacto humano sobre la vegetación fue sensiblemente mayor.

\section{La Anomalía Climática Medieval y la PEH}

Las dos oscilaciones climáticas más importantes de los últimos 2000 años son la Anomalía Climática Medieval (ACM) y la Pequeña Edad del Hielo (PEH). Su estudio se ha basado sobre todo en el análisis multiproxy de alta resolución en los lagos de Estaña, Montcortés y Basa de la Mora, localizados en el Pirineo Central, así como en la cartografía de detalle de los depósitos morrénicos de los avances glaciares durante la Pequeña Edad del Hielo (Figura 4 A). También ha sido muy útil el estudio de espe- 


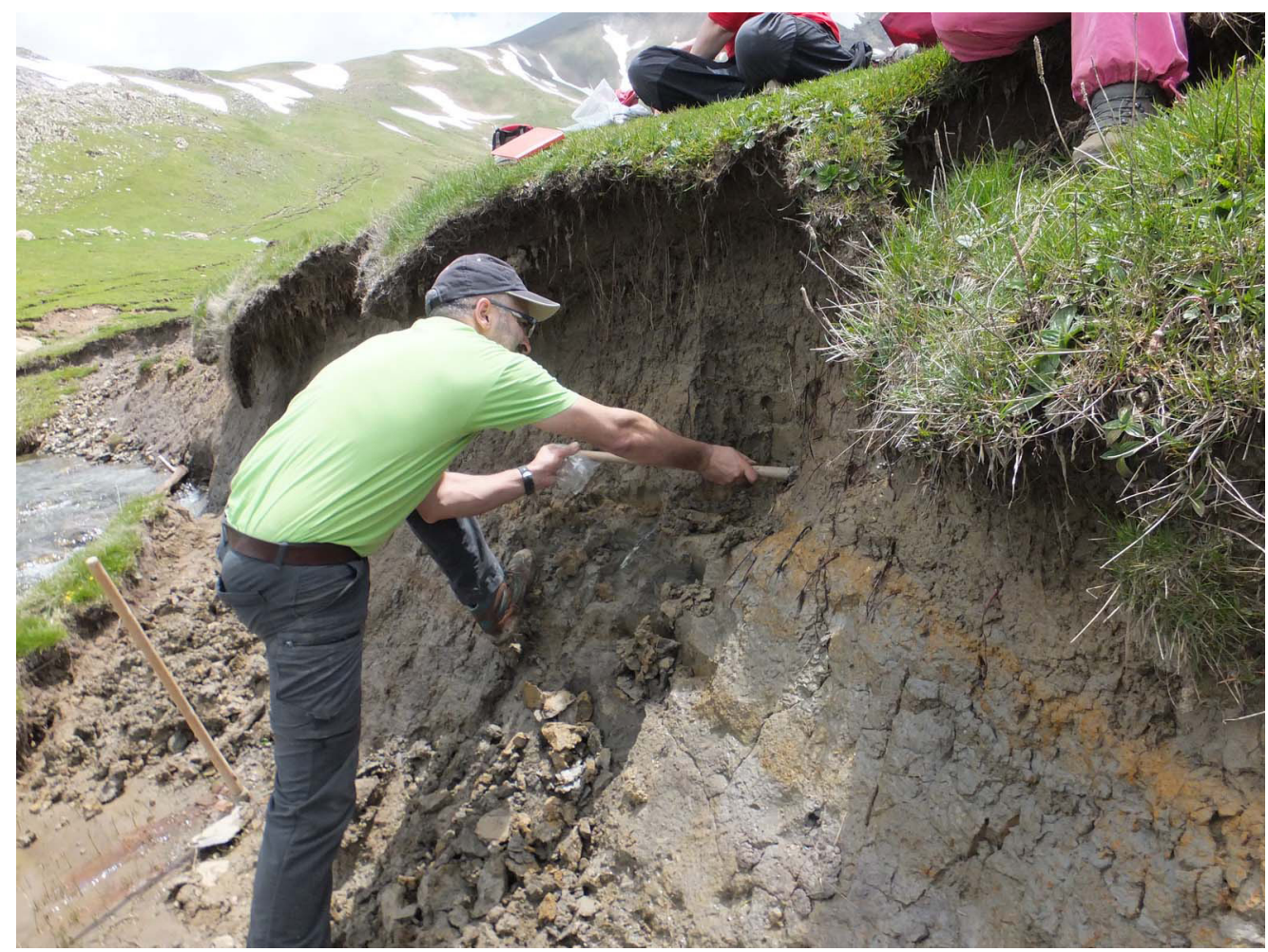

Figura 5: Corte en el depósito glaciolacustre de Plandániz, paleolago localizado en un afluente del río Aragón Subordán (o Valle de Hecho), con presencia de un horizonte con restos de cenizas y microcarbones, datados en algo más de 1000 años cal. BP. Figure 5: Sampling of a charcoal-bearing layer dated at approximately $1000 \mathrm{cal}$. yr BP in the glacio-lacustrine deposit of Plandániz, a paleolake located in a tributary of the Aragón Subordán River (Hecho Valley).

leotemas en cuevas del Pirineo, donde se ha registrado crecimiento espeleotémico incluso en el marco de una menor disponibilidad de agua (Moreno et al., 2013).

Moreno et al. (2012) han centrado la ocurrencia de la Anomalía Climática Medieval entre los años 900 y 1300 CE. Estos autores comprobaron que en la zona mediterránea de la Península Ibérica, este periodo se caracterizó por un acentuado descenso del nivel de los lagos, la expansión de una vegetación más xerofítica y heliófila, una menor frecuencia de avenidas, un incremento en la ocurrencia de eventos eólicos saharianos y un menor aporte sedimentario fluvial al mar Mediterráneo. Por el contrario, algunas secuencias sedimentarias de la margen atlántica de la Península Ibérica sugieren un aumento de la humedad en ese mismo periodo.

Diferentes estudios reflejan que durante los últimos siglos el impacto humano en la vegetación, la hidrología y la erosión en el Pirineo son tan intensos que no siempre es fácil separarlos de las respuestas de los lagos frente al clima (Morellón et al., 2011; Rull et al., 2011; ValeroGarcés \& Moreno, 2011; Corella et al., 2012; Catalán et al., 2013). Esa respuesta de la vegetación ha sido más contundente en lagos de alta montaña, como en la Basa de la Mora (Pérez Sanz et al., 2011). También se ha podido deducir que durante los últimos 2000 años el impacto humano ha sido más intenso y continuado en las tierras bajas que en el piso subalpino, donde por razones eviden- tes la presión humana ha sido más estacional y ligada al pastoreo. En el sedimento y el polen del Lago de Estaña se reflejan muy bien las condiciones cálidas y secas de época medieval, con un predominio de enebros y otros elementos mediterráneos, y una menor abundancia de taxones leñosos mesofíticos, quizás también como consecuencia de la deforestación del entorno. De hecho, entre 1250 y $1300 \mathrm{CE}$ se refleja la ocurrencia de frecuentes incendios. El descenso del nivel del lago condujo a un aumento de la salinidad de las aguas (Morellón et al., 2011, 2012). En el mismo lago, los estudios polínicos y sedimentológicos de Riera et al. (2004) concluyeron que las grandes deforestaciones en las zonas bajas ocurrieron entre 820 y 1075 , con mayor presencia de polen de viña y cereales y, algo más tarde, del olivo. A finales del siglo XIV y comienzo del xv, el cáñamo llegó a alcanzar un notable desarrollo alterando algunas propiedades de la sedimentación en el lago. El aumento de la salinidad durante la ACM se registró también más al oeste y a menor altitud en el Lago Arreo (Álava) (Corella et al., 2013). La creciente presencia humana durante la Edad Media ha sido también detectada en el Lago de Montcortés (Rull et al., 2011; Corella et al., 2012), donde se registra un aumento de los aportes sedimentarios, especialmente entre 959 y 1044 CE y entre 1124 y 1179 CE.

El descenso de superficie ocupada por los bosques mesófitos y la mayor presencia de Pinus, Juniperus y 
Artemisia se ha registrado también durante la Anomalía Climática Medieval. El abeto llega incluso a estar ausente. Más ligeramente se detecta la expansión de algunos cultivos, cuyo polen llega desde las tierras bajas, especialmente Cerealia, Vitis, Olea, Castanea y Juglans (Pérez Sanz et al., 2011). Un nivel con abundantes restos de carbones encontrado por Montserrat (1992) en el Lago de Tramacastilla, y asociado a importantes cambios de vegetación, permitió datar en torno a hace 1000 años la deforestación del piso subalpino y la expansión de formaciones de pastos de aprovechamiento estival, que hoy aparecen de manera general por encima de 1600 m s.n.m. e incluso por debajo (en la cabecera del río Aragón Subordán, por ejemplo). Esta deforestación transformó profundamente el paisaje de la alta montaña pirenaica y, a la vez, cambió su funcionamiento hidrológico y los procesos geomórfológicos. El propio Montserrat (1992) atribuyó la deforestación a la necesidad de contar con una mayor extensión de pastos de verano a medida que avanzaba la Reconquista de las tierras bajas de la Depresión del Ebro, se creaba una descompensación entre pastos de invierno y de verano, y se consolidaba una trashumancia de envergadura entre el centro de la Depresión del Ebro y los altos pastos pirenaicos (Pascua, 2012). Cunill et al. (2012) también se refieren a la expansión ganadera trashumante en la cuenca superior del río Noguera Pallaresa como argumento para explicar el aumento de incendios en época medieval y el descenso del límite superior del bosque. Bal et al. (2011) señalan que desde el inicio de la Edad Media se produjo un cambio en el uso del fuego, pasando de una etapa de aclareo a otra en que predomina el mantenimiento de los espacios abiertos anteriormente.

La PEH presenta una mayor complejidad que la ACM. Se trata de un periodo más fresco y húmedo, aunque con una importante variabilidad climática (Morellón et al., 2012), en el que muchos glaciares pirenaicos se reconstruyeron y avanzaron hasta alcanzar, en general, la máxima extensión de todo el Holoceno. Ese avance se ha podido constatar muy bien en los macizos pirenaicos más elevados (particularmente, de oeste a este: Infierno, Monte Perdido, Posets y Aneto-Maladeta) (Martínez de Pisón \& Arenillas Parra, 1988; Julián \& Chueca, 1998; GarcíaRuiz \& Martí-Bono, 2001; Martín Moreno, 2004; González Trueba et al., 2008, entre los más recientes). Los depósitos morrénicos en el Circo de Marboré (Figura 4 A) reflejan bien la ocurrencia de dos episodios especialmente fríos y húmedos: (i) El máximo avance glaciar de la $\mathrm{PEH}$ tendría lugar a finales del siglo XVII o comienzos del XVIII (González Trueba et al., 2008), coincidiendo con el Mínimo de Maunder, es decir, un periodo de baja actividad solar entre 1645 y $1715 \mathrm{CE}$. Este avance fue confirmado con datos dendrocronológicos (Saz \& Creus, 2001), si bien análisis liquenométricos sitúan el avance máximo entre los años 1600 y 1620 en el Macizo de Maladeta (Julián \& Chueca, 1998). (ii) El segundo avance de importancia tuvo lugar durante el Mínimo de Dalton (1790-1830), con una expansión breve y rápida de los glaciares de Monte Perdido, que llegan a sobremontar parcialmente sobre las morrenas de la primera etapa (García-Ruiz et al., 2014), creando una típica serie de acanaladuras conocidas como fluted moraines. Entre las dos etapas hubo un corto periodo de retroceso caracterizado por un descenso de las precipitaciones y un ascenso de la temperatura. También hay confirmación a partir del crecimiento de estalagmitas en la cueva de Seso, cerca de Boltaña (Bartolomé et al., 2012), entre 1400 y $1800 \mathrm{CE}$, coincidiendo con el periodo fresco y húmedo de la PEH.

Esta información geomorfológica se complementa con los datos registrados en los sondeos lacustres pirenaicos. Así, Rull et al. (2011), Pérez Sanz et al. (2011), Morellón et al. $(2011,2012)$ y Corella et al. (2012) detectan niveles lacustres más altos, temperaturas invernales más duraderas y condiciones más húmedas desde ca. $1300 \mathrm{CE}$, con expansión de taxa caducifolios y coníferas adaptadas al frío, a la vez que se limita la presión humana sobre el territorio $\mathrm{y}$, consecuentemente, los aportes sedimentarios a los lagos. A partir de la posición de las morrenas en el siglo XIX y de la actual situación de los frentes glaciares y de las Líneas de Equilibrio Glaciar (ELA), se ha estimado que la temperatura media durante el periodo más frío de la $\mathrm{PEH}$ fue al menos $0,9^{\circ} \mathrm{C}$ inferior a la actual (López-Moreno, 2000; González Trueba et al., 2008). El ascenso de la ELA fue mayor en el Macizo de Maladeta (255 m, según Chueca et al., 2005) lo que sugiere una temperatura en torno a $1,5^{\circ} \mathrm{C}$ inferior durante la $\mathrm{PEH}$.

\section{El calentamiento global desde mediados del siglo XIX}

A mediados del siglo XIX finaliza la PEH. Desde entonces puede hablarse de un calentamiento progresivo, de carácter global, que se prolonga hasta la actualidad, con cortas interrupciones a comienzos del siglo $\mathrm{xx}$ y entre 1957 y 1980 (Jones et al., 2012). La Figura 6 muestra claramente el aumento de la temperatura media anual (incremento de $0,25^{\circ} \mathrm{C}$ por década entre 1960 y 2010), de la estación fría (incremento de $0,24^{\circ} \mathrm{C}$ por década) y de la cálida (aumento de $0,26^{\circ} \mathrm{C}$ por década), todos ellos estadísticamente significativos al umbral de 0.05 . Los glaciares pirenaicos reflejaron muy pronto ese calentamiento. Desde 1830-1850 no han dejado de retroceder, primero con una cierta lentitud, pero de manera constante, hasta que el ritmo de fusión se ha acelerado después de 1980. Esta evolución coincide con un aumento térmico generalizado desde la segunda mitad del siglo XIX en España (Brunet et al., 2007). En siglo y medio han desaparecido numerosos glaciares, otros han pasado a ser simples neveros y, finalmente, otros continúan dentro de la categoría de glaciares por la presencia de grietas, pero han experimentado notables disminuciones en tamaño y espesor. Todos los glaciares pirenaicos muestran un frente biselado en continuo retroceso, con muy poca neviza en la parte superior, y con una marcada tendencia a subdividirse en cuerpos de hielo menores a medida que la pérdida de espesor hace aflorar umbrales rocosos (glaciares de Maladeta y Monte Perdido Inferior). La evolución de algunos glaciares y del manto de nieve en el piso subalpino está 

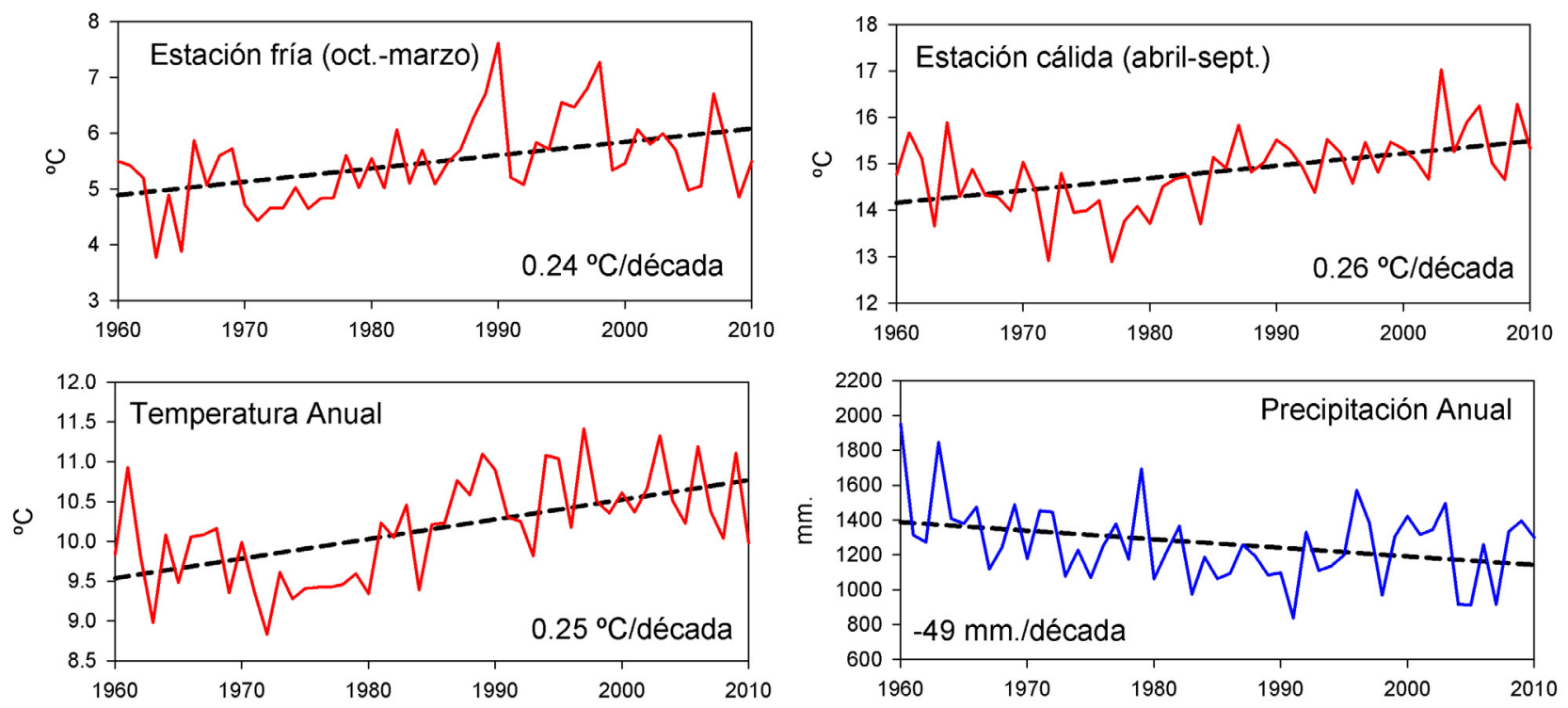

Figura 6: Evolución de la temperatura en las estaciones fría, cálida y anualmente desde 1960 a 2010 considerando el promedio de la temperatura en siete observatorios (Canfranc, Torla, Ansó, Aratorés, Castiello de Jaca, Biescas y Yésero) y precipitación total anual promedio desde 1960 a 2010 en los observatorios de Canfranc, Aratorés, El Pueyo de Jaca, Biescas, Boltaña, Parzán, Saravillo, Sesué y Eriste.

Figure 6: Annual and seasonal temperature evolution since 1960 based on seven weather stations (Canfranc, Torla, Ansó, Aratorés, Castiello de Jaca, Biescas and Yésero), and evolution of the annual precipitation since 1960 from Canfranc, Aratorés, El Pueyo de Jaca, Biescas, Boltaña, Parzán, Saravillo, Sesué and Eriste weather stations.

siendo seguida actualmente mediante técnicas de láser escáner terrestre (Revuelto et al., 2013), reflejando que incluso en años con elevada innivación los glaciares siguen retrocediendo, lo que sugiere que se encuentran en un estado de claro desequilibrio frente a las condiciones climáticas dominantes.

Un ejemplo de la reducción de tamaño de los glaciares lo proporciona el Circo de Marboré, donde los glaciares de la cara norte del Macizo de Monte Perdido han pasado de ocupar 239 ha al final de la PEH, a 62,1 ha en 1999, y 49,2 ha en 2011 (Chueca \& Julián, 2010). En el caso del glaciar de Maladeta ha pasado de 152,3 ha en 1820-1830 a 54,5 ha en 2000 (Chueca et al., 2005). Estos autores demostraron que el retroceso de los glaciares pirenaicos está relacionado con el aumento de la temperatura anual y el descenso de la precipitación invernal. A este respecto es importante señalar que López-Moreno (2005) estudió la evolución del espesor del manto nival en el Pirineo Central. El resultado más importante fue el descenso, estadísticamente significativo, del espesor de nieve durante la segunda mitad del siglo xx (Figura 7), debido sobre todo a una menor precipitación entre enero y marzo. La temperatura, como parece lógico, sólo tuvo un peso significativo en el espesor de nieve de mediados de primavera. No obstante, a pesar del calentamiento global, pequeños sectores con permafrost siguen presentes por encima de 2600 m s.n.m. y hasta un total de 13 glaciares rocosos están todavía en activo (Lugon et al., 2004). Suelos poligonales se están formando en el frente deglaciado del Taillón en tan sólo 10 años (Feuillet \& Mercier, 2012), y se rehacen cada día en otoño en pequeños rellanos del fondo del circo de Marboré.

Vicente-Serrano et al. (2007) y López-Moreno et al. (2010) han comprobado además la existencia de una tendencia negativa en la precipitación en el Pirineo durante la segunda mitad del siglo Xx, sobre todo en primavera y verano, y un aumento en la duración de las rachas secas, que se puede explicar por un desplazamiento del cinturón de altas presiones subtropicales hacia el norte, y por el descenso de precipitaciones convectivas. La Figura 6 confirma la ocurrencia de un descenso en la precipitación anual, estimada en $49 \mathrm{~mm}$ por década entre 1960 y 2010, a partir del promedio de nueve observatorios (Canfranc, Aratorés, El Pueyo de Jaca, Biescas, Boltaña, Parzán, Saravillo, Sesué y Eriste). Las tendencias observadas entre las distintas localidades muestran una cierta variabilidad espacial, y eso obliga a considerar con prudencia los patrones de cambio, que están seguramente provocados por la heterogeneidad del relieve; sin embargo, el patrón de reducción pluviométrica puede considerarse bastante general. Las predicciones para el siglo XXI confirman un descenso de la precipitación de entre un 10,7 y un 14,8\% (López-Moreno et al., 2008a), aunque es bien conocido que la proyección futura de la precipitación está sujeta a una gran incertidumbre, especialmente en la región Mediterránea. Este descenso se atribuye a la creciente influencia de la Oscilación del Atlántico Norte (North Atlantic Oscillation: NAO) durante el invierno, cuyos efectos se reforzarían previsiblemente de cara al futuro (VicenteSerrano \& López-Moreno, 2008), conduciendo a una ma- 


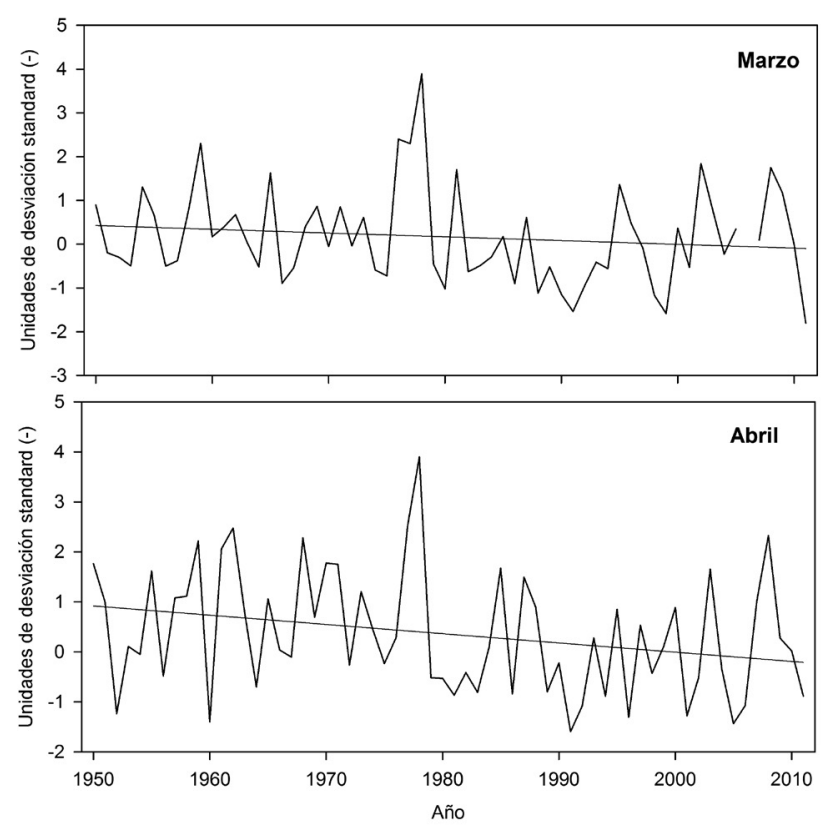

Figura 7: Evolución simulada del manto de nieve en el Pirineo Central Español en marzo y finales de abril obtenida mediante la metodología presentada en López-Moreno (2005). Las unidades son anomalías de desviación estándar respecto al promedio del periodo. Líneas continuas son valores observados. Líneas discontinuas son valores simulados a partir de la precipitación acumulada en el periodo diciembre-febrero para el manto de nieve de marzo, y la precipitación acumulada entre diciembre y marzo y la temperatura de abril para el manto de nieve en abril.

Figure 7: Simulated evolution of snowpack in the Central Spanish Pyrenees at March and the end of April based on the methodology of López-Moreno (2005). The units are anomalies of standard deviation in relation to the average of the period. Black lines denote observed values. Discontinuous lines are simulated values from the accumulated precipitation during the period December-February for the snowpack in March, and the accumulated precipitation between December and March and the temperature of April for the snowpack in April.

yor frecuencia de tipos de tiempo que dan lugar a inviernos secos (López-Moreno et al., 2011a).

De todas formas, los cambios más significativos en el clima de cara al siglo xxi se centran en el aumento de la temperatura y en el descenso de la acumulación de nieve. En la mayoría de las montañas del mundo, se espera un marcado aumento de temperatura como consecuencia de las emisiones de efecto invernadero (Nogués Bravo et al., 2007; García-Ruiz et al., 2011b). Los modelos climáticos regionales sugieren que los cambios más significativos esperados en el Pirineo se relacionan con la temperatura, que es el principal parámetro implicado en los procesos nivales futuros (López-Moreno et al., 2008b). Las proyecciones climáticas para finales del presente siglo sugieren, respecto a las condiciones actuales, un descenso de hasta el 50-60\% en el maximum snow water equivalent, un adelanto en un mes en la ocurrencia de la máxima acumulación anual de nieve y una reducción de la duración del manto de nieve en alrededor de dos meses. La magnitud de estos impactos será mayor a altitudes en torno a 1600-1700 m s.n.m., donde la cantidad de agua acumulada en forma de nieve podría descender hasta en un 78\%, y ser mucho menor en las altitudes más elevadas, donde las características del manto nival pueden permanecer más o menos estables (López-Moreno et al., 2009). Además, las áreas más expuestas a una radiación solar más intensa $(\mathrm{S}$, SE y SW) verían aumentada la sensibilidad del manto de nieve frente al cambio climático (López-Moreno et al., 2013).

\section{Despoblación y abandono de tierras en el siglo $\mathrm{xx}$}

A finales del siglo XIX, cuando se alcanzó la máxima extensión de la superficie cultivada, los bosques dominaban en las vertientes umbrías, mientras que en las solanas quedaron relegados a una estrecha franja muy discontinua, entre 1250 y 1500-1600 m s.n.m. Fue también el momento en que los pastos subalpinos y la superficie cultivada alcanzaron su máxima extensión, coincidiendo con el momento en que se registran en el Pirineo los censos de población más elevados. Los campos de cultivo se localizaban en los fondos de valle y en rellanos colgados, asociados generalmente a antiguas obturaciones glaciares. La ocupación de las laderas pendientes fue general en las solanas, con campos pendientes (a veces con un ligero abancalamiento en la parte inferior de cada parcela) y bancales con muro de piedra seca o con el salto entre parcelas colonizado por herbáceas y matorral (Lasanta, 1989). Bajo una fuerte presión demográfica y un sistema de herencia muy eficaz para el sostenimiento de la propiedad, pero muy negativo para los hijos no herederos (los llamados «tiones»), se cultivaron laderas en pendientes muy fuertes, a veces mediante sistemas de agricultura nómada (slash-and-burn, shifting agriculture) que consistían en desbrozar una parcela, quemar lentamente el producto de los desbroces y distribuir las cenizas en la parcela como fertilizante (Lasanta et al., 2006a). De este modo se podían obtener cosechas durante 2 ó 3 años consecutivos y luego abandonar el campo hasta un nuevo desbroce 25 ó 30 años después. La utilización recurrente del fuego como estrategia para desbrozar o para controlar la vegetación tuvo resultados catastróficos, como se ha sugerido en ambientes muy diferentes (por ejemplo, Keesstra et al., 2014; Zavala et al., 2014). Además, en torno a 1600 m s.n.m., se crearon bancales en el límite altitudinal para los cultivos, muchas veces sobre sedimentos morrénicos. Eran los llamados panares, que ocasionalmente ponían en contacto las áreas de cultivo con los pastos subalpinos (Figura 8), cultivándose con centeno en ciclos de 13 meses (Daumas, 1976).

La mayor parte de los asentamientos pirenaicos alcanzaron su máximo demográfico en la segunda mitad del siglo XIX. Desde entonces se ha producido un progresivo descenso en los censos de población, primero muy lento hasta los primeros años del siglo xx para acelerarse progresivamente hasta ca. 1980, cuando la tendencia decre- 


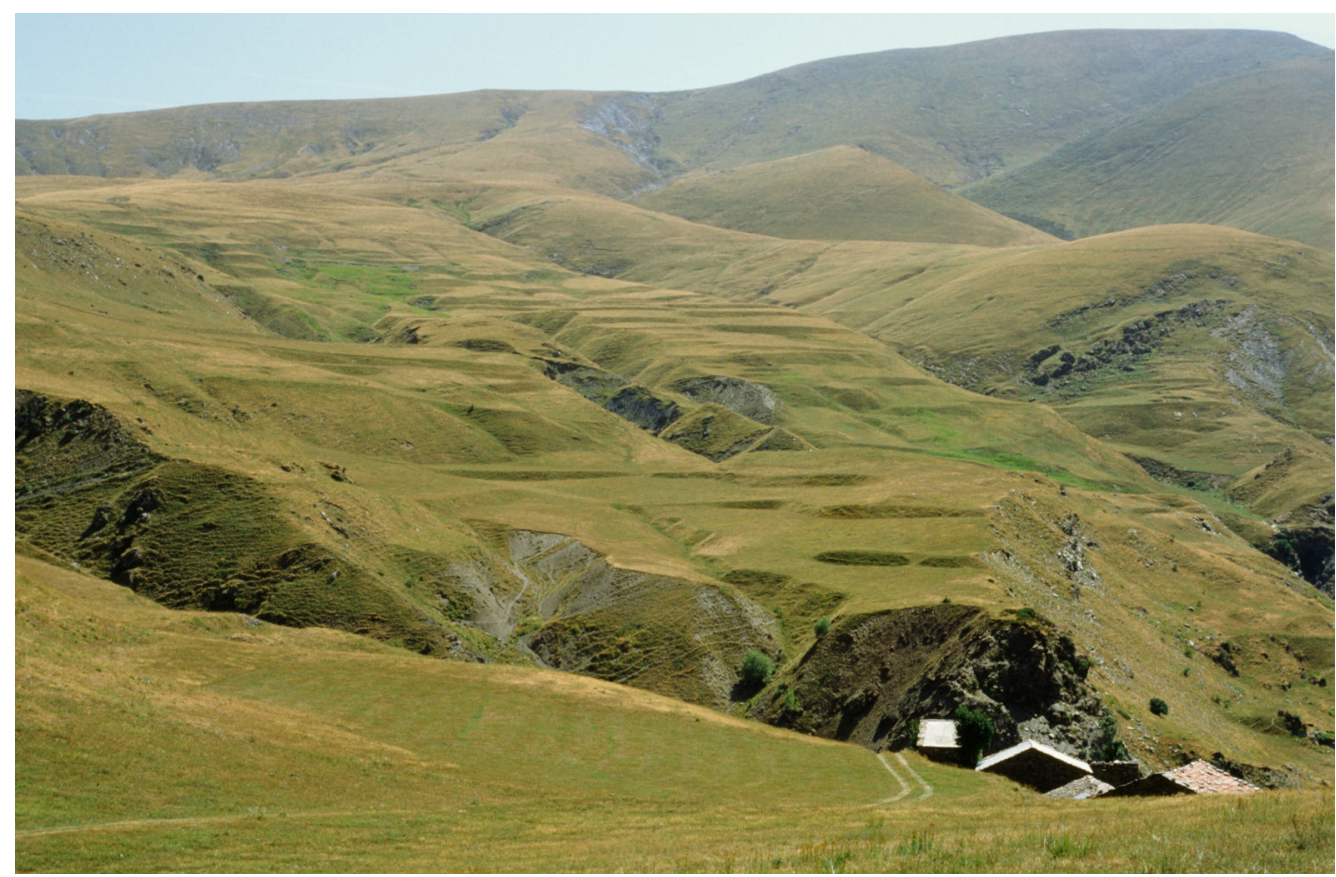

Figura 8: Panares en la cabecera del Valle de Castanesa, en la cuenca del río Noguera Ribagorzana. Los panares eran campos abancalados, cultivados con centeno en ciclos de 13 meses en el límite superior del piso montano, ya en contacto con el piso subalpino.

Figure 8: Panares in the headwater of the Castanesa Valley, Noguera Ribagozana River basin. Panares were bench-terraced fields, cultivated with rye in 13-month cycles in the upper limit of the montane belt, close to the contact with the subalpine belt.

ciente se suaviza o incluso se invierte (Figuras 9 y 10 ). Pocos núcleos de población han escapado a esta tendencia general. Entre ellos puede citarse a Jaca, que mantiene un ascenso demográfico desde mediados del siglo XIX, incluso si se descuenta la población de los municipios incorporados en las últimas décadas. También es el caso de Sabiñánigo, que en 1900 contaba con 264 habitantes y que inicia un proceso de crecimiento que llega hasta 6979

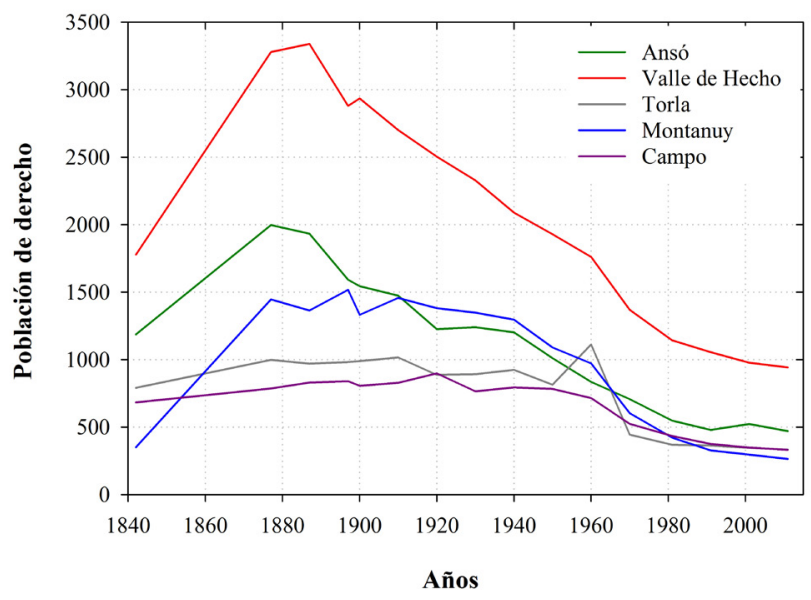

Figura 9: Evolución demográfica regresiva en una selección de municipios pirenaicos.

Figure 9: Declining demographic evolution in a selection of Pyrenean villages. habitantes en 1970 después de una importante industrialización (industria química y metalúrgica, principalmente), además del consiguiente crecimiento comercial, y 7943 habitantes en 2001 sin contar con los municipios anexionados. La caída demográfica ha sido brutal en el Prepirineo y en los pueblos localizados en laderas, lejos de los

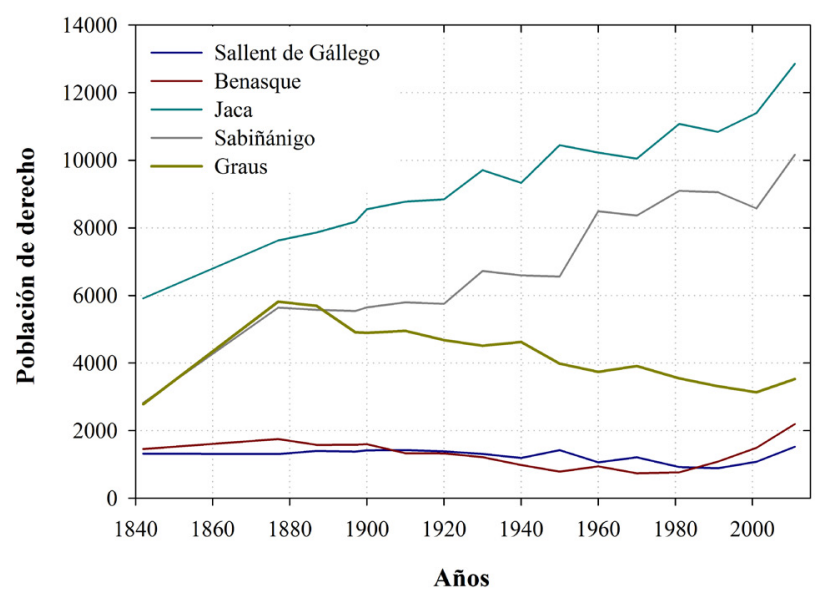

Figura 10: Evolución demográfica positiva en algunas cabeceras comarcales y municipios afectados por actividades turísticas de invierno y verano.

Figure 10: Positive demographic evolution in some county capitals and villages affected by touristic activities in winter and summer. 
medios de comunicación y de las mejores tierras, como ha ocurrido en el Sobrepuerto, entre los valles del Gállego y del Ara, el Valle de la Solana en el Valle del Ara, o La Fueva en el Valle del Cinca. En todos ellos la despoblación ha podido ser tan intensa que muchos pueblos han quedado despoblados o con un número tan pequeño de habitantes que pueden considerarse inviables a medio plazo si no cambian las circunstancias sociales y económicas. Este proceso ha afectado incluso a algunos núcleos de población tradicionalmente fuertes que también han visto muy reducida su población, al hundirse las bases económicas sobre las que se sustentaba su fuerza: es el caso de Ansó tras la crisis de la ganadería trashumante (1977 habitantes en 1842; 523 en 2001); también en menor medida es el caso de Hecho (1406 habitantes en 1842; 644 en 2001); y Broto (1758 habitantes en 1900; 468 en 1991). Incluso ha alcanzado a antiguas cabeceras de comarca, como Aínsa y Boltaña, al desmoronarse la organización social y demográfica de los núcleos de población a los que atendían. Aínsa, no obstante, ha conseguido una cierta estabilidad reciente gracias al impulso del turismo, del que también se han beneficiado algunos municipios de cabecera en el Pirineo Central, especialmente los más relacionados con deportes de invierno (Sallent de Gállego, Aísa-Candanchú, Panticosa y Benasque). Incluso los municipios del entorno del Parque Nacional de Ordesa y Monte Perdido (Torla y Bielsa, por ejemplo) han perdido mucha población, a pesar del elevado número de visitantes y del crecimiento de las infraestructuras turísticas. Esto sugiere que el turismo, por sí solo, no es un factor capaz de invertir la tendencia demográfica negativa del Pirineo Central, excepto en el caso de un turismo de invierno y verano que estabilice o incremente los censos demográficos, pero que compite con fuerza con las actividades tradicionales a las que deja en una posición marginal (Laguna \& Lasanta, 2003). Al proceso de despoblación y al consiguiente envejecimiento y desestructuración de la organización social debe añadirse el efecto demográfico de la construcción de embalses, que ocuparon algunas de las mejores tierras de los fondos de valle, causando el abandono de muchos pueblos y la desorganización de las jerarquías y de las relaciones entre ellos, además de crear condiciones irreversibles para las actividades ligadas al sector primario (García-Ruiz, 1977; Sabio Alcutén, 2011).

Las dos consecuencias más importantes de la despoblación fueron el abandono generalizado de tierras de cultivo y el descenso de la presión ganadera sobre los pastos. Desde principios del siglo xx comenzó el abandono de muchas tierras de cultivo, empezando por las peores (es decir, las situadas en laderas más pendientes), las más alejadas de los núcleos de población. El primer retroceso demográfico, que afectó sobre todo a población marginal (tiones desheredados que trabajaban casi gratuitamente para el hermano heredero), se llevó por delante los peores campos, principalmente los cultivados en régimen de nomadeo, que ocasionalmente se retomaron por cierto tiempo durante el periodo crítico inmediatamente posterior a la Guerra Civil española. Luego, a medida que el proceso de despoblación se fue haciendo más intenso, se abando- naron campos en pendiente que se cultivaban en régimen de año y vez, y paralelamente también los bancales, con suelos profundos y complejas infraestructuras de conservación del suelo, cuyo tamaño impedía todo intento de mecanización (Lasanta, 1988). Este abandono de tierras de cultivo ha sido detectado con claridad en el espectro polínico de algunos lagos, como en el de Estaña, donde Riera et al. (2004) observan un descenso general de la actividad agrícola, especialmente de Vitis y Olea, y también una menor incidencia del fuego, o en la Basa de la Mora, por ejemplo, con un marcado aumento de la proporción arbórea, relacionado tanto con el abandono de tierras de cultivo como con el incremento de la temperatura global y el consecuente ascenso de los pisos de vegetación (Pérez-Sanz et al., 2013). En el último tercio del siglo xx solamente los fondos de valle se han mantenido como áreas de cultivo permanente, aprovechando terrazas fluviales, pies de vertiente y conos de deyección parcialmente estables (Lasanta, 1989). En la actualidad, al margen de la Depresión Interior Altoaragonesa, donde la suave topografía de glacis y terrazas fluviales favorece el mantenimiento de los cultivos, el espacio cultivado representa menos del 3\% del total, cuando en los momentos de máxima extensión alcanzó entre el 20 y el $40 \%$ del espacio situado por debajo de 1600 m s.n.m.

\section{La evolución geomorfológica y la expansión reciente del bosque en el piso subalpino}

Se ha comentado anteriormente que el piso subalpino fue deforestado de manera casi general en diversos momentos, quizás con una notable variabilidad temporal y espacial. También se indicó que durante el Holoceno temprano el fuego fue recurrente, si bien se ha relacionado más con la insolación y la disponibilidad de biomasa (Gil-Romera et al., 2014). El inicio de la impronta humana como factor rector de sus paisajes comenzó a manifestarse con claridad a través del impacto de la ganadería a partir del 4000 cal. años BP (incendios registrados en el Lago de Tramacastilla: Montserrat, 1992), y a lo largo de las edades del Bronce y del Hierro (Utrilla \& Rodanés, 1997), aunque en este periodo la incidencia del fuego fue muy variable. Hay, no obstante, frecuentes dataciones alrededor de 2500-3000 cal años BP, coincidiendo con la presencia de población nómada, como atestiguan los abundantes túmulos pirenaicos. De nuevo los registros sedimentarios lacustres reflejan un momento álgido del uso del fuego en la Edad Media, alrededor de 1000 años cal BP. El resultado final fue que los bosques originales de $P$. sylvestris y $P$. uncinata quedaron relegados a lugares poco menos que marginales: por ejemplo, los escarpes verticales de los valles de Ordesa y de Añisclo, Peña Foratata, o el macizo granítico de Panticosa. En tales lugares y en otros muchos similares, los pinos aparecen hoy día dispersos, sometidos a una fuerte explotación natural debido a una profunda y prolongada innivación, bajas temperaturas, breve estación vegetativa, aludes y caídas de rocas, localizándose en suelos con poca capacidad de al- 


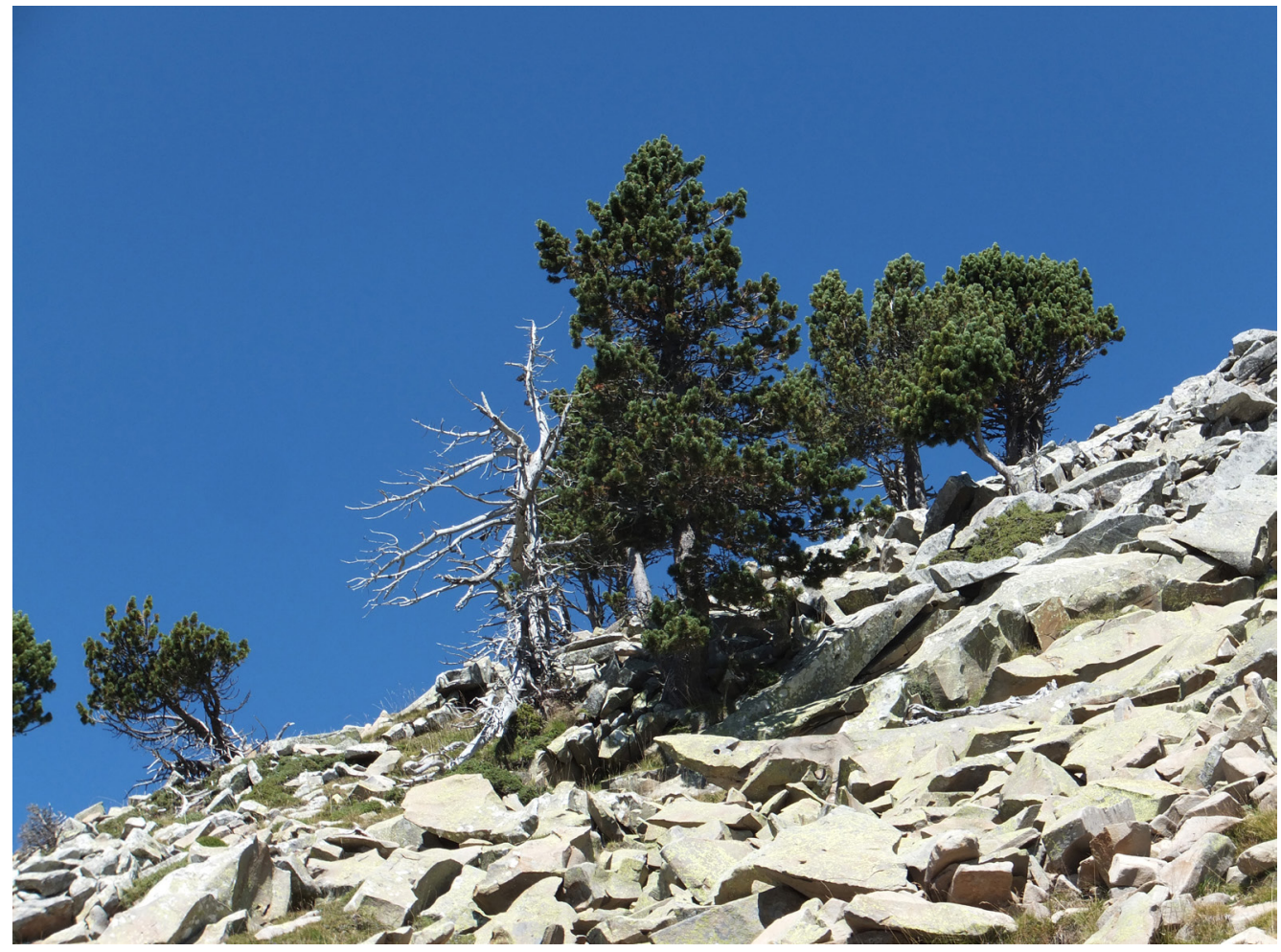

Figura 11: Pino negro (P. uncinata) en el límite superior del bosque, Sierra de las Cutas, Parque Nacional de Ordesa y Monte Perdido. En un ambiente climático muy extremo la supervivencia es difícil y los pinos crecen lentamente entre bloques calizos desgajados por la gelifracción.

Figure 11: Pinus uncinata in the upper forest limit, Las Cutas Sierra, Ordesa and Monte Perdido National Park. In this extreme climatic environment, tree survival is compromised and pines grow slowly among limestone blocks broken by gelifraction.

macenamiento de agua (Figura 11). En cambio, los lugares con suelos más profundos y topografía relativamente más suave por encima de 1500-1600 m s.n.m. aparecen deforestados y colonizados por diferentes comunidades de pastos. En ningún caso puede hablarse de auténticos treelines maduros, entendiéndose por tales a las formaciones boscosas que desarrollan de forma natural un bien definido límite superior del bosque (Figura 12). De igual forma, es muy difícil hablar de krummholz, una formación degradada del bosque por encima del treeline donde los árboles aparecen dispersos, achaparrados y frecuentemente deformados por el viento o la presión de la nieve, en el límite ecológico posible de desarrollo del arbolado. Algún ejemplo hay en torno a 2300 m s.n.m. en el Parque Nacional de Ordesa y Monte Perdido. La acción humana se ha dirigido a facilitar el pastoreo y ha eliminado todo vestigio de bosque allí donde pudiera crecer la hierba para ser pastada en verano.

La transformación de los bosques subalpinos en pastos ha tenido la gran ventaja de propiciar la ganadería trashumante entre la alta montaña pirenaica y las estepas de la Depresión del Ebro. Por otro lado, ha facilitado el equilibrio entre recursos pastorales de invierno y de verano, de manera que se ha optimizado el aprovechamiento de recursos caracterizados por una fuerte estacionalidad (García-Ruiz \& Lasanta-Martínez, 1993). Sin embargo, esta transformación ha tenido un coste muy elevado desde el punto de vista de la erosión y la conservación del suelo. La eliminación del bosque tuvo claras consecuencias hidrológicas y geomorfológicas: (i) aumento de la cantidad de lluvia efectiva que alcanza el suelo al dejar de actuar la interceptación; (ii) aumento de la humedad del suelo, al disminuir la evapotranspiración por parte del arbolado; (iii) descenso de la resistencia y cohesión del suelo, al desaparecer las raíces del bosque y al aumentar la humedad en el suelo; y (iv) el desarrollo de una amplia gama de movimientos en masa, entre los que destacan los deslizamientos superficiales (shallow landslides) y la solifluxión, además de incisiones paralelas. Según Van Asch et al. (1999), el principal factor que explica este tipo de deslizamientos es la pérdida de cohesión provocada por un aumento de la presión hidráulica durante periodos de lluvias intensas o prolongadas.

Ya Höllermann (1985) había sugerido que la deforestación del piso subalpino en el Pirineo había causado un descenso del cinturón de solifluxión en aproximadamente $400 \mathrm{~m}$, pudiendo observarse la presencia de lóbulos de solifluxión desde 1500-1600 m s.n.m., especialmente grandes en pies de vertiente (valle de Aguas Tuertas, por ejemplo). En torno a 1900-2100 m s.n.m. son de menores dimensiones, con aproximadamente 2-3 m de longitud por $2 \mathrm{~m}$ de anchura, forma convexa en su frente y escasos 


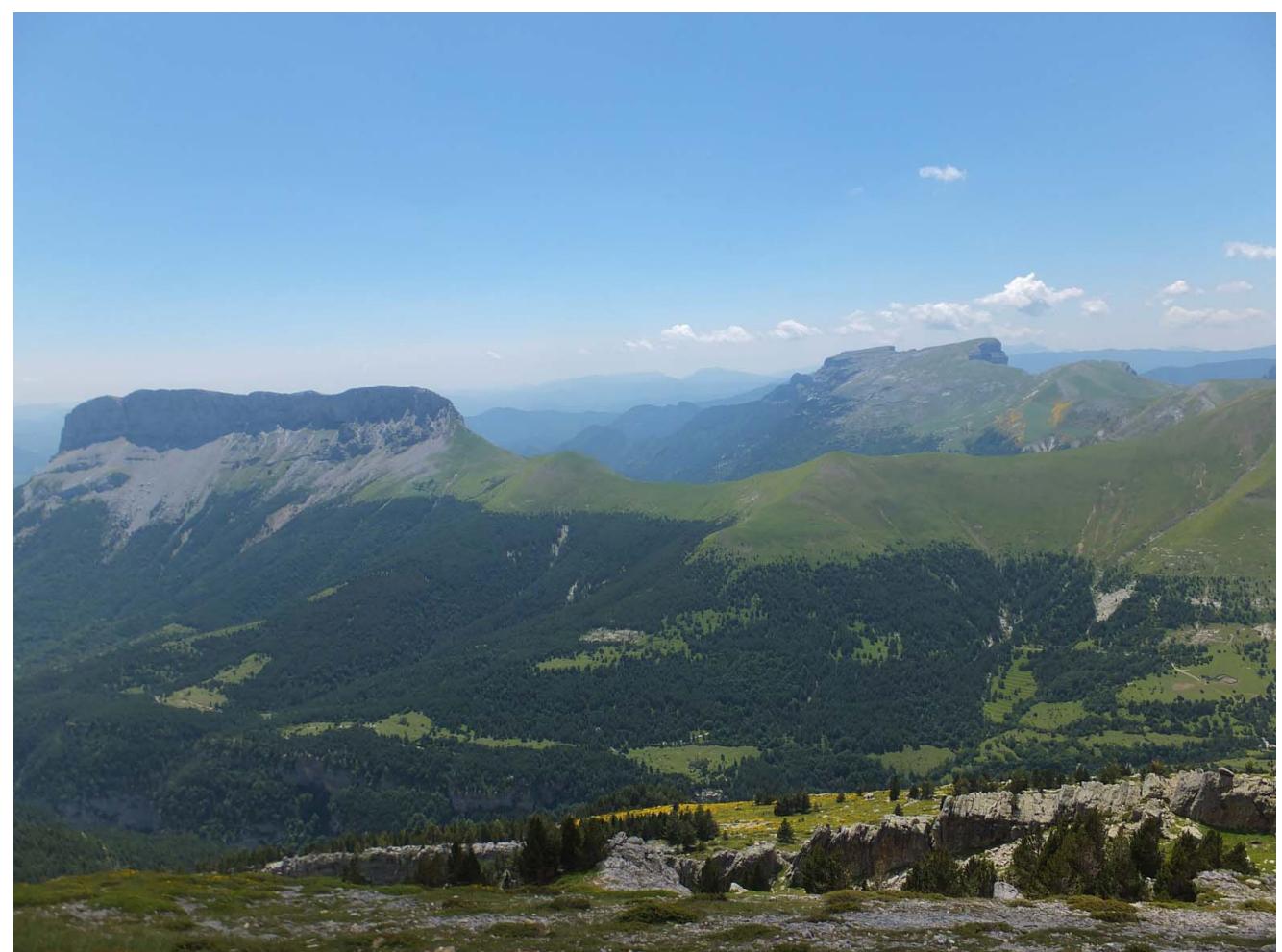

Figura 12: Treeline artificial (aprox. 1650 m s.n.m.) en el Valle de Escuaín. El límite rectilíneo del bosque es una consecuencia de la deforestación para la creación de pastos subalpinos.

Figure 12: Human-made treeline (aprox. $1650 \mathrm{~m}$ a.s.l.) in the Escuain Valley. The sharp and lineal forest limit is a consequence of deforestation aimed to enlarge the area of subalpine grasslands.

signos de movilidad, dada la lentitud del fenómeno. Creus Novau \& García Ruiz (1977) demostraron que en las laderas de Formigal (Alto Valle del Gállego) la velocidad de desplazamiento en el frente de los lóbulos está directamente relacionada con el contenido en humedad del suelo y con la proporción de arcillas. Ahora bien, el fenómeno geomorfológico más destacado es la formación de deslizamientos superficiales (Figura 13), localizados preferentemente entre 1900 y $2000 \mathrm{~m}$ de altitud, relativamente cerca de las divisorias, y preferentemente, en laderas rectilíneas del Sector del Flysch (García-Ruiz \& Puigdefábregas, 1982), y en otras más irregulares de las Sierras Interiores (Barranco Pardina, en el Parque Nacional de Ordesa y Monte Perdido, por ejemplo). Estos deslizamientos están relacionados con la presencia de suelos con una profundidad superior a $40-70 \mathrm{~cm}$ (suelos pardos forestales), y en ocasiones excepcionales hasta más de $4 \mathrm{~m}$ por acumulaciones sucesivas de deslizamientos, como en el Barranco Pardina. La pendiente es un factor limitante muy importante en su origen (García-Ruiz et al., 2010a). Así, las laderas con pendientes superiores a $30^{\circ}$ son inestables y tienden a deslizarse incluso en condiciones de suelo seco, mientras que las laderas con pendiente inferior a $15^{\circ}$ son estables incluso en condiciones de saturación. Este resultado corrobora las observaciones de campo de Puigdefábregas \& García-Ruiz (1984). Los deslizamientos desarrollan cicatrices de forma irregular, preferentemente semicircular, a veces alargadas, y formando ocasionalmente lóbulos de acumulación al pie. Es frecuente que los deslizamientos se formen encadenados en el sentido de la pendiente. No suelen conectar directamente con la red fluvial, por lo que no contribuyen a la carga de sedimento de los ríos, si bien éste es un problema que aún está pendiente de estudio. La localización de estos deslizamientos superficiales exclusivamente en el piso subalpino deforestado es una prueba de que son y han sido una consecuencia directa de la transformación del paisaje por el hombre. Su presencia en laderas forestales no perturbadas está descartada, aunque, excepcionalmente, sí son posibles los flujos de derrubios.

Los efectos de los deslizamientos superficiales en el piso subalpino a largo plazo se centran en la desaparición del suelo, dando lugar a laderas pedregosas con muy escaso material fino. Sobre restos degradados del suelo original se forman terracillas de soli/gelifluxión, con la típica alternancia de rellanos y pequeños escalones, estos últimos colonizados por matas de Festuca eskia y signos de movilidad estacional.

Llama además la atención la presencia de densas redes de incisiones paralelas, cuyo origen aún no está claro (Figura 14). Se forman sobre laderas regularizadas donde el suelo ya ha sido movilizado, con una pendiente en torno a $30-35^{\circ}$, y preferentemente en exposiciones umbrías. Las incisiones, muy poco integradas entre sí, llegan a te- 


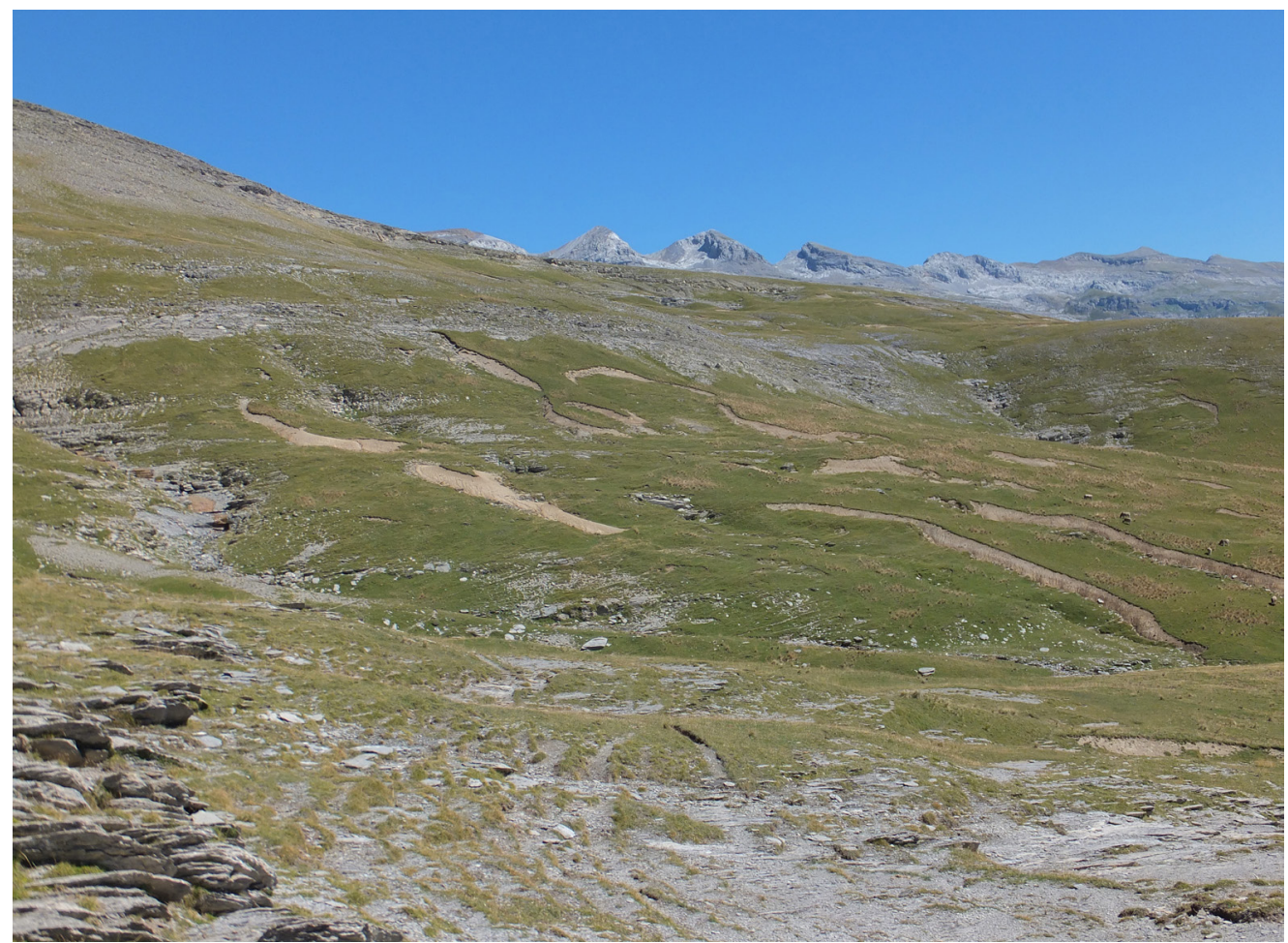

Figura 13: Deslizamientos superficiales en la margen izquierda del Barranco Pardina, en el Valle de Añisclo, Parque Nacional de Ordesa y Monte Perdido.

Figure 13: Shallow landslides in the left margin of the Pardina Ravine, Añisclo Valley, Ordesa and Monte Perdido National Park.

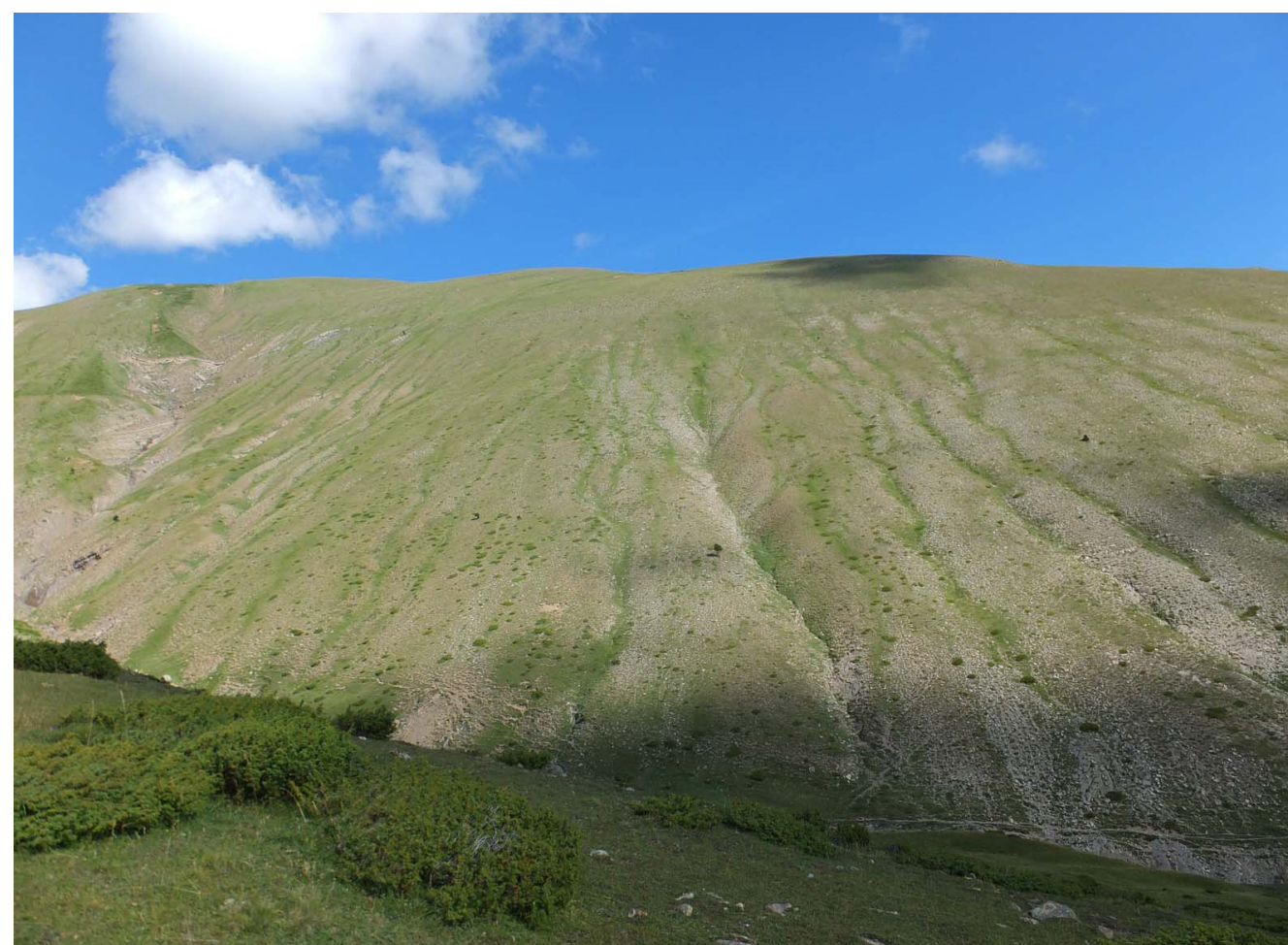

Figura 14: Incisiones paralelas en ladera rectilínea orientada al noroeste en la cabecera del Valle de Aragüés. Figure 14: Parallel incisions in a northwest-facing rectilinear hillslope, headwater of the Aragüés Valley. 


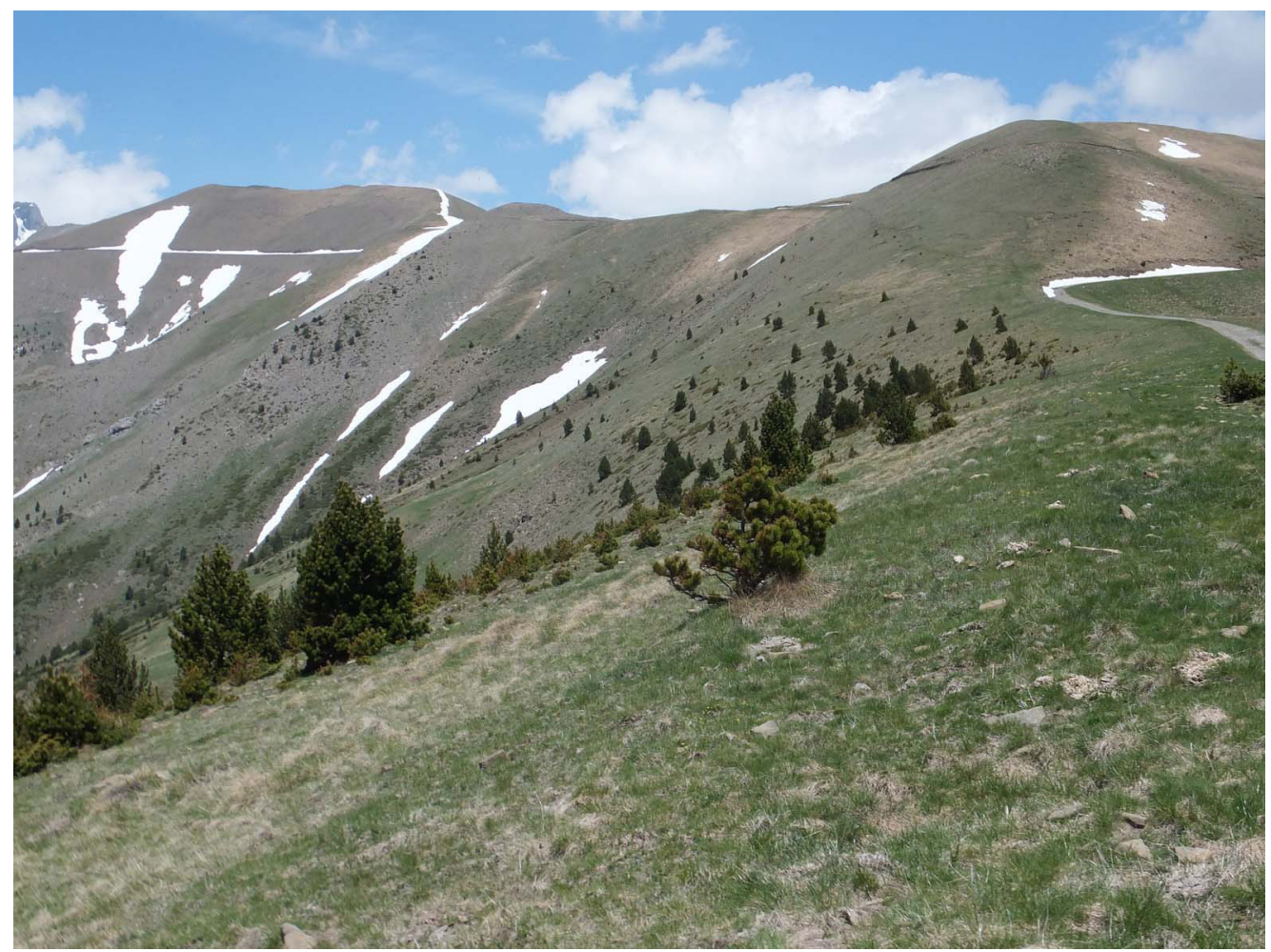

Figura 15: Expansión del bosque hacia la divisoria de Las Blancas, entre los valles de los ríos Estarrún y Aragón.

En la mayor parte del Pirineo Central se observa numerosos árboles jóvenes que forman un frente de avance del bosque como consecuencia del descenso de la presión ganadera.

Figure 15: Forest expansion towards the divide in Las Blancas, between the Estarrún and Aragón River Valleys. In most Pyrenean mountains, an advance forest front composed by young trees develop as a consequence of the declining livestock pressure.

ner 3-4 $\mathrm{m}$ de profundidad en su parte baja y se difuminan hacia la parte superior, dejando un amplio espacio entre su inicio y la divisoria. Es posible que sean la consecuencia de una mezcla compleja de factores: eliminación del bosque, forma rectilínea de la ladera y persistencia de la nieve durante más tiempo.

Es evidente que hoy el paisaje del piso subalpino no es estable. Evoluciona con cierta rapidez como consecuencia de la formación de nuevos deslizamientos superficiales durante eventos pluviales de baja frecuencia, mientras que algunas cicatrices son colonizadas por la vegetación. Sin embargo, el cambio más relevante tiene lugar como consecuencia de la reciente expansión del bosque. Debe tenerse en cuenta que la presencia generalizada de pastos no sólo se debe a la deforestación en siglos precedentes. Sin la introducción de grandes rebaños de ovejas la recuperación del bosque hubiera sido muy rápida. Ha sido el ganado el que ha permitido el mantenimiento estable de las comunidades herbáceas y el control de matorrales y árboles (Montserrat Recoder, 1964), así como el uso frecuente del fuego en las formaciones rastreras de Juniperus. Pero eso sólo era posible con una fuerte presión ganadera. En el momento en que la presión se ha relajado mucho, sobre todo en laderas pendientes y alejadas de los puntos de agua, el bosque está retomando progresivamente el piso subalpino, formando frentes de avance con numerosos renuevos que progresan hacia la divisoria (Figura 15). No es ni siquiera necesario que haya un suelo profundo. Un ejemplo bastará para mostrar la intensidad de este fenómeno: en la cuenca superior del río Ijuez los pastos subalpinos representaban en 1956 el 33,9\% de la superficie, y en 2006 el 19,9\% (Sanjuán et al., 2014); en cambio, el pinar ha experimentado en ese tiempo un avance espectacular, pasando del 2,8 al 45,3\%, incluyendo su expansión en el piso montano. El descenso de la ganadería que acompañó a la despoblación del valle y la desaparición del fuego como factor de control de la expansión de matorrales y árboles explica esta evolución, que muestra tendencias similares en muchos otros valles. No debe olvidarse que el municipio de Ansó ha pasado de tener 45.000 ovejas en 1900, a 6.102 en 2012. A comienzos del siglo xx el censo ovino de los valles de Ansó, Hecho, Tena y Gistaín superaba las 150.000 cabezas, que quedaron reducidas a 80.436 cabezas en 1960 y a 24.055 en 2009. La pérdida de ganado ovino se compensó parcialmente con el incremento del vacuno, que no alcanzaba las 1.500 cabezas en 1900, para llegar a 2.934 en 1960 y a 4.554 en 2009 .

No obstante, debe tenerse en cuenta que, en algunos casos, muy probablemente el ascenso reciente del treeline 


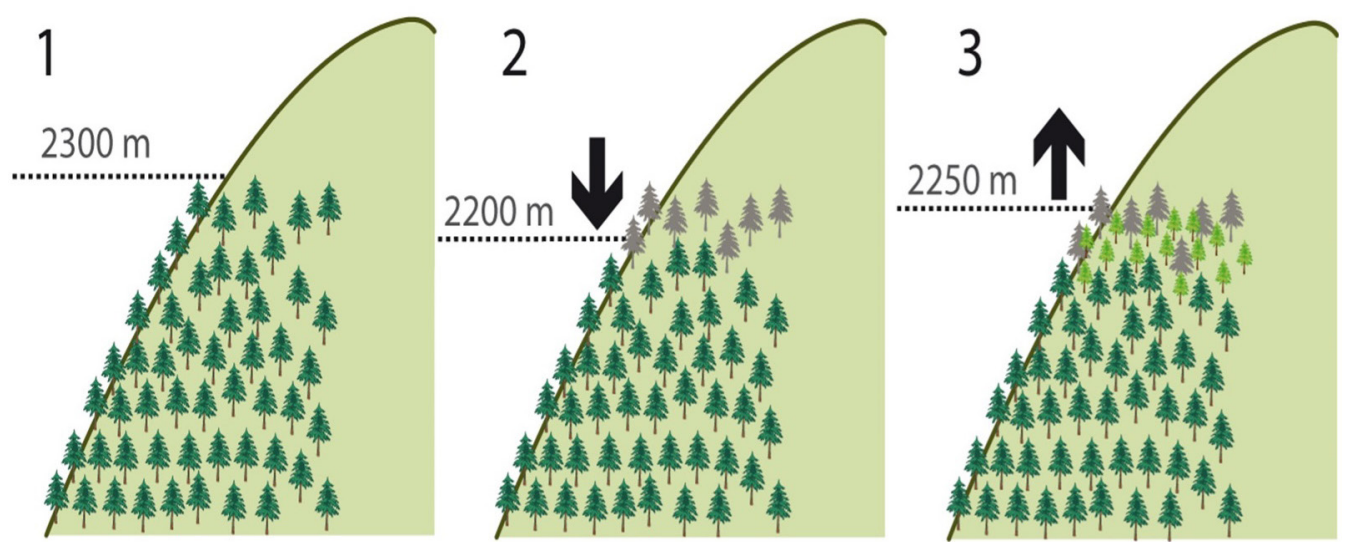

Figura 16: Esquema de cambios en el límite superior del bosque en Foratarruego, cabecera del Valle de Escuaín, Parque Nacional de Ordesa y Monte Perdido. La Pequeña Edad del Hielo forzó el descenso del límite del bosque, dando lugar a la muerte de numerosos árboles. Por el contrario, el calentamiento global a lo largo del siglo xx ha propiciado la recuperación del bosque y el ascenso altitudinal de su límite superior.

Figure 16. Changes in the upper forest limit at Foratarruego, headwater of the Escuain Valley, Ordesa and Monte Perdido National Park. During the Little Ice Age the upper forest limit decreased, resulting in the death of numerous trees. Conversely, global warming along the 20th century favoured the forest recovery and the elevation of its upper limit.

tenga más que ver con el calentamiento global que con el descenso de la presión ganadera. Esto sólo puede probarse allí donde el treeline se encuentra muy cerca de su límite natural, como se ha demostrado en la cabecera del valle de Escuaín, dentro del Parque Nacional de Ordesa y Monte Pedido. En la zona llamada Foratarruego, a una altitud próxima a los $2300 \mathrm{~m}$, se descubrió la presencia de numerosos árboles adultos muertos, y a la vez el ascenso de un elevado número de pinos negros ( $P$. uncinata) jóvenes, tanto más jóvenes cuanto mayor era la altitud. Un estudio dendrocronológico de los árboles muertos informó de que los pinos murieron entre mediados del siglo XVII y comienzos del siglo XVIII y, más aún, entre 1820 y 1860, coincidiendo en ambos casos con los momentos más fríos de la PEH (Camarero et al., enviado). En esos momentos el límite superior del bosque habría descendido unos 100 metros, causando la muerte de los pinos que quedaron atrapados en ese cinturón crítico. Desde la segunda mitad del siglo xx, el calentamiento global habría favorecido la recuperación del pinar hacia cotas más elevadas, al ascender de nuevo el límite superior del bosque, al igual que lo han hecho numerosas especies termófilas (Gottfried et al., 2012) (Figura 16).

\section{Colonización vegetal y erosión del suelo tras el abandono de tierras en el piso montano}

El descenso de la presión humana también ha afectado muy directamente al piso montano, donde la despoblación, el pequeño tamaño de las parcelas y su dispersión, así como las dificultades de mecanización, dieron lugar muy pronto a un abandono generalizado de tierras de cultivo, fundamentalmente aquellas que se localizaban en las laderas. La consecuencia inmediata fue el inicio de un proceso de colonización vegetal que depende de una serie compleja de factores: las condiciones climáticas, las características edáficas de los antiguos campos, el tipo de gestión posterior al abandono, la composición vegetal en las proximidades, y la calidad del suelo en el momento del abandono. En general, la colonización ha seguido un patrón bien conocido (ver García-Ruiz \& Lana-Renault, 2011). En menos de 10 años se desarrolla una cubierta herbácea relativamente densa, gracias al régimen de precipitaciones en el Pirineo, con más de $800 \mathrm{~mm}$ anuales. En ese estado se consideran prados de diente aprovechados directamente por el ganado entre octubre y mayo. Si la presión ganadera permanece relativamente alta, esos campos se mantienen como prados por tiempo indefinido, impidiendo el paso al estado de matorral o de bosque. Sin embargo, donde la presión ganadera ha disminuido, especialmente en los campos más alejados de los núcleos de población menos frecuentados por el ganado, los prados tienden a evolucionar hacia formaciones más o menos densas de matorral, con abundante presencia de Buxus sempervirens, Juniperus oxycedrus, Rosa gr. canina, Genista scorpius y Echinospartum horridum como especies más representativas. Al cabo de décadas los bosques acaban extendiéndose, con dominio de $Q$. faginea, pinares de $P$. sylvestris y $P$. nigra, a veces en formaciones mixtas, y con presencia ocasional de Amelanchier ovalis y Crataegus monogyna. En una fase avanzada de esta evolución el paisaje se simplifica mucho, de manera que alrededor de los asentamientos dominan los prados de diente $\mathrm{y}$, a cierta distancia, las laderas están cubiertas por un matorral cerrado y árboles dispersos, además de algunas manchas de bosque denso (Vicente-Serrano et al., 2005; Lasanta et al., 2009). En todo caso, las relaciones entre pastoreo y colonización vegetal después del abandono de tierras de cultivo son muy difíciles de estudiar, debido a la gran va- 
riedad de situaciones posibles desde el punto de vista de la gestión y de las características de los campos.

Ahora bien, aunque la tendencia natural es hacia el bosque, alcanzar el estadio forestal puede costar décadas o incluso siglos. Las áreas cultivadas que se abandonaron tempranamente sufrieron una presión ganadera relativamente intensa y el uso del fuego para eliminar los matorrales espinosos y favorecer el renuevo de una cubierta herbácea. Como la aplicación del fuego era recurrente cada pocos años durante la primera mitad del siglo Xx, esos campos experimentaron periodos cortos pero relevantes de erosión del suelo, hasta que la parcela se convertía en ocasiones en un pavimento de piedras (RuizFlaño et al., 1992; Navas et al., 2005). En el caso de los campos nómadas o articas, el problema ha sido muy similar: tras varios ciclos de desbroce y cultivo, el suelo quedaba agotado y erosionado, dificultando el avance de la sucesión vegetal (Lasanta et al., 2006a). Los estudios desarrollados en la Estación Experimental Valle de Aísa han confirmado las dificultades para un avance rápido de la sucesión vegetal en articas abandonadas y la intensa erosión asociada a la escasa cubierta de vegetación (NadalRomero et al., 2013), especialmente durante eventos de baja frecuencia (Nadal-Romero et al., 2012b). A veces, una densa cubierta de Genista scorpius puede permanecer durante décadas sin avanzar hacia estadios más maduros de la sucesión, llegando incluso a abrirse claros por senescencia debido a la falta de nutrientes o al alejamiento de fuentes de semillas. En cambio, la colonización puede ser muy rápida en antiguos campos con suelos profundos y ricos en nutrientes. En consecuencia, las relaciones entre topografía, edad de abandono, gestión posterior, calidad del suelo y colonización vegetal son extremadamente complejas en estas unidades de paisaje y difícilmente pueden establecerse pautas generales (ver también Ruiz Sinoga \& Martínez Murillo, 2012).

En general, el abandono del cultivo en laderas pendientes reduce la erosión debido al efecto protector de la cubierta vegetal y a la ausencia de laboreo (Lasanta et al., 2010). Ruiz-Flaño (1993) demostró que la mayor actividad geomórfica tenía lugar en los primeros años tras el abandono, cuando aún no se había instalado una densa cubierta de herbáceas, pero después la erosión era muy baja, en parte también debido a la mejora de las características del suelo (Martínez-Fernández et al., 1995). A escala de pequeñas cuencas, se ha comprobado que el abandono de tierras ha conducido a una marcada contracción de las fuentes de sedimento y a una reducción de la conectividad entre laderas y cauces, debido a la presencia de matorrales densos y bosque (Lana-Renault et al., 2007a; Lana-Renault \& Regüés, 2009). Esto ocurre incluso aunque se generen frecuentes flujos de derrubios (debris flows) en laderas antiguamente cultivadas (Lorente et al., 2002), pues con mucha frecuencia no llegan a conectar directamente con la red fluvial (Lorente et al., 2003). Esta sería la razón por la que los flujos de derrubios contribuyen, sólo en una pequeña parte, a la carga sedimentaria de los ríos pirenaicos (Bathurst et al., 2007).
A escala regional, el abandono de tierras de cultivo se ha considerado el principal factor responsable de la reducción de la tasa de aterramiento en los embalses pirenaicos (Valero-Garcés et al., 1996-97, 1999; García-Ruiz et al., 2010b). Alatorre et al. (2012, 2013) aplicaron el modelo WATEM/SEDEM a la cuenca de Arnás, totalmente ocupada por campos abandonados en fase de colonización vegetal, con el fin de predecir la localización de las áreas sujetas a mayor riesgo de erosión. Los mapas resultantes muestran la gran extensión e intensidad de las áreas erosionadas a comienzos del siglo XX, cuando la cuenca estaba aún en cultivo. El mapa actual, tras el cese de la actividad agrícola, muestra una clara reducción de las áreas erosionadas debido a la expansión de matorrales y pequeñas manchas de bosque, concentrándose la erosión sobre todo en las laderas más pendientes de exposición solana. Finalmente, en un escenario de expansión generalizada del bosque, las simulaciones de futuro sugirieron una marcada reducción de la erosión, localizada en las proximidades de los cauces. La aplicación de este modelo refleja razonablemente la evolución de la erosión en relación con los cambios de uso del suelo y de cubierta vegetal conocida por estudios empíricos, y la gran incidencia de los usos agrícolas tradicionales en la erosión del suelo de las laderas pendientes (García-Ruiz, 2010).

La comparación de la producción de sedimento y sus características granulométricas entre diferentes cuencas de montaña confirmó el papel determinante de la vegetación (García-Ruiz et al., 2008; Nadal-Romero et al., 2012a), con altísimas tasas de exportación de sedimento desde la cuenca de cárcavas (Araguás) frente a la cuenca de bosque (San Salvador) y frente a la cuenca de campos abandonados (Arnás), esta última con un comportamiento cada vez más parecido a la cuenca forestal, aunque manteniendo una cierta torrencialidad que se manifiesta en la presencia de carga de fondo en el balance de sedimento (Lana-Renault \& Regüés, 2007; Nadal-Romero et al., 2012a). Como consecuencia del descenso de aportes de sedimento desde las laderas, el cauce se ha convertido en la principal fuente de sedimento en la cuenca de campos abandonados.

En el caso de las terrazas de cultivo o bancales abandonados, se dan además otras circunstancias. Las terrazas son estructuras artificiales construidas para propiciar el aprovechamiento agrícola de laderas pendientes, favoreciendo la infiltración del agua de lluvia y limitando el riesgo de erosión del suelo. Esas infraestructuras representan una enorme inversión de trabajo, incluyendo el desplazamiento de suelo desde otras áreas próximas, pero exigen también un gran esfuerzo de mantenimiento. En particular, el salto entre bancales es muy inestable y evoluciona fácilmente hacia pequeños movimientos en masa, que pueden acabar por degradar la funcionalidad de las terrazas, tal como demostraron Lasanta et al. (2001) en el Valle de Jubera (Sistema Ibérico). Mientras los campos se mantuvieron en cultivo, los agricultores se encargaban de reparar las cicatrices de los deslizamientos, pero una vez se abandonaron el deterioro ha sido progresivo, especialmente en las concavidades por la mayor humedad del 
suelo. Por supuesto, la pendiente de la ladera es otro factor relevante a la hora de explicar la rapidez en la evolución de los bancales. Gallart et al. (1994) demostraron que el abandono de terrazas conduce además a cambios en la organización espacial de zonas saturadas y, en ocasiones, al establecimiento de una nueva (y muy erosiva) red de drenaje que aprovecha en parte los drenajes artificiales construidos para derivar la escorrentía superficial (Gallart, 2009).

El abandono de tierras de cultivo también ha impulsado la política de repoblaciones forestales en el Pirineo, que tuvo su auge durante los años sesenta y setenta del siglo xx (Chauvelier, 1990). Algunas repoblaciones, entre ellas muchas de las más extensas, estuvieron relacionadas con la construcción de embalses, con el fin de reducir el aporte de sedimento hacia estos últimos (Ortigosa et al., 1990). Ese es el caso de las realizadas en el Prepirineo, dentro de la cuenca de drenaje del embalse de La Peña (río Gállego) o las del valle del río Ijuez, una cuenca extremadamente degradada a mediados del siglo xx y que fue casi completamente reforestada. En ambos casos se ha detectado una notable disminución de la producción de sedimento (García-Ruiz \& Ortigosa, 1988; Sanjuán et al., 2014) y de su tamaño, dando lugar además al restablecimiento de la vegetación en los cauces y orillas (Ortigosa \& García-Ruiz, 1995). Sin embargo, Ortigosa (1991) demostró en el Sistema Ibérico riojano que la utilización de técnicas agresivas de repoblación (construcción de terrazas de bulldozer) no había contribuido en muchos casos a un descenso de la erosión del suelo. También comprobó que la respuesta hidromorfológica de las repoblaciones estaba muy directamente relacionada con el estado del suelo antes de la repoblación; es decir, los lugares previamente muy degradados no ofrecían una respuesta positiva frente a los trabajos de repoblación y seguían produciendo mucho sedimento, de donde cabía deducir la necesidad de discriminar bien los espacios sujetos a repoblación.

\section{La ocurrencia de eventos extremos y su efecto erosivo}

Es bien conocido el hecho de que un pequeño número de eventos de alta intensidad son los responsables de una gran proporción de la erosión y transporte de sedimento que ocurren en laderas y cuencas. La alta energía cinética de las lluvias más intensas, así como la incapacidad del suelo para absorber una parte importante de la precipitación, explican los elevados coeficientes de escorrentía superficial durante eventos extremos. La ocurrencia de deslizamientos superficiales y profundos suele estar ligada a lluvias de muy baja frecuencia, así como también la formación y rápida evolución de cárcavas, la erosión lateral o la incisión en cauces, el desarrollo de tramos trenzados (braided) en ríos, y el transporte de grandes volúmenes de sedimento en suspensión y de carga de fondo. Un evento pluviométrico extremo es capaz de producir grandes cambios en las laderas e incluso en la morfología de cauces, con repercusiones duraderas.
En el Pirineo Central, los efectos de estos eventos han sido estudiados a varias escalas espaciales. En las parcelas de la Estación Experimental Valle de Aísa se comprobó que la producción de sedimentos dependía de un corto número de eventos, y que los diferentes usos del suelo reaccionaban de forma diferente frente a las lluvias más cuantiosas (Nadal-Romero et al., 2012b). En total, los 25 principales eventos registrados entre 1991 y 2012 representaron más del $80 \%$ del sedimento movilizado, mientras que los tres eventos más intensos oscilaron entre el 25,4 y el $71,2 \%$ del total de sedimento movilizado en el periodo de estudio. En todo caso, está claro que lluvias de gran intensidad y crecidas catastróficas son fenómenos comunes en el Pirineo, aunque sus efectos más excepcionales se presentan con una gran variabilidad espacial y temporal.

A escala de cuencas y regional, se han estudiado varias lluvias extremas que han tenido importantes consecuencias en el paisaje, con riesgos para vidas humanas e infraestructuras. A este respecto es importante tener en cuenta que los ríos de montaña cuentan con elevados gradientes longitudinales, cauces relativamente estrechos y un rápido tiempo de concentración, debido a la fuerte pendiente de las laderas. Además, con demasiada frecuencia se ha ocupado parte de la llanura aluvial y se ha forzado el estrechamiento del cauce, para construir viviendas e infraestructuras deportivas o turísticas, que son fácilmente abatidas por el empuje de las aguas (Serrano Notivoli et al., 2014). Algunos ejemplos ilustran la trascendencia hidrológica y geomorfológica de los eventos pluviométricos extremos, que a veces pueden tener sólo un alcance local:

(i) Las lluvias del 19 al 21 de octubre de 2012 afectaron sobre todo a la cuenca alta del río Aragón, donde la suma de lluvia de los días 19 y 20 fue el evento más extremo registrado en dos días en todos los observatorios de la cuenca excepto uno (Serrano-Muela et al., 2013). La consiguiente avenida, que en algunos aforos correspondió a un periodo de retorno de 400 a 500 años, destruyó parte de una urbanización, ensanchó notablemente algunos tramos del río Aragón, provocó varios deslizamientos profundos y una intensa erosión en campos de cultivo recién sembrados de cereal. Además, el volumen de agua almacenado en el embalse de Yesa pasó en muy pocos días del 16 al 53\%. En el caso de la urbanización, localizada en Castiello de Jaca, se había desviado un canal del cauce del río Aragón hacia la orilla opuesta y así dar una sensación de seguridad; sin embargo, durante la avenida el río sobreexcavó en la base de una terraza fluvial, que se desplomó sobre el cauce y obligó a éste a retomar el cauce primitivo, a cuyo costado se había construido la urbanización. De esta crecida pudo disponerse además de información detallada en cuatro cuencas experimentales del Instituto Pirenaico de Ecología, pudiéndose comprobar la notable importancia de la cubierta vegetal en la respuesta hidrológica (Lana-Renault et al., 2014a). Así, la cuenca de San Salvador, con un bosque denso no perturbado, esperó hasta el tercer pico de intensidad de lluvia para empezar a reaccionar, y su principal pico de avenida fue re- 
lativamente moderado en comparación con la cuenca de Araguás, caracterizada por la presencia de cárcavas sobre margas poco permeables. Esta última cuenca reaccionó de manera inmediata y violenta a las primeras lluvias del evento. En cambio, la cuenca de Arnás, ocupada por antiguos campos de cultivo abandonados y en plena etapa de colonización vegetal, reaccionó muy moderadamente a las primeras lluvias y luego alcanzó un pico importante a medio camino entre la cuenca forestal y la cuenca de cárcavas. Por su parte, la cuenca de Izas, con pastos subalpinos y cárcavas sobre pizarras en la zona de cabecera, reaccionó también muy pronto a la lluvia y produjo un gran pico de avenida por la rápida concentración de la escorrentía superficial. Lamentablemente, la cuenca de Repoblación no llegó a funcionar y no pudimos tener información sobre la respuesta de un bosque repoblado frente a lluvias extremas.

(ii) En la cabecera del río Ésera las lluvias intensas y la rápida fusión de la nieve entre los días 17 y 19 de junio de 2013 provocaron la reactivación de procesos geomorfológicos fluviales y la reocupación del llano de inundación, con ensanchamiento del cauce y afecciones a urbanizaciones y a complejos deportivos, debido sobre todo a la intensa ocupación del fondo del Valle de Benasque en los últimos 50 años, que ha dado lugar a un aumento de la exposición al riesgo (Serrano Notivoli et al., 2014).

(iii) La crecida de noviembre de 1982 en el Pirineo Central tuvo origen en una baja presión centrada en el Mediterráneo y afectó, sobre todo, a las cuencas más orientales. Así, los valles del Noguera Ribagorzana, Ésera, Cinqueta, Cinca y Ara recibieron localmente más de $600 \mathrm{~mm}$. Las avenidas alteraron la forma y dimensiones de la llanura aluvial, hubo un gran aporte de sedimento grueso al cono de deyección del Remáscaro (Valle del Esera) y se formaron muchos deslizamientos superficiales en el piso subalpino. Incluso se reactivó ligeramente el gran deslizamiento profundo donde se asienta la localidad de Gistaín, con la apertura de grietas transversales, atribuidas al abandono de la red de drenaje que se había construido para derivar las aguas de escorrentía superficial y su infiltración en la cabecera del deslizamiento (Martí Bono \& Puigdefábregas, 1983).

(iv) El evento pluviométrico e hidrológico más relevante registrado recientemente en el Pirineo Central es el que ocurrió en el Barranco de Arás, afluente del río Gállego, junto a la localidad de Biescas, en la tarde del 7 de agosto de 1996. Su relevancia viene condicionada por sus consecuencias catastróficas: arrasamiento de un camping instalado en el cono de deyección del torrente y fallecimiento de 87 personas. Este es un buen ejemplo de (i) la ocurrencia de eventos excepcionales que afectan a territorios muy pequeños, y (ii) la importancia de una adecuada localización de las infraestructuras en relación con riesgos geomorfológicos que apenas son considerados (García Ruiz et al., 1996; White et al., 1997; Benito et al., 1998; Gutiérrez et al., 1998). Esta avenida se generó en un pequeño sector de la cuenca de Arás, donde estuvo lloviendo muy intensamente (en torno a $225 \mathrm{~mm}$ en poco más de una hora) hasta derivar en una avenida estimada en algo más de $400 \mathrm{~m}^{3} \mathrm{~s}^{-1}$, aunque esta cifra, deducida a partir de la altura que alcanzó el agua, el tamaño de la sección mojada y la velocidad que teóricamente registró la avenida en distintos puntos del cauce, está sobrevalorada debido a la incorporación de un gran volumen de sedimento durante el pico de crecida. El sedimento procedió en parte de la erosión del propio cauce y también del derumbamiento de casi 40 presas de retención de sedimento que habían sido construidas desde comienzos del siglo xx en el tramo inferior del barranco, contribuyendo con un total de entre 122.000 y 136.000 toneladas de sedimento (García Ruiz et al., 1996; White et al., 1997). El ápice del cono de deyección fue bloqueado por el gran aporte de sedimento, obligando a la avenida a desviarse hacia el lugar donde pocos años antes se había instalado un camping sobre el sector del cono que era funcional o activo antes de la canalización del cauce a principios del siglo xx. Para limitar o incluso evitar la ocurrencia de fenómenos similares en el futuro, se han construido nuevas presas de retención de sedimento y una gran presa en el ápice del cono de deyección, así como un nuevo cauce artificial que admitiría un caudal de avenida de unos $300 \mathrm{~m}^{3} \mathrm{~s}^{-1}$.

Los ejemplos anteriores son el testimonio de lo que representa un evento de gran magnitud en zonas de montaña, con probabilidad de ocurrencia en cualquier lugar, a veces afectando a espacios muy reducidos y otras veces a la generalidad de cuencas de alcance regional. Históricamente hay también pruebas de este tipo de eventos, destacando las avenidas que enterraron casi completamente la iglesia del Monasterio de San Adrián de Sasave, construida en el siglo XI en la cabecera del valle de Borau (Martí et al., 1997). Eventos de este tipo en pequeñas cuencas son capaces de agotar la disponibilidad de sedimento durante bastantes años, como ocurrió en la avenida de octubre de 1987 en la cuenca de Izas (Alto Valle del Gállego), que produjo un gran aporte de carga de fondo, de manera que en años sucesivos apenas hubo contribución de sedimento grueso incluso aunque ocurrieran avenidas de magnitud similar (Alvera \& García-Ruiz, 2000). En general, estos eventos son también los que producen un mayor aporte de carga gruesa al balance anual e interanual de sedimentos, como se ha comprobado en la propia cuenca de Izas (Martínez-Castroviejo et al., 1991) o en la cuenca de Arnás (Lana-Renault \& Regüés, 2007).

\section{Las consecuencias del Cambio Global sobre los recursos hídricos. La gestión de los embalses}

En páginas precedentes se han señalado los importantes cambios ocurridos en la cubierta vegetal y el clima durante las últimas décadas. En particular, el Pirineo Central ha asistido a un descenso de la presión humana en las laderas, con abandono general de tierras de cultivo, disminución de la actividad ganadera, reducción del número de incendios, reforestación de extensos perímetros y, consecuentemente, una expansión de la vegetación hacia formaciones de matorral y forestales. A la vez se ha consta- 

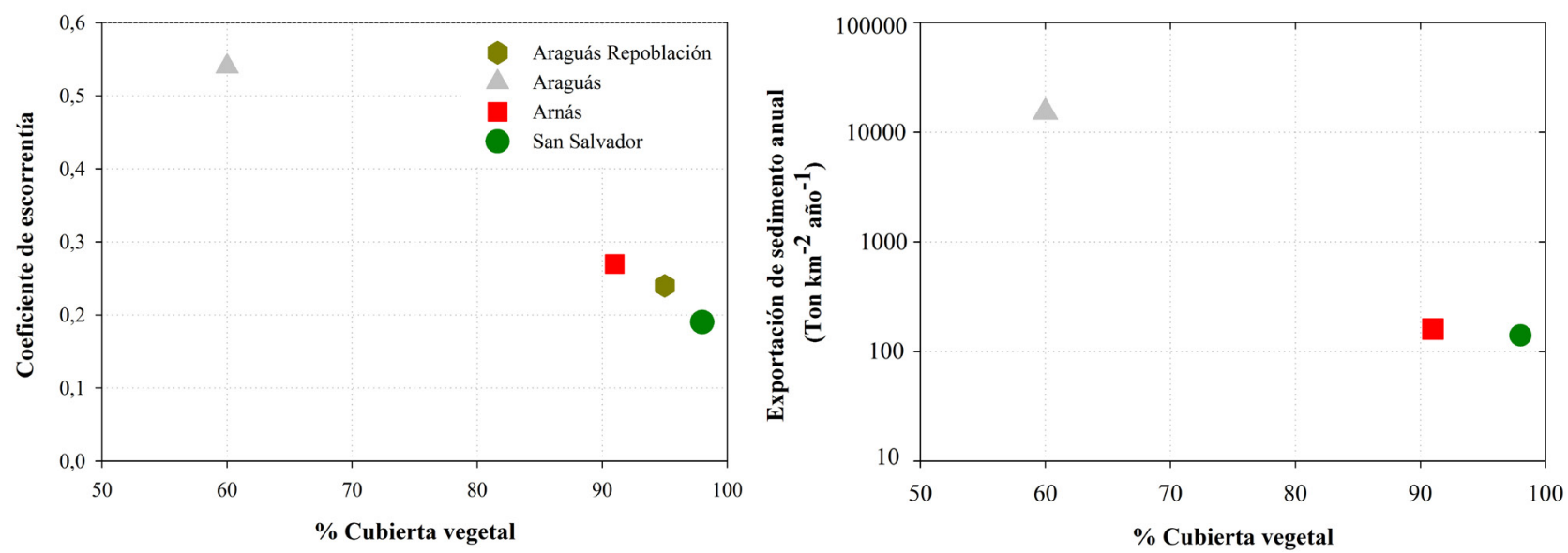

Figura 17: Relaciones entre la cubierta vegetal, por un lado, y el coeficiente de escorrentía y la exportación de sedimento, por otro, en las cuatro cuencas experimentales del piso montano pirenaico.

Figure 17: Relationships between plant cover, (i) runoff coefficient, and (ii) sediment yield in the four experimental catchments of the Pyrenean montane belt.

tado un aumento progresivo de la temperatura media anual, un descenso de la cantidad de nieve acumulada a finales de invierno, y una reducción de la precipitación en algunas estaciones. De ahí debe deducirse que los regímenes fluviales han experimentado cambios de notable envergadura, cuyas consecuencias son muy importantes para el manejo de los recursos hídricos, algo que puede hacerse extensivo a otras áreas de montaña Mediterránea (García-Ruiz et al., 2011b). Entre los cambios que han podido identificarse están los relacionados con la producción de escorrentía, la variabilidad espacio-temporal de las áreas productoras de escorrentía y las tendencias en los picos de crecida. Además, por supuesto, se ha detectado un notable descenso en los caudales de los ríos y un adelantamiento del máximo primaveral.

Tanto la Estación Experimental Valle de Aísa como las cuencas experimentales de San Salvador, Arnás, Araguás, Repoblación e Izas han servido, entre otros fines, para demostrar la importancia hidrológica de la cubierta vegetal. La citada Estación confirmó que el abandono de tierras de cultivo reducía la cantidad de agua exportada, favoreciendo la infiltración y la evapotranspiración, si bien esta respuesta era menos clara en el caso de las parcelas abandonadas de agricultura nómada, donde el efecto del cultivo sin prácticas de conservación perduraba mucho en el tiempo (Lasanta et al., 2006a). La expansión de una cubierta densa de matorral conducía a una notable reducción de la escorrentía superficial y, consiguientemente, de la erosión del suelo frente a la gran cantidad de agua y sedimentos producidos desde las parcelas cultivadas. La transformación de los campos cultivados en prados de diente significaba también una notable reducción de la escorrentía y la conservación del suelo (Lasanta et al., 2010; Nadal-Romero et al., 2013).

La monitorización de las cuencas experimentales sirvió para demostrar que el cambio de la escala de estudio mantenía la misma tendencia que las parcelas experimen- tales (García-Ruiz et al., 2010b): el abandono de tierras de cultivo favorecía una rápida expansión de la colonización vegetal (ciertamente más rápida en laderas de pendiente más suave y mejor conservadas, y en los bancales; más lenta en laderas muy pendientes con pocas estructuras de conservación) y una contracción de las áreas fuente de escorrentía y sedimento (Figura 17). Lana-Renault et al. (2007a, 2014b) y Lana-Renault (2011) comprobaron, no obstante, que esas áreas varían mucho en extensión según la época del año, según las características de cada evento lluvioso y en función del estado del nivel freático. El patrón espacial de saturación del suelo, que está parcialmente relacionado con el índice topográfico, es muy heterogéneo debido a la influencia de las actividades agrícolas del pasado. Las relaciones entre los niveles de la capa freática y el caudal son bastante débiles, especialmente durante la fase de recarga, lo que sugiere que en este tipo de ambiente todavía predominan, bajo determinadas condiciones, procesos de escorrentía hortoniana. Por otra parte, esta escasa relación también indica que hasta que la cuenca no alcanza un cierto umbral de humedad, la respuesta del caudal no es importante (Lana-Renault et al., 2007b, 2014b). Durante la estación fría y la primavera, con una notable extensión de los suelos saturados o muy húmedos, toda la cuenca está en condiciones de contribuir con agua y sedimento, de manera que la concentración de este último se diluye entre caudales muy elevados. Por el contrario, durante la estación seca, con el nivel freático muy bajo, lluvias de corta duración y elevada intensidad producen escorrentía en pequeños lugares degradados cerca de los cauces fluviales, dando lugar a pequeños picos de crecida con una elevada concentración de sedimento en suspensión (Lana-Renault, 2011; Lana-Renault et al., 2007b). El cauce se comporta ahora como la principal fuente de sedimento.

Frente a la complejidad de la cuenca de campos abandonados (Arnás), las restantes cuencas experimentales 
presentan un funcionamiento hidrológico más sencillo y predecible. Así, la cuenca forestal (San Salvador), con un suelo y un coluvión pedregoso profundos, además de una elevada interceptación de la lluvia y evapotranspiración, cuenta con coeficientes de escorrentía muy bajos a escala interanual y de eventos concretos. Durante la mayor parte del año apenas hay respuesta hidrológica frente a las precipitaciones, e incluso en verano deja de haber circulación de agua en el cauce. La evolución de los niveles piezométricos refleja que la capa freática sufre una lenta recarga durante el otoño y el invierno, hasta alcanzar un nivel próximo a la superficie a mediados de primavera. Es entonces cuando, durante una breve ventana temporal, pueden producirse crecidas de gran importancia. Desde junio, en cambio, se asiste a un rápido agotamiento de la capa freática y la cuenca vuelve a condiciones secas, incluso aunque las lluvias sean de alta intensidad (Serrano-Muela et al., 2008). Una comparación entre la cuenca forestal y la de campos abandonados arrojó diferencias muy notables en cuanto a los picos de crecida, el tiempo de respuesta (entre dos y tres veces más rápido en la última) y en el tramo de recesión del hidrograma (entre 1 y 2 órdenes de magnitud más rápido) (Lana-Renault et al., 2011a). Dependiendo del régimen de lluvias y del estado de humedad del suelo, en otras cuencas pirenaicas el periodo de aguas altas se adelanta al invierno, como sucede en el Pirineo y el piedemonte navarro (Giménez et al., 2012).

En el extremo opuesto, la cuenca de cárcavas (Araguás) tiene una respuesta inmediata frente a cualquier precipitación, con abruptos ascensos y descensos del hidrograma de crecida. También es la cuenca que tiene un más alto caudal específico $\left(1 \mathrm{~s}^{-1} \mathrm{~km}^{-2}\right)$ de todas las estudiadas, acompañado de muy altas tasas de exportación de sedimento en suspensión, contribuyendo junto a las restantes cuencas de cárcavas de la Depresión Interior Altoaragonesa, al aterramiento del embalse de Yesa (NadalRomero, 2011). Es importante precisar, no obstante, que las margas son rocas inicialmente muy resistentes a la erosión, pero evolucionan hacia un regolito muy erosionable debido a su rápida meteorización por los contrastes de temperatura y por la pérdida de cohesión interna debida a los contrastes de humedad y la penetración del hielo (Nadal-Romero \& Regüés, 2010). De hecho, estos autores demostraron que las laderas que miran al norte, más afectadas por la humedad y las heladas, son las que evolucionan más deprisa y contribuyen con más sedimento al balance de la cuenca, fenómeno que ha sido confirmado también mediante Láser Escáner Terrestre: en el periodo entre julio de 2013 y julio de 2014 la pérdida media de materiales en una ladera norte fue de $77 \mathrm{~mm}$, mientras que en la ladera sur fue de $32 \mathrm{~mm}$ (Nadal-Romero et al., enviado a). Tanto la escorrentía como la concentración de sedimento en suspensión en el torrente están muy relacionadas con la intensidad de la precipitación, confirmando la importancia de la escorrentía de tipo hortoniano (Nadal-Romero et al., 2008a, 2008b).

Dentro de la cuenca de cárcavas se monitorizó una pequeña cuenca de cabecera sobre sustrato de flysch, carac- terizada por la presencia de una repoblación forestal realizada en la década de 1960. Esta subcuenca, llamada Repoblación, cuenta con una densa cubierta vegetal sobre antiguos campos aterrazados. Su funcionamiento hidrológico es muy moderado, con hidrogramas de crecida de pendiente suave en sus tramos de ascenso y descenso y un tiempo de respuesta bastante retardado. Sin embargo, aún no puede equipararse al comportamiento hidrológico de la cuenca forestal, pues presenta mayores coeficientes de escorrentía y caudal específico, debido, muy probablemente, al hecho de que las décadas o siglos de cultivo previo a la reforestación contribuyeron a la degradación y erosión del suelo. En todo caso, la reforestación ha contribuido a reducir muy notablemente la respuesta hidrológica y a suavizar los picos de crecida (Nadal-Romero et al., enviado b).

Los resultados obtenidos en la Estación Experimental Valle de Aísa y en las cuencas experimentales contribuyen a explicar la evolución de los caudales a escala de cuencas regionales. Un estudio llevado a cabo en todo el Pirineo aragonés, desde el Valle de Ansó al Valle del río Noguera Ribagorzana, confirmó una tendencia regresiva, estadísticamente significativa, en el caudal de los ríos pirenaicos desde el segundo tercio del siglo xx. Esa tendencia demostró que, aunque caudales y precipitaciones han seguido una evolución paralela, desde comienzos de la década de 1970 hay un cambio en las relaciones entre ambas variables, de manera que para una misma precipitación se produce cada vez menos caudal. Este resultado se confirmó al contrastar los caudales observados y los caudales predichos por un sencillo modelo en el que los factores determinantes son la precipitación y la temperatura. Hasta la década de 1970 los caudales observados quedan por encima de la curva de caudales predichos, mientras que estos últimos superan a los caudales observados a partir de esa década, es decir, que el modelo predice que los ríos pirenaicos deberían llevar, de acuerdo con precipitaciones y temperatura, más agua de la que llevan actualmente (Beguería et al., 2003). Este cambio coincide precisamente con el momento en que se manifiesta de manera más acusada la recolonización vegetal tras el abandono del cultivo en laderas y el descenso de los incendios de origen humano. En un estudio más amplio sobre la evolución de los caudales en la cuenca del Ebro, López-Moreno et al. (2011b) comprobaron la ocurrencia de un marcado descenso de los caudales en la mayoría de las subcuencas. La evolución temporal de los residuales de modelos empíricos que relacionan el clima y la escorrentía en cada subcuenca proporcionaron evidencias de que el clima por sí solo no puede explicar el descenso observado en el caudal, si no se tiene en cuenta el aumento de la evapotranspiración por la vegetación natural, asociada al abandono de tierras de cultivo y al descenso de la presión ganadera. Las proyecciones de caudal estimadas para la cuenca del río Aragón mediante el modelo Regional Hydro-Ecologic Simulation System (RHESSys) para el periodo 2021-2050 indican que una ampliación de la superficie ocupada por bosques provocará un descenso en torno al $16 \%$ en el caudal anual, principalmente durante 
la primavera temprana, el verano y el otoño (López-Moreno et al., 2014). Sucede lo mismo cuando se observa la tendencia de los caudales a escala de toda la cuenca mediterránea (García-Ruiz et al., 2011). Y, en cierto modo, también cuando se analiza la evolución de las crecidas fluviales en el Pirineo Central. Los resultados obtenidos muestran una tendencia negativa en la intensidad de las avenidas en las últimas décadas, junto a un aumento en la importancia de los caudales más bajos en la contribución total anual, sin que se haya observado un cambio en la distribución de frecuencias de los eventos de precipitación. Este diferente comportamiento de escorrentía y precipitación sólo puede explicarse por el aumento de la cubierta vegetal relacionada con el abandono de cultivos y la reforestación durante la segunda mitad del siglo $\mathrm{xx}$ (López-Moreno et al., 2006).

Hay además razones climáticas de peso para explicar la evolución de los regímenes fluviales en el Pirineo Central. Se ha comentado en el apartado 7 que se ha producido un descenso en la cantidad de nieve acumulada en alta montaña al final del invierno, en parte relacionado con un aumento de las temperaturas y, sobre todo, con un descenso de la precipitación invernal. No debe olvidarse que los procesos de fusión y acumulación de nieve tienen una importancia extraordinaria en los ríos pirenaicos. GarcíaRuiz et al. (1986) estudiaron la dependencia respecto de la fusión nival en los distintos aforos pirenaicos, siendo tanto mayor cuanto más elevada es la altitud de la cuenca de drenaje. No obstante, se demostró que la relevancia de la nieve aumentaba hacia las cuencas más occidentales (Aragón Subordán, especialmente) por unidad de superficie situada por encima de 2000 m s.n.m., debido a la mayor influencia oceánica y al paso más frecuente de frentes en pleno invierno. Lana-Renault et al. (2010, 2011b) estimaron la precipitación, el caudal y el transporte de sedimento durante el periodo principal de fusión (mayo y junio) en la cuenca experimental de Izas (Alto Valle de Gállego), situada por encima de 2200 m s.n.m, es decir, en la transición entre el piso subalpino y el alpino. La precipitación de ese periodo representó entre el 11 y el 13\% del total anual; el caudal anual, en cambio, osciló entre el 48 y el 54\%; entre el sedimento transportado, los solutos representaron entre el 41 y el $51 \%$, y el sedimento en suspensión entre el 20 y el $22 \%$, mientras que la carga de fondo no se movilizó en absoluto, debido a que las fluctuaciones diarias de caudal carecen de la suficiente energía.

López-Moreno \& García-Ruiz (2004) confirmaron que en la mayor parte de las cuencas, incluidos sus tramos inferiores, la fusión de nieve contribuye más a los caudales primaverales que la precipitación. Esto da una idea de la extrema importancia de la nieve en los regímenes fluviales de los ríos pirenaicos que, por supuesto, se matiza hacia los tramos inferiores debido a la mayor influencia de las precipitaciones líquidas en altitudes más bajas. Desde un punto de vista erosivo la presencia de un extenso manto de nieve reduce la probabilidad de ocurrencia de avenidas en primavera y la erosión del suelo, ya que está protegido frente al impacto de las gotas de lluvia, como demostraron Puigdefábregas \& Alvera (1986) y Alvera et al. (1991). Además, no debe olvidarse que la presencia de un extenso manto nival introduce en los caudales pirenaicos una notable regularidad estacional y diaria. Así, durante el invierno los ríos pirenaicos, al menos en sus aforos de cabecera, mantienen caudales muy bajos y estables, incluso aunque se produzcan elevadas precipitaciones, mientras que en primavera los caudales son mucho más elevados y sujetos a grandes fluctuaciones diarias debidas a los contrastes de temperatura entre el día y la noche (García-Ruiz et al., 2001c; LópezMoreno et al., 2004; Lana-Renault et al., 2010, 2011b).

Desde un punto de vista hidrológico la consecuencia de la tendencia regresiva en la función de la nieve es bien evidente: los caudales primaverales de los ríos pirenaicos, que corresponden a la suma de abundantes lluvias y la fusión de nieve, tienen cada vez menos peso. Además, el momento del máximo anual tiende a adelantarse aproximadamente un mes, pasando de mayo a abril en los ríos más occidentales (Aragón, Gállego), y de junio a mayo en los más orientales (Ara, Cinca, Ésera y Noguera Ribagorzana). En consecuencia, se adelanta y acentúa el estiaje anual, al agotarse antes la reserva de nieve, un fenómeno también detectado en la mayoría de los ríos de los Alpes (Zampieri et al., 2015).

Asistimos, pues, a un cambio hidrológico de envergadura, directamente relacionado con el Cambio Global (evolución de precipitaciones y temperaturas, cambios profundos en las características de la vegetación y los usos del suelo) y cuya consecuencia inmediata es un cambio en la disponibilidad y variabilidad temporal de los recursos hídricos. Esto tiene importantes implicaciones desde el punto de vista de la gestión y aprovechamiento de tales recursos y, en particular, el manejo de los embalses.

La mayor parte de los grandes ríos del Pirineo central, con excepción de los ríos Ara y Aragón Subordán, cuentan con uno o varios embalses cuya finalidad es (i) la regulación de los caudales para optimizar el almacenamiento de agua de cara a su aprovechamiento en las grandes áreas de regadío del centro de la Depresión del Ebro (Bardenas, Monegros, Riegos de Aragón y Cataluña), y (ii) la producción de energía hidroeléctrica, especialmente en pequeños embalses de cabecera (antiguos lagos de origen glaciar) y en algunos de los grandes embalses para regadío (Mediano, El Grado, Lanuza, Canelles).

Los embalses que están destinados al abastecimiento de agua de riego tienen un régimen muy sencillo pero también muy vinculado a los regímenes fluviales. La demanda de agua para riego exige que los embalses alcancen su máximo volumen almacenado a finales de primavera (preferentemente junio). Este volumen máximo se consigue, sobre todo, reteniendo caudales durante los periodos de aguas altas, es decir, primavera y, en menor medida, el otoño (López-Moreno et al., 2000, 2004). Lo normal es que los embalses alcancen su volumen más bajo a comienzos de otoño, después de haber atendido a las necesidades de agua de los regadíos. Con las lluvias intensas de otoño, comienza el llenado que suele detenerse en 
invierno (cuando las crecidas no son casi nunca retenidas por el embalse) a la espera de los caudales elevados de primavera, contando con la seguridad de la fusión de la nieve, de manera que esta última y las lluvias primaverales contribuyen al llenado final del embalse (López-Moreno et al., 2002). Sin embargo, a veces las lluvias de otoño son menores de lo esperado, en cuyo caso, el llenado del embalse ocurre más lentamente durante todo el invierno y se completa en primavera, si ha habido suficiente nieve acumulada en cabecera en invierno. En todo caso, la dependencia del llenado del embalse respecto de los caudales de primavera (que a su vez están muy condicionados por la fusión de la nieve) es muy grande, y cada vez más inestable en la medida en que la acumulación de nieve muestra una tendencia regresiva. López-Moreno et al. $(2004,2008 \mathrm{c})$ demostraron que el régimen de llenado de los embalses pirenaicos tiende a adaptarse al nuevo régimen fluvial, con menor peso de los caudales primaverales, a iniciar antes la temporada de riego, a veces sin estar lleno el embalse, y a llegar a comienzos del otoño con un menor volumen embalsado. Ésta es la consecuencia de los menores caudales y del cambio de régimen fluvial, mientras que la demanda de agua en las zonas de regadío se mantiene estable o incluso ha tendido a aumentar en la medida en que se han introducido cultivos que exigen un mayor consumo de agua (Playán \& Mateos, 2006).

Es evidente que la construcción de embalses en los ríos pirenaicos ha alterado profundamente el régimen de estos últimos y también su dinámica geomorfológica, como se ha comprobado en otros embalses de la cuenca del Ebro (Batalla et al., 2014). Según López-Moreno \& García-Ruiz (2003), el tipo de actividad a la que se destina el agua almacenada en los embalses contribuye a explicar la distribución estacional de los cambios producidos aguas abajo en el régimen fluvial. También depende de que exista o no un canal de derivación al pie de presa destinado a abastecer los regadíos, como sucede en los embalses de Yesa y El Grado. En ese caso, el río se ve afectado por un notable descenso de caudal a lo largo de todo el año, especialmente en verano. Esto es aún más acusado en los últimos años debido al menor caudal de los ríos pirenaicos y a la necesidad de atender a la demanda, lo que se consigue únicamente reduciendo al máximo el caudal que sale desde el embalse hacia el río. Si el canal de derivación no está a pie de presa, el efecto de embalse se manifiesta en un descenso de caudales en otoño y primavera, especialmente, y un aumento de los mismos en verano, como sucede en los embalses de Mediano y Búbal. El funcionamiento de los embalses destinados a la producción hidroeléctrica es más complejo, puesto que además de adaptarse a las condiciones hidrológicas tienen que hacerlo también a la demanda de electricidad. Así, los embalses de Lanuza y Búbal, en la cabecera del río Gállego, y de Escales, en el río Noguera Ribagorzana, muestran frecuentemente volúmenes de salida más elevados que los de entrada desde octubre hasta abril con el fin de atender a la demanda energética invernal. Los pequeños embalses de alta montaña en la cuenca del Gállego se llenan entre mayo y junio, aprovechando la fusión de nieve, y su desembalsado se produce a partir de agosto hasta el mes de marzo.

El descenso en las aportaciones de los ríos pirenaicos a los embalses, el abandono de cultivos en laderas pendientes y la expansión de matorrales y bosques explican también el descenso en la tasa de aterramiento de los embalses. Así lo demostraron Valero-Garcés et al. (1996-97, 1999) en el embalse de Barasona (cuenca del Ésera), y López-Moreno et al. (2003) en el embalse de Yesa.

\section{Cambios en la morfología y dinámica de los cauces fluviales}

La dinámica hidrológica y geomorfológica de las laderas se transmite finalmente a los ríos, cuyo funcionamiento está muy relacionado con la cantidad de agua y sedimento que llega desde las vertientes. Cambios en la cubierta vegetal o en las características de la precipitación introducen alteraciones en la generación de escorrentía, la erosión del suelo y la conectividad entre laderas y cauces.

En el momento de máxima presión demográfica, la mayor parte del territorio se explotaba intensamente, con el cultivo de laderas pendientes y empleo frecuente del fuego en áreas de pastos. La erosión debió de ser muy alta, así como la capacidad para generar escorrentía en las laderas, dando lugar a una elevada torrencialidad en los cauces fluviales. Muy probablemente, en el Sector del Flysch, es decir, allí donde la presencia humana era más constante, los ríos evolucionaron hacia cauces de tipo trenzado (braided), con escombrado de cantos y bloques en toda la llanura aluvial, y varios canales inestables que cambiaban de posición durante cada avenida (Figura 18). La cartografía geomorfológica elaborada por Rubio Fernández \& Hernández Santón (1990) para el cauce del río Ara sugiere que el transporte de sedimento grueso dominaba la dinámica del cauce, caracterizado por la presencia de canales y barras inestables desprovistos de vegetación. El mismo fenómeno se aprecia en la cartografía geomorfológica del cauce del río Cinca elaborada por Beguería et al. (2006). En ambos casos se utilizaron las fotografías aéreas de 1929 de la Confederación Hidrográfica del Ebro, si bien la torrencialidad se ponía también de manifiesto en las fotografías aéreas de 1956-57 en muchos otros ríos pirenaicos. Era la mejor evidencia de la interacción, siempre compleja, entre laderas y cauces, que igualmente se ponía de manifiesto en los conos de deyección, tan activos a comienzos del siglo xx.

Un excelente ejemplo de torrencialidad durante el siglo XIX y parte del Xx es el del río Ijuez, en la cabecera del río Aragón. Instalada en el Sector del Flysch, la cuenca del río Ijuez fue intensamente explotada por cinco pequeños pueblos que deforestaron y cultivaron casi todas las laderas, dejando la parte superior del valle para el aprovechamiento ganadero de pastos subalpinos. En el momento de máxima presión humana, la actividad geomorfológica de las laderas debió ser muy intensa, con barrancos afluentes muy pendientes y bien conectados con el cauce 


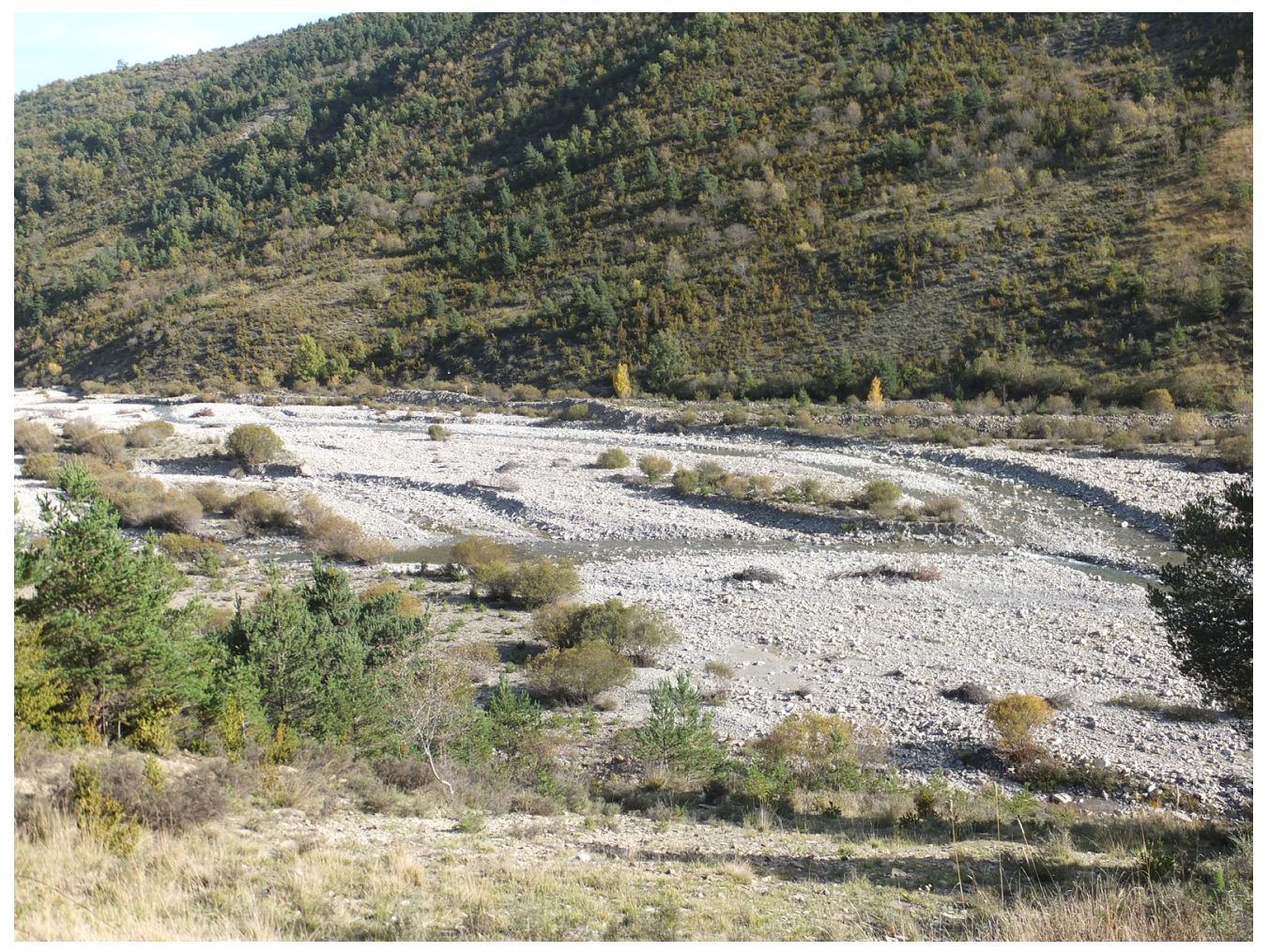

Figura 18: El río Aurín en su curso inferior, mostrando aún algunos rasgos de torrencialidad a pesar del descenso de aportes sedimentarios desde las laderas como consecuencia de la reforestación.

Figure 18: The Aurin River in its lower reach, with torrential features in spite of the declining sediment supply from the hillslopes as a consequence of reforestation.

principal (Martínez-Castroviejo \& García-Ruiz, 1990). De entonces es el desarrollo de numerosos flujos de derrubios (debris flows), que llegaron a cubrir la terraza baja. Entre los flujos de derrubios se encontraron varios restos de troncos y ramas que pudieron datarse mediante ${ }^{14} \mathrm{C}$ en unos 125 años cal BP, es decir que corresponden a finales del siglo XIX, coincidiendo con el máximo periodo de deforestación (Sanjuán et al., 2014).

La reforestación consiguiente al abandono de tierras de cultivo provocó un marcado cambio de tendencia en la dinámica fluvial, que se ha comprobado en cuencas de diferentes tamaños. Así, los cauces de los ríos Cinca y Ara han experimentado una reducción en el número de cauces secundarios y la colonización con arbolado de numerosas barras laterales y centrales en la llanura aluvial (Rubio Fernández \& Hernández Santón, 1990; Beguería et al., 2006), lo que sugiere que esta última es barrida con menos frecuencia por avenidas intensas, y que los sedimentos en el cauce se renuevan con más lentitud. Por ejemplo, en el cauce del río Cinca las barras sin vegetación pasaron del $69,6 \%$ a ocupar el $29,4 \%$ de la llanura aluvial entre 1929 y 1981 (Beguería et al., 2006). A otra escala, en la cuenca del río Ijuez, la espectacular expansión del bosque (en gran parte inducida por repoblaciones artificiales) ha dado lugar a un descenso de la erosión y de la conectividad entre laderas y cauces desde la década de
1960, tal como demostraron Beguería (2005) y Bathurst et al. (2007). El resultado es un estrechamiento de la llanura aluvial, que se ha cubierto parcialmente de arbolado, y un encajamiento del cauce en sus propios sedimentos, hasta un total de $3 \mathrm{~m}$, dejando colgado el enlace entre los afluentes y el cauce principal (Sanjuán et al., 2014). Esto significa que un descenso en el aporte de sedimento desde las laderas no significa necesariamente un descenso en el transporte de carga de fondo en el cauce, puesto que este último se encaja para compensar el déficit de sedimento. En ese caso, la erosión del cauce es la principal fuente de sedimento (Surian \& Cisotto, 2007; Sanchis-Ibor \& Segura-Beltrán, 2014) y, consiguientemente, la exportación de carga de fondo desde una cuenca no siempre es un buen indicador de su actividad geomórfica (Trimble, 1999), puesto que las fuentes de sedimento en las laderas pueden ser sustituidas por otras fuentes en el propio cauce. La incisión ha dado lugar a un aumento en el tamaño de los bloques del cauce cuando se comparan las medidas tomadas en 1991 (Martínez-Castroviejo \& García-Ruiz, 1990) y en 2013 (Gómez-Villar et al., 2014), provocando un típico efecto de armouring que ha sido detectado en otros ríos mediterráneos (Liébault \& Piégay, 2001). Una evolución similar se ha producido en conos de deyección, donde se ha constatado un marcado encajamiento del cauce y un estrechamiento de las áreas más activas e inesta- 
bles (Beguería et al., 2006), en buena parte debido también a la construcción de presas de retención de sedimento en el tramo inferior de algunos barrancos y en el propio ápice de los conos.

\section{Discusión y conclusiones}

Lejos de ser estables, las condiciones ambientales en el Pirineo Central y, en general, en el resto de montañas mediteráneas, han experimentado importantes fluctuaciones, tanto hidrológicas, climáticas, de intensidad de procesos geomorfológicos y de cobertera vegetal (Montserrat, 1992; González-Sampériz et al., 2005, 2006, 2009; Pérez-Sanz et al., 2013). Estos cambios ambientales han condicionado la intensidad de la ocupación del territorio desde el Neolítico, pero ha sido a partir de la época medieval y, sobre todo, de mediados del siglo XIX cuando el principal factor que determina la evolución del paisaje y su dinámica es la gestión humana y su capacidad para interferir en la colonización vegetal y en la forma en que la precipitación se distribuye en el suelo entre los diferentes componentes del ciclo hidrológico.

Las páginas precedentes demuestran que el Pirineo Central ha experimentado notables cambios de paisaje y de dinámica hidromorfológica a medida que lo hacían el clima y la presión humana sobre el territorio (Morellón et al., 2009; Corella et al, 2011; Rull et al., 2011). La evolución climática a lo largo del Holoceno, con condiciones mucho más benignas en cuanto a precipitaciones y temperatura que durante los últimos periodos fríos del Pleistoceno Superior, propició el establecimiento de masas forestales cada vez más complejas y variadas (Gil-Romera et al., 2014), llegando a estabilizarse la presencia de formaciones de abetos y de hayas complementando a los pinares, abedulares y robledales (Montserrat, 1992; PérezSanz, 2014). El avance del bosque no estuvo exento de variaciones, interrupciones e incluso retrocesos (Ver Figuras 15 y 16), pero las condiciones templadas submediterráneas y la consiguiente expansión forestal pueden darse por consolidadas a lo largo de todo el Holoceno. No obstante, algunos cambios climáticos dentro del Holoceno se han presentado de forma abrupta y han provocado importantes alteraciones en la vegetación y, sobre todo, en la capacidad de los grupos humanos para generar sistemas sostenibles de organización del espacio, siendo el evento 8.2, la Anomalía Climática Medieval o la Pequeña Edad del Hielo los que hasta el momento parece que más han afectado a las relaciones entre las sociedades humanas y los recursos naturales (González-Sampériz et al., 2009; Pérez-Sanz et al., 2011; Morellón et al., 2012). La Pequeña Edad del Hielo causó incluso un ligero descenso del límite superior del bosque (Camarero et al., enviado), que está ascendiendo en altitud actualmente con el calentamiento global, tal como se registra también en las secuencias palinológicas de altitud, como la de la Basa de la Mora (1914 m s.n.m., Pérez-Sanz et al., 2013), Estanilles (2200 m s.n.m., Pérez-Obiol et al., 2012), o incluso el todavía inédito registro del ibón de Marboré (2612 m s.n.m., Leunda, 2013; Valero-Garcés et al., 2013), por ejemplo.
La acción humana, primero muy incipiente a mediados del Holoceno y cada vez más activa desde la Edad del Bronce (Figura 4), ha producido grandes alteraciones en las formaciones vegetales, con la deforestación del piso subalpino y de gran parte del piso montano, especialmente en las solanas, ocupadas de manera general por campos de cultivo o por formaciones de matorral que se quemaban frecuentemente para favorecer el pastoreo. Cuando a mediados del siglo xIx se alcanza la máxima densidad demográfica en el Pirineo, se registra también la mayor ocupación de laderas y fondos de valle y se cultiva todo lo que era posible cultivar. En los valles más occidentales (la cuenca superior del río Aragón) predominaron los campos en pendiente, a veces con un ligero abancalamiento en su parte inferior, llegando a cultivarse algunos campos incluso por medio de procedimientos tan poco conservadores como la agricultura nómada (articas), que producía escasas cosechas de cereal para sostener al excedente demográfico en condiciones extremas de pendiente. En cambio, hacia el este, los valles del Ara, Cinca, Ésera y Noguera Ribagorzana vieron el desarrollo de bancales o terrazas que consumieron mucha energía y dieron lugar a culturas basadas en el aprovechamiento complejo y cuidadoso del paisaje, incluso en pendientes muy fuertes. Algunos de esos campos se instalaron en el límite climático de la agricultura de montaña; son los panares, localizados en el entorno de los 1600 m s.n.m., conectando generalmente con los pastos estivales del piso subalpino. Hoy todos los bancales están amenazados por la inestabilidad que provoca la ocurrencia de deslizamientos entre bancal y bancal, amenazando con arruinar el esfuerzo de siglos anteriores. ¿Por qué en unos valles, hacia el oeste, predominan los campos en pendiente y en otros valles, hacia el este, la agricultura se basó sobre todo en bancales? No hemos sabido responder a esta pregunta, necesitada de estudios más profundos sobre la influencia de culturas basadas en una diferente percepción del paisaje y de sus limitaciones frente a los riesgos naturales (Balcells, 1976). Tenemos hipótesis, pero querríamos más certezas a este respecto.

Lo cierto es que muchos suelos llegaron esquilmados a comienzos del siglo xx después de siglos de incendios, deforestaciones, pastoreo que apelmazaba suelos en la estación húmeda, soportando lluvias intensas, deslizamientos profundos y superficiales, arroyamiento difuso y formación de cárcavas, tanto en el piso subalpino como en el piso montano, donde se instalaron asentamientos y campos de cultivo. En esas condiciones, los ríos recibieron grandes volúmenes de sedimentos cada vez que una lluvia intensa conectaba laderas y cauces, generándose avenidas violentas que cambiaban la forma de las llanuras aluviales, la distribución de la vegetación y la localización de las huertas. Eran ríos torrenciales, con cauces trenzados que transportaban bloques y gravas, a veces con tendencia a la agradación, dada la incompetencia de los ríos para desplazar todo el sedimento que llegaba desde las laderas (Martínez-Castroviejo \& García-Ruiz, 1990). La inestabilidad pluviométrica de algunos momentos de la PEH contribuyó aún más al desorden, difi- 
cultando así la percepción de las relaciones entre impacto humano, transformación del paisaje y consecuencias hidrológicas y geomorfológicas. En todo caso, la evolución del paisaje y de la erosión durante el siglo XIX y comienzos del xx confirma que la pérdida y degradación del suelo, la deforestación, y el acarreo de grandes volúmenes de sedimento hacia y desde los ríos, son una consecuencia de las tensiones producidas por las desigualdades sociales del sistema de producción típico de la montaña y por la presión ejercida sobre un medio (las áreas de montaña), caracterizado por su alta energía, es decir, por su capacidad para reaccionar con rapidez frente a cambios en alguno o varios de los factores que explican el funcionamiento de los sistemas naturales. Las fluctuaciones climáticas ocurridas en el último milenio (la Anomalía Climática Medieval y la Pequeña Edad del Hielo, principalmente) no han hecho otra cosa que poner de relieve las contradicciones internas del sistema y las resultantes de sus relaciones con el exterior, ahondando en las tensiones generadas por la intensa presión humana.

El descenso del número de habitantes que ha tenido lugar en el Pirineo Central desde comienzos del siglo xx, y los cambios que se ha producido tanto en la economía española como en la función de las montañas en un contexto territorial más amplio, explican el abandono general de actividades agropecuarias en las laderas, la menor presión sobre el medio forestal y la concentración de algunas actividades en lugares muy concretos (estaciones de esquí, construcción de urbanizaciones junto a núcleos rurales tradicionales, extracción de áridos, producción de forraje en fondos de valle). La consecuencia más importante ha sido la colonización vegetal de los antiguos campos de cultivo y áreas de pastoreo, que se ha traducido en la expansión del bosque (muchas veces favorecida de forma artificial), la entrada de formaciones densas de matorral, el descenso en la capacidad de producción de escorrentía y sedimento desde las laderas, los cambios en la localización de las áreas fuente de agua y sedimento, la disminución de la conectividad entre laderas y cauces, y el estrechamiento de la llanura aluvial, donde además los ríos han tendido a la incisión (hasta $3 \mathrm{~m}$ en algunos casos). Desaparecieron los cultivos cerealistas en laderas, tan propensos a la erosión, como se demostró en la Estación Experimental Valle de Aísa, y en su lugar bosque y matorrales aumentan la interceptación de la lluvia, favorecen la infiltración y protegen al suelo del impacto de las gotas de lluvia o del arrastre por el arroyamiento superficial. También hay mucho menos ganado, lo que ha favorecido la desaparición del uso del fuego como medio para despejar el monte de matorrales espinosos. Por supuesto, sigue habiendo erosión en muchas áreas del Pirineo Central: los deslizamientos que afectan al piso subalpino durante lluvias de baja frecuencia, y que crean cicatrices con suelo desnudo difíciles de sellar. También se forman flujos de derrubios durante lluvias intensas en el piso montano, especialmente en laderas que han sufrido una fuerte presión humana en el pasado (Lorente et al., 2002; Bathurst et al., 2007), aunque su frecuencia tiende a remitir en las últimas décadas (Beguería, 2005) como consecuencia del mayor cubrimiento vegetal. Hay cárcavas muy activas, que no van a frenarse en las próximas décadas. Son inestables por naturaleza, y en un medio subhúmedo o húmedo a la vez que frío como el del Pirineo Central los procesos de meteorización en margas alientan la erosión y el transporte de sedimento en cualquier época del año, especialmente en primavera y otoño, convirtiéndose en espacios muy productores de sedimento por su fácil conexión con la red fluvial principal (Nadal-Romero \& Regüés, 2010).

Pero, en general, las áreas erosionadas han visto reducida su extensión en los últimos 50 años (ver, por ejemplo, el caso de la cuenca del río Ijuez: Sanjuán et al., 2014) y se limitan cada vez más a los sectores que sufrieron una degradación extrema por la agricultura nómada (slash-and-burn o shifting agriculture), o por el paso frecuente del ganado. Además, algunas de las principales fuentes de sedimento conectan difícilmente con la red fluvial. Lana-Renault (2011) llegó a la conclusión de que las zonas que habían sufrido una fuerte presión humana y luego se habían abandonado funcionan como un mosaico muy complejo, en el que sus distintas unidades son el resultado de la discriminación espacial que el hombre ha introducido históricamente en el paisaje. Algunas de las piezas de ese mosaico aún no se han recuperado, y quizás tarden aún décadas en hacerlo. Por eso, todavía los ríos pueden fluir con una elevada carga de sedimento en suspensión durante lluvias cortas pero intensas, que afectan a las zonas degradadas con suelo desnudo cerca de la red fluvial. Sus efectos tienden a diluirse durante lluvias más duraderas, cuando la escorrentía procede de toda la cuenca (Lana-Renault et al., 2007a), aunque la erosión en el propio cauce y sus laterales contribuye a mantener una carga sólida relativamente importante.

Los efectos de estos cambios de uso del suelo y de cubierta vegetal, además de la reducción de las precipitaciones invernales y el aumento de la temperatura, se están dejando ya sentir en los recursos hídricos. Diferentes estudios han confirmado un descenso estadísticamente significativo en los caudales anuales (por supuesto, en ríos no alterados por embalses o por derivaciones de agua) (Beguería et al., 2003; López-Moreno et al., 2011b, 2014), y un adelanto en aproximadamente un mes del momento en que se produce el máximo primaveral (López-Moreno \& García-Ruiz, 2004). Naturalmente, esto introduce cambios en la gestión de los embalses, que cada vez más se ven obligados a almacenar agua de forma constante desde octubre o noviembre hasta junio, cuando hace tan sólo 20 años casi se paralizaba el llenado de los embalses durante el invierno (López-Moreno et al., 2004). Además, dado que la demanda de agua para riego se mantiene constante o incluso al alza, la salida de agua desde los embalses hacia los ríos se ve notablemente disminuida, mientras que los embalses finalizan el periodo de riego a un nivel muy bajo, lo que pone en riesgo el llenado durante el siguiente año hidrológico (López-Moreno et al., 2008c). La parte más positiva de esta evolución está en el descenso del ritmo de aterramiento de los embalses, que han visto prolongada su vida útil en las ac- 
tuales circunstancias de transporte de sedimento (ValeroGarcés et al., 1996-97, 1999; López Moreno et al., 2003).

Nuevos esfuerzos son necesarios para interpretar la evolución del paisaje, los recursos hídricos y la erosión del suelo en las próximas décadas. Resulta evidente que, salvo interrupciones dramáticas ocasionadas por incendios de alcance regional, la colonización vegetal va a seguir evolucionando hacia formaciones de bosque y matorral cada vez más densas, lo que significa un aumento de la evapotranspiración real y una menor recarga de los acuíferos. En el piso subalpino hay todavía un importante recorrido hasta que se recupere el bosque, sobre todo si se mantiene una aceptable presión ganadera. No obstante, la tendencia de las últimas décadas sugiere que el treeline va a seguir ascendiendo en altitud y, por lo tanto, reduciendo la generación de escorrentía, a la vez que se limitan las zonas más erosionadas. En general, las fuentes de sedimento en el Pirineo Central se van a limitar a las áreas más activas desde un punto de vista geomorfológico, es decir, las cárcavas instaladas sobre margas y las márgenes de los cauces fluviales, obligados a retomar sedimentos de su propia llanura aluvial. Será apasionante estudiar cómo van a evolucionar los paisajes en el futuro y cómo van a afectar a la producción de escorrentía y sedimento.

La aplicación de modelos predictivos sugiere que el peso de la nieve en el régimen fluvial seguirá disminuyendo, lo que necesariamente se reflejará en las avenidas primaverales y, de nuevo, en la gestión de los embalses, obligados a depender de la mayor inestabilidad de los caudales entre marzo y junio. Por otro lado, los modelos climáticos regionales (RCMs) predicen para el siglo XXI condiciones adversas para la generación de escorrentía. Así, López-Moreno et al. (2008a) estiman un aumento de la temperatura media anual en el Pirineo entre 2,8 y $4^{\circ} \mathrm{C}$ para los escenarios $\mathrm{B} 2$ y $\mathrm{A} 2$, respectivamente, frente al incremento de $0,9^{\circ} \mathrm{C}$ registrados durante el siglo xx (Bucher \& Dessens, 1991). Las predicciones sobre la precipitación refieren un descenso medio entre el 10 y el 15\% en los escenarios B2 y $\mathrm{A} 2$, respectivamente, si bien es notorio el hecho de que cualquier predicción pluviométrica está sujeta a una enorme incertidumbre. Si los modelos climáticos e hidrológicos están en lo cierto, sólo cabe pensar en un marcado descenso en el caudal de los ríos pirenaicos, amenazando el llenado de los grandes embalses y el mantenimiento del nivel actual de abastecimiento de agua a los regadíos del centro de la Depresión del Ebro.

Es cierto que la generación de escorrentía puede aumentar mediante un manejo adecuado de la cubierta vegetal, puesto que ya se ha visto la importancia de esta última en la compartimentación de la precipitación y en la evolución reciente de los caudales. Pero ese manejo de la vegetación es una tarea ardua y muy compleja, de la que no se controlan todos los factores, sobre todo si el objetivo final es producir más agua en un escenario de estabilidad de laderas, menos erosión, menos aterramiento de los embalses, cauces cada vez más estables, descenso en la conectividad entre laderas y cauces, y menor riesgo de ocurrencia de avenidas súbitas. La única forma de alcan- zar esos objetivos de manera conjunta es mediante la transformación de matorrales densos en prados de diente, que faciliten el pastoreo directo y contribuyan a ampliar el espacio ganadero. Esa transformación será posible en antiguos campos de cultivo localizados en los mejores sitios topográficos (pies de vertiente, concavidades, rellanos colgados) (Lasanta et al., 2006b). Esto requiere un trabajo de detalle (o de grano fino) para identificar las áreas más favorables, sin riesgo de que se desencadenen otros problemas no deseables. Los datos procedentes de la Estación Experimental Valle de Aísa sugieren que el paso de matorral denso a prado de diente produce algo más de agua y no provoca más erosión (Lasanta et al., 2010; Nadal-Romero et al., 2013). ¿Cuánta más agua? Es imposible saberlo porque la información procedente de las parcelas experimentales no puede trasladarse directamente a otras escalas. No obstante, experiencias en otras regiones españolas sugieren que el desbroce del matorral y su sustitución por prados de diente aumenta el potencial ganadero, mejora también la calidad del paisaje y reduce el riesgo de incendios al crear un mosaico de unidades de vegetación y topografía que rompe la homogeneidad que caracteriza a los grandes espacios abandonados (Lasanta et al., 2009, 2013, 2015). En todo caso, la aplicación de modelos predictivos indica que la cuenca experimental de Arnás apenas tendría incrementos erosivos al transformarse en una cuenca ocupada totalmente por prados en sustitución de los actuales bosques y matorrales (LópezVicente et al., 2011).

Construir un paisaje de manera discriminada, atendiendo a la variabilidad de la topografía y de las formas de generación de escorrentía, es quizás el reto más importante y arriesgado de cara al futuro, de manera que la montaña sea útil a sus habitantes y a los de las tierras bajas, propiciando más la estabilidad que el beneficio a corto plazo. A fin de cuentas eso es lo que se espera de la montaña, un espacio capaz de proporcionar muchos servicios, pero sujeto a deterioros difícilmente reversibles si se superan determinados umbrales de presión sobre la vegetación y los suelos. Por otro lado, la consecución de una estabilidad dinámica, adaptable a las señales de alerta temprana, es imprescindible en un escenario de cambio climático y de posibles cambios abruptos como los que han ocurrido en un pasado no tan alejado en el tiempo como podríamos pensar.

\section{Agradecimientos}

Este trabajo ha contado con el apoyo de los proyectos INDICA (CGL2011-27753-C02-01 y 02), DINAMO2 (CGL2012-33063), CALIBRE (CGL2006-13327-C04-01), financiados por el Ministerio de Economía y Competitividad, y HORDA (083/2009) y CRYORDESA (844/2013), financiados por el Organismo de Parques Nacionales del Ministerio de Medio Ambiente, así como de un acuerdo entre el CSIC y el Ministerio de Medio Ambiente a través de la RESEL. El grupo de investigación sobre Geomorfología y Cambio Global ha sido financiado por el Gobierno 
de Aragón y la Fundación Social Europea. Estela NadalRomero y Yasmina Sanjuan disfrutan de un contrato postdoctoral «Marie Curie-IEF» (Proyecto «MED-AFFOREST» PIEF-GA 2013-624974) y un contrato predoctoral FPI, financiados respectivamente por la Comisión Europea y el Ministerio de Economía y Competitividad.

\section{Referencias}

Alatorre, L.C., Beguería, S., Lana-Renault, N., Navas, A. \& García-Ruiz, J.M., 2012. Soil erosion and sediment delivery in a mountain catchment under scenarios of land use change using a spatially distributed numerical model. Hydrology and Earth System Sciences, 16 (5): 1321-1334. http://dx.doi. org/10.5194/hess-16-1321-2012

Alatorre, L.C., Beguería, S., Lana-Renault, N. \& Navas, A., 2013. Modelización espacialmente distribuida de la erosión $\mathrm{y}$ el transporte de sedimento en cuencas de montaña del Pirineo aragonés: retos para la calibración y validación. Cuadernos de Investigación Geográfica, 39 (2): 287-314.

Alvera, B. \& García-Ruiz, J.M., 2000. Variability of sediment yield from a high mountain catchment, Central Spanish Pyrenees. Arctic, Antarctic, and Alpine Research, 32 (4): 478-484.

Alvera, B., del Barrio, G., Puigdefábregas, J. \& Díez, J.C., 1991. Effects of land use (ski-resort vs. traditional grazing) on stream water quality of two Pyrenean basins. IAHS Publ., 203: 153-160.

Andersen, B.J. \& Borns JR, H.W., 1994. The Ice Age World. Scandinavian University Press, 208 pp., Oslo.

Andrieu, V., Hubschman, J., Jalut, G. \& Hérail, G., 1988. Chronologie de la déglaciation des Pyrénées françaises. Dynamique de sédimentation et contenu pollinique des paleolacs: application à l'interprétation du retrait glaciaire. Bulletin de l'Association Française pour l'Étude du Quaternaire, 2/3, 55-67.

Bal, M.C., Pèlachs, A., Pérez-Obiol, R., Julià, R. \& Cunill, R., 2011. Fire history and human activities during the last 3300 cal yr BP in Spain's Central Pyrenees: The case of the Estany de Bourg. Palaeogeography, Palaeoclimatology, Palaeoecology, 300 (1-4): 179-190. http://dx.doi.org/10.1016/j.palaeo. 2010.12.023

Balcells, E., 1976. El Pirineo: Contraste de paisaje; enlace de pueblos. Imprenta del Ministerio de Asuntos Exteriores, 77 pp., Madrid.

Bartolomé, M., Moreno, A., Sancho, C., Hellstrom, J. \& Belmonte, A., 2012. Cambios climáticos cortos en el Pirineo Central durante el final del Pleistoceno Superior y Holoceno a partir del registro estalagmítico de la cueva de Seso (Huesca). Geogaceta, 51: 59-62.

Batalla, R.J., Vericat, D. \& Tena, A., 2014. The fluvial geomorphology of the lower Ebro (2002-2013): Bridging gaps between management and research. Cuadernos de Investigación Geográfica, 40 (1): 29-51.

Bathurst, J.C., Moretti, G., El-Hames, A., Beguería, S. \& García-Ruiz, J.M., 2007. Modelling the impact of forest loss on shallow landslide sediment yield, Ijuez catchment, Spanish Pyrenees. Hydrology and Earth System Sciences, 11 (1): 569-583. http://dx.doi.org/10.5194/hess-11-569-2007

Beguería, S., 2005. Changes in land cover and shallow landslide activity: a case study in the Spanish Pyrenees. Geomorphology, 74 (1-4): 196-206. http://dx.doi.org/10.1016/j.geomorph. 2005.07.018

Beguería, S., López-Moreno, J.I., Lorente, A., Seeger, M., García-Ruiz, J.M., 2003. Assessing the effect of climate oscillations and land-use changes on streamflow in the Central
Spanish Pyrenees. Ambio, 32 (4): 283-286. http://dx.doi. org/10.1579/0044-7447-32.4.283

Beguería, S., López-Moreno, J.I., Gómez-Villar, A., Rubio, V., Lana-Renault, N. \& García-Ruiz, J.M., 2006. Fluvial adjustments to soil erosion and plant cover changes in the Central Spanish Pyrenees. Geografiska Annaler, 88 A (3): 177186. http://dx.doi.org/10.1111/j.1468-0459.2006.00293.x

Benito, G., Grodek, T. \& Enzel, Y., 1998. The geomorphic and hydrologic impacts of the catastrophic failure of floodcontrol-dams during the 1996-Biescas flood (Central Pyrenees, Spain). Zeitschrift für Geomorphologie, 42 (4): 417-437.

Bradley, R.S. 1985. Quaternary paleoclimatology. Methods of paleoclimatic reconstruction. Allen \& Unwin Inc., 472 pp.

Brunet, M., Jones, P.D., Sigro, J., Saladie, O., Aguilar, E., Moberg, A., Della-Marta, P.M., Lister, D., Walther, A. \& López, D., 2007. Temporal and spatial temperature variability and change over Spain during 1850-2005. Journal of Geophysical Research, 112, D12117, http://dx.doi.org/10.1029/ 2006JD008249

Bucher, A. \& Dessens, J., 1991. Secular trends of surface temperatures at an elevated observatory in the Pyrenees. Journal of Climate, 4 (8): 859-868. http://dx.doi.org/10.1175/15200442(1991)004<0859:STOSTA >2.0.CO;2

Calle, M., Sancho, C., Peña, J.L., Cunha, P., Oliva-Urcia, B. \& Pueyo, E., 2013. La secuencia de terrazas cuaternarias del río Alcanadre (provincia de Huesca): caracterización y consideraciones paleoambientales. Cuadernos de Investigación Geográfica, 39 (1): 159-178.

Camarero, J.J., García-Ruiz, J.M., Sangüesa-Barreda, G., Galván, J.D., Alla, A.Q., Beguería, S., Sanjuán, Y. \& Gutiérrez, E., enviado. Inertia or reprise? Recent and intense dynamics in a formerly static Pyrenean treeline. Arctic, Antarctic, and Alpine Research.

Catalán, J., Pèlachs, A., Gassiot, E., Antolín, F., Ballestero, A., Batalla, M., Burjachs, F., Buchaca, T., Camarero, L., Clement, I., Clop, X., García, D., Giralt, S., Lluch, L., Madella, M., Mazzuco, N., Mur, E., Ninyerola, M., Obea, L., Oltra, J., Pérez-Obiol, R., Piqué, R., Pla-Rabés, S., Rondón, C.R., Rodríguez, J.M., Rodriguez, D., Sáez, A. \& Soriano, J.M., 2013. Interacción entre clima y ocupación humana en la configuración del paisaje vegetal del Parque Nacional de Aigüestores i Estany de Sant Maurici a lo largo de los últimos 15.000 años. In: Proyectos de investigación en Parques $\mathrm{Na}$ cionales: 2009-2012, L. Ramírez \& B. Asensio (eds.), Organismo Autónomo Parques Nacionales, Madrid, pp. 71-92.

Cerdà, A. \& Lasanta, T., 2005. Long-term erosional after fire in the Spanish Pyrenees. 1 Water and sediment yield. Catena, 60(1): 58-80. http://dx.doi.org/10.1016/j.catena.2004.09.006

Chauvelier, F., 1990. La repoblación forestal en la provincia de Huesca y sus impactos geográficos. Instituto de Estudios Altoaragoneses: 164 pp., Huesca.

Chueca, J. \& Julián, A., 2010. Dinámica de los glaciares del Pirineo aragonés: Resultados de la campaña glaciológica del año 2011. Boletín Glaciológico Aragonés, 11: 9-183.

Chueca, J., Julián Andrés, A., Saz Sánchez, M.Á., Creus, J. \& López-Moreno, J.I., 2005. Responses to climatic changes since the 'Little Ice Age' on Maladeta Glacier (Central Pyrenees). Geomorphology, 68: 167-182. http://dx.doi. org/10.1016/j.geomorph.2004.11.012

Clague, J.J., Menounos, B., Osborn, G., Luckman, B.H. \& Koch, J., 2009. Nomenclature and resolution in Holocene glacial chronologies. Quaternary Science Reviews, 28 (21-22): 22312238. http://dx.doi.org/10.1016/j.quascirev.2008.11.016

Corella, J.P., Moreno, A., Morellón, M., Rull, V., Giralt, S., Rico, M.T., Pérez-Sanz, A., Valero-Garcés, B.L., 2011. Climate and human impact on a meromictic lake during the last 6,000 years (Montcortès Lake, Central Pyrenees, Spain). 
Journal of Palaeolimnology, 46 (3): 351-367. http://dx.doi. org/10.1007/s10933-010-9443-3

Corella, J.P., Brauer, A., Mangili, C., Rull, V., Vegas-Villarrúbia, T., Morellón, M. \& Valero-Garcés, B.L., 2012. The 1.5-ka varved record of Lake Montcortès (Southern Pyrenees, NE Spain). Quaternary Research, 78 (2): 323-332. http://dx.doi. org/10.1016/j.yqres.2012.06.002

Corella, J.P., Stefanova, V., El Anjoumi, A., Rico, E., Giralt, S., Moreno, A., Plata-Montero, A. \& Valero-Garcés, B.L., 2013. A 2500-year multi-proxy reconstruction of climate change and human activities in northern Spain: The Lake Arreo record. Palaeogeography, Palaeoclimatology, Palaeoecology, 386: 555-568. http://dx.doi.org/10.1016/ j.palaeo.2013.06.022

Creus Novau, J. \& García Ruiz, J.M., 1977. Observaciones sobre solifluxión en el Alto Valle del río Gállego. Trabajos sobre Neógeno-Cuaternario, 6: 57-64.

Cunill, R., Soriano, J.M., Bal, M.C., Pèlachs, A. \& PérezObiol, R., 2012. Holocene treeline changes on the south slope of the Pyrenees: a pedoanthropological analysis. Vegetation History and Archaeobotany, 21 (4-5): 373-384. http://dx.doi.org/10.1007/s00334-011-0342-y

Daumas, M., 1976. La vie rurale dans le Haut Aragon Oriental. Consejo Superior de Investigaciones Científicas: 774 pp., Madrid.

Davis, P.T., Menounos, B. \& Osborn, G., 2009. Holocene and latest Pleistocene alpine glacier fluctuations: A global perspective. Quaternary Science Reviews, 28 (21-22): 20212033. http://dx.doi.org/10.1016/j.quascirev.2009.05.020

Dawson, A.G., 1992. Ice Age Earth. Late Quaternary geology and climate. Routledge Physical Environment series, Univ. of Cambridge, $293 \mathrm{pp}$

Dearing, J., Battarbee, R., Dikau, R., Larocque, I. \& Oldfield, F., 2006. Human-environment interactions: towards synthesis and simulation. Regional Environmental Change, 6: 115123. http://dx.doi.org/10.1007/s10113-005-0011-8

Del Barrio, G., Creus, J. \& Puigdefábregas, J., 1990. Thermal seasonality of the high mountain belts of the Pyrenees. Mountain Research and Development, 10 (3): 227-233.

Deline, P. \& Orombelli, G., 2005. Glacier fluctuations in the western Alps during the Neoglacial, as indicated by the Miage morainic amphitheatre (Mont Blanc massif, Italy). Boreas, 34 (4): 456-467. http://dx.doi.org/10.1111/j.15023885.2005.tb01444.x

Delmas, M., 2015. The last deglaciation in the Pyrenees. Cuadernos de Investigación Geográfica, 41 (2).

Delmas, M., Calvet, M., Gunnell, Y., Braucher, R. \& Bourlès, D., 2011. Palaeogeography and $10 \mathrm{Be}$ exposure-age chronology of Middle and Late Pleistocene glacier systems in the northern Pyrenees: Implications for reconstructing regional palaeoclimates. Palaeogeography, Palaeoclimatology, $\mathrm{Pa}$ laeoecology, 305: 109-122. http://dx.doi.org/10.1016/j. palaeo.2011.02.025

Dupré, M., 1988. Palinología y paleoambiente. Nuevos datos españoles. Referencias. Serie de Trabajos Varios, Servicio de Investigación Prehistórica de la Diputación Provincial de Valencia. 160 pp., Valencia.

El Kenawy, A., López-Moreno, J.I., Stepanek, P. \& VicenteSerrano, J.I., 2013. An assessment on the role of homogenization protocols in the performance of daily temperature series and trends: application to Northeastern Spain. International Journal of Climatology, 33: 87-108. http:// dx.doi.org/10.1002/joc. 3410

Feuillet, T. \& Mercier, D., 2012. Post-Little Ice Age patterned ground development on two Pyrenean proglacial areas: from glaciation to periglaciation. Geografiska Annaler, Series A, Physical Geography, 94 (3): 363-376. http://dx.doi.org/10.1111/j.1468-0459.2012.00459.x
Gallart, F., 2009. Algunos criterios topográficos para identificar el origen antrópico de cárcavas. Cuadernos de Investigación Geográfica, 35 (2): 215-221.

Gallart, F., Llorens, P. \& Latron, J., 1994. Studying the role of old agricultural terraces on runoff generation in a small Mediterranean mountainous basin. Journal of Hydrology, 159 (1-4): 291-303. http://dx.doi.org/10.1016/0022-1694(94)90262-3

Galop, D., Vanniere, B. \& Fontugne, M., 2002. Human activities and fire history since $4500 \mathrm{BC}$ on the northern slope of the Pyrenees: a record from Cuguron (Central Pyrenees, France). In: Thièbault, S. (Ed.), Charcoal analysis: methodological approaches, palaeological results and wood uses. Proceedings of the Second International Meeting of Anthracology, Paris, September 2000: BAR International Series, 1063, pp. 43-51.

García-Ruiz, J.M., 1977. Grandes embalses y desorganización del espacio: El ejemplo del Alto Aragón. Cuadernos de Investigación Geográfica, 3: 31-46.

García-Ruiz, J.M., 2010. The effects of land uses on soil erosion in Spain: A review. Catena, 81: 1-11. http://dx.doi.org/ 10.1016/j.catena.2010.01.001

García-Ruiz, J.M., 2015. Why geomorphology is a global science? Cuadernos de Investigación Geográfica, 41 (1): 87-105.

García-Ruiz, J.M. \& Balcells, E., 1978. Tendencias actuales de la ganadería en el Pirineo Central. Estudios Geográficos, 153: 539-560.

García-Ruiz, J.M. \& Puigdefábregas, J. 1982. Formas de erosión en el flysch eoceno surpirenaico. Cuadernos de Investigación Geográfica, 8: 83-126.

García-Ruiz, J.M. \& Ortigosa, L., 1988. Algunos efectos geomorfológicos de las repoblaciones forestales: Cambios en la dinámica de cauces en cuencas del Pirineo Central español. Cuaternario y Geomorfología, 2: 33-41.

García-Ruiz, J.M. \& Lasanta-Martínez, T., 1993. Land-use conflicts as a result of land-use change in the Central Spanish Pyrenees: A review. Mountain Research and Development, 13 (3): 295-304.

García-Ruiz, J.M. \& Valero, B., 1998. Historical geomorphic processes and human activities in the Central Spanish Pyrenees. Mountain Research and Development, 18 (4): 309-320.

García-Ruiz, J.M. \& Martí-Bono, C., 2001. Mapa geomorfológico del Parque Nacional de Ordesa y Monte Perdido. Organismo Autónomo de Parques Nacionales, Madrid, 106 pp.

García-Ruiz, J.M. \& Martí-Bono, C., 2011. Los depósitos glaciares del valle del Aragón Subordán, Pirineo centro-occidental español. Cuaternario y Geomorfología, 25 (1-2): 57-81.

García-Ruiz, J.M. \& Lana-Renault, N., 2011. Hydrological and erosive consequences of farmland abandonment in Europe, with special reference to the Mediterranean region - A review. Agriculture, Ecosystems and Environment, 140 (3-4), 317-338. http://dx.doi.org/10.1016/j.agee.2011.01.003

García-Ruiz, J.M., Puigdefábregas, J. \& Creus, J., 1986. La acumulación de nieve en el Pirineo Central y su influencia hidrológica. Pirineos, 127: 27-72.

García-Ruiz, J.M., Lasanta, T. \& Biarge, F., 2003a. Agua, tierra y paisaje: Complejidad y diversidad en el territorio de Riegos del Alto Aragón. Confederación Hidrográfica del Ebro y Comunidad General de Riegos del Alto Aragón, Zaragoza, $164 \mathrm{pp}$.

García-Ruiz, J.M., Beguería, S., Alatorre, L.C. \& Puigdefábregas, J., 2010a. Land cover changes and shallow landsliding in the flysch sector of the Spanish Pyrenees. Geomorphology, 124 (3-4): 250-259. http://dx.doi.org/10.1016/ j.geomorph.2010.03.036

García-Ruiz, J.M., Lana-Renault, N., Beguería, S., Lasanta, T., Regüés, D., Nadal-Romero, E., Serrano-Muela, P., LópezMoreno, J.I., Alvera, B., Martí-Bono, C. \& Alatorre, L.C., 
2010b. From plot to regional scales: interactions of slope and catchment hydrological and geomorphic processes in the Spanish Pyrenees. Geomorphology, 120 (3-4): 248-257. http://dx.doi.org/10.1016/j.geomorph.2010.03.038

García-Ruiz, J.M., Valero-Garcés, B.L., González-Sampériz, P., Lorente, A., Martí-Bono, C., Beguería, S., \& Edwards, L., 2001a. Stratified scree in the Central Spanish Pyrenees. Permafrost and Periglacial Processes, 12 (3): 233-242. http:// dx.doi.org/10.1002/ppp.388

García-Ruiz, J.M., Martí-Bono, C., Valero-Garcés, B.L., González-Sampériz, P., 2001b. La evolución de los glaciares del Pleistoceno Superior en el Pirineo Central español. El ejemplo de los glaciares de Escarra y Lana Mayor, Alto Valle del Gállego. Cuaternario y Geomorfología, 15 (1-2): 103-120.

García-Ruiz, J.M., Beguería, S., López-Moreno, J.I., Lorente, A. \& Seeger, M. 2001c. Los recursos hidricos superficiales del Pirineo aragonés y su evolución reciente. Geoforma Ediciones, 192 pp., Logroño.

García-Ruiz, J.M., Valero-Garcés, B.L., Martí-Bono, C. \& González-Sampériz, P., 2003b. Asynchroneity of maximum glacier advances in the central Spanish Pyrenees. Journal of Quaternary Science, 18 (1): 61-72. http://dx.doi.org/10.1002/jqs.715

García-Ruiz, J.M., Lasanta, T., Ortigosa, L., Ruiz-Flaño, P. Martí, C. \& González, C., 1995. Sediment yield under different land-uses in the Spanish Pyrenees. Mountain Research and Development, 15 (3): 229-240.

García Ruiz, J.M., White, S.M., Martí, C., Valero, B., Errea, M.P. \& Gómez Villar, A., 1996. La catástrofe del Barranco de Arás (Biescas, Pirineo aragonés) y su contexto espacio-temporal. Instituto Pirenaico de Ecología, $54 \mathrm{pp}$. Zaragoza.

García-Ruiz, J.M., Peña-Monné, J.L., Martí-Bono, C., GómezVillar, A., Constante Orrios, A. \& Espinalt-Brillas, M., 2011a. El relieve del Alto Aragón Occidental. Cartografía y síntesis geomorfológica. Publicaciones del Consejo de Protección de la Naturaleza de Aragón, 91 pp., Zaragoza.

García-Ruiz, J.M., López-Moreno, J.I., Serrano-Vicente, S.M., Lasanta, T. \& Beguería, S., 2011b. Mediterranean water resources in a global change scenario. Earth-Science Reviews, 105 (3-4): 121-139. http://dx.doi.org/10.1016/j.earscirev.2011.01.006

García-Ruiz, J.M., Palacios, D., De Andrés, N., Valero-Garcés, B.L., López-Moreno, J.I. \& Sanjuán, Y., 2014. Holocene and 'Little Ice Age' glacial activity in the Marboré Cirque, Monte Perdido Massif, Central Spanish Pyrenees. The Holocene, 24 (11): 1439-1452. http://dx.doi.org/10.1177/ 0959683614544053

García-Ruiz, J.M., Regüés, D., Alvera, B., Lana-Renault, N., Serrano-Muela, P., Nadal-Romero, E., Navas, A., Latron, J., Martí-Bono, C. \& Arnáez, J., 2008. Flood generation and sediment transport in experimental catchments affected by land use changes in the central Pyrenees. Journal of Hydrology, 356: 245-260. http://dx.doi.org/10.1016/j.jhydrol.2008.04.013

García-Ruiz, J.M., Nadal-Romero, E., Lana-Renault, N. \& Beguería, S., 2013. Erosion in Mediterranean landscapes: Changes and future challenges. Geomorphology, 198: 2036. http://dx.doi.org/10.1016/j.geomorph.2013.05.023

García-Ruiz, J.M., Martí-Bono, C., Peña-Monné, J.L., Sancho, C., Rhodes, E.J., Valero-Garcés, B., González-Sampériz, P. \& Moreno, A., 2013b. Glacial and fluvial deposits in the Aragón Valley, Central-Western Pyrenees: Chronology of the Pyrenean Late Pleistocene glaciers. Geografiska Annaler, Series A, Physical Geography, 95 (1): 15-32. http:// dx.doi.org/10.1111/j.1468-0459.2012.00478.x

Gellatly, A.F., Grove, J.M. \& Switsur, V.R., 1992. Mid-Holocene glacial activity in the Pyrenees. The Holocene, 2-3: 266270. http://dx.doi.org/10.1177/095968369200200309

Gil-Romera, G., González-Sampériz, P., Lasheras-Álvarez, L., Sevilla-Callejo, M., Moreno, A., Valero-Garcés, B., López-
Merino, L., Carrión, J.S., Pérez-Sanz, A., Aranbarri, J. \& García-Prieto, E., 2014. Biomass-modulated fire dynamics during the Last Glacial-Interglacial Transition at the Central Pyrenees (Spain). Palaeogeography, Palaeoclimatology, Palaeoecology, 402: 113-124. http://dx.doi.org/10.1016/j. palaeo.2014.03.015

Giménez, R., Casalí, J. \& Díez, J., 2012. Evaluación de la producción de sedimentos y calidad de las aguas en cuencas agrarias de Navarra. Cuadernos de Investigación Geográfica, 38 (1): 7-25.

Gómez-Villar, A., 1996. Conos aluviales en pequeñas cuencas torrenciales de montaña. Geoforma Ediciones, 191 pp., Logroño.

Gómez-Villar, A. \& García-Ruiz, J.M., 2000. Surface sediment characteristics and present dynamics in alluvial fans of the Central Spanish Pyrenees. Geomorphology, 34 (3-4): 127 144. http://dx.doi.org/10.1016/S0169-555X(99)00116-6

Gómez-Villar, A., Sanjuán, Y., García-Ruiz, J.M., Nadal-Romero, E., Álvarez-Martínez, J., Arnáez, J. \& Serrano Muela, M.P., 2014. Sediment organization and adjustment in a torrential reach of the Upper Ijuez River, Central Spanish Pyrenees. Cuadernos de Investigación Geográfica, 40 (1): 191-214.

González-Sampériz, P., Valero-Garcés, B.L., Carrión, J.S., Peña-Monné, J.L., García-Ruiz, J.M. \& Martí-Bono, C., 2005. Glacial and Lateglacial vegetation in northeastern Spain: New data and a review. Quaternary International, 140-141: 4-20. http://dx.doi.org/10.1016/j.quaint.2005.05.006

González-Sampériz, P., Valero-Garcés, B.L., Moreno, A., Jalut, G., García-Ruiz, J.M., Martí-Bono, C., DelgadoHuertas, A., Navas, A., Otto, T. \& Dedoubat, J.J., 2006. Climate variability in the Spanish Pyrenees during the last 30,000 yr revealed by the El Portalet sequence. Quaternary Research, 66 (1): 38-52. http://dx.doi.org/10.1016/ j.yqres.2006.02.004

González-Sampériz, P., Utrilla, P., Mazo, C., Valero-Garcés, B., Sopena, M.C., Morellón, M., Sebastián, M., Moreno, A., Martínez-Bea, M., 2009. Patterns of human occupation during the early Holocene in the Central Ebro Basin (NE Spain) in response to the $8.2 \mathrm{kyr}$ climate event. Quaternary Research, 71 (2): 121-132. http://dx.doi.org/ 10.1016/j.yqres.2008.10.006

González Trueba, J.J., Martín Moreno, R., Martínez de Pisón, E. \& Serrano, E., 2008. 'Little Ice Age' glaciation and current glaciers in the Iberian Peninsula. The Holocene, 18 (4): 551568. http://dx.doi.org/10.1177/0959683608089209

Gottfried, M., Pauli, H., Futschik, A., Akhalkatsi, M., Barancok, P., Benito Alonso, J.L., Coldea, G., Dick, J., Erschbamer, B., Fernández-Calzado, M.R., Kazakis, G., Krajci, J., Larsson, P., Mallaun, M., Michelsen, O., Moiseev, D., Moiseev, P., Molau, U., Merzouki, A., Nagy, L., Nakhutsrishvili, G., Pedersen, B., Pelino, G., Puscas, M., Rossi, G., Stanisci, A., Theurillat J.-P., Tomaselli, M., Villar, L., Vittoz, P., Vogiatzakis, I. \& Grabherr, G., 2012. Continent-wide response of mountain vegetation to climate change. Nature Climate Change, 2 (2): 111-115. http://dx.doi.org/10.1038/nclimate1329

Goudie, A., 1981. The human impact on the natural environment. Basil Blackwell, 338 pp., Oxford.

Guerrero, J., Gutiérrez, F., Carbonel, D., Bonachea, J., GarcíaRuiz, J.M., Galve, J.P. \& Lucha, P., 2012. 1: 5000 landslide map of the upper Gállego Valley (Central Spanish Pyrenees). Journal of Maps, 8 (4): 484-491. http://dx.doi.org/10. $1080 / 17445647.2012 .751345$

Gutiérrez, F., Gutiérrez, M. \& Sancho, C., 1998. Geomorphological and sedimentological analysis of a catastrophic flash flood in the Arás drainage basin (Central Pyrenees, Spain). Geomorphology, 22 (3-4): 265-283. http://dx.doi.org/10.1016/S0169-555X(97)00087-1 
Higuera, P.E., Gavin, D.G., Bartlein, P.J. \& Hallett, D.J., 2010. Peak detection in sediment-charcoal records: impacts of alternative data analysis methods on fire-history interpretations. International Journal of Wildland Fire, 19: 996-1014. http://dx.doi.org/10.1071/WF09134

Höllermann, P., 1985. The periglacial belt of mid-latitude mountains from a geoecological point of view. Erdkunde, 39: 259-270.

Hughes, P.D., Woodward, J.C. \& Gibbard, P.L., 2006. Glacial history of the Mediterranean mountains. Progress in Physical Geography, 30 (3): 334-364. http://dx.doi.org/ 10.1191/0309133306pp481ra

Hughes, P.D., Gibbard, P.L. \& Ehlers, J., 2013. Timing of glaciation during the last glacial cycle: evaluating the concept of a global 'Last Glacial Maximum' (LGM). Earth-Science Reviews, 125: 171-198. http://dx.doi.org/10.1016/j.earscirev. 2013.07.003

Jones, P.D., Lister, D.H., Osborn, T.J., Harpham, C., Salmon, M. \& Morice, C.P., 2012. Hemispheric and large-scale landsurface air temperature variations: an extensive revision and an update to 2010. Journal of Geophysical Research-Atmosphere, 117 (5): D05127. http://dx.doi.org/10.1029/ 2011JD017139

Julián, A. \& Chueca, J., 1998. Le Petit Âge Glaciaire dans les Pyrénées Centrales Méridionales: estimation à partir d'inférences géomorphologiques. Sud-Ouest Européen, 3: 79-88.

Keesstra, S.D., Maroulis, E., Argaman, E., Voogt, L. \& Wittenberg, L., 2014. Effects of controlled fire on hydrology and erosion under simulated rainfall. Cuadernos de Investigación Geográfica, 40 (2): 269-293.

Laguna, M. \& Lasanta, T., 2003. Competing for meadows. A case study on tourism and livestock farming in the Spanish Pyrenees. Mountain Research and Development, 23 (2): 169-176. http://dx.doi.org/10.1659/0276-4741(2003)023[0169:CFM] 2.0.CO;2

Lana-Renault, N., 2011. El efecto de los cambios de cubierta vegetal en la respuesta hidrológica y sedimentológica de áreas de montaña: la Cuenca experimental de Arnás, Pirineo Central. Publicaciones del Consejo de Protección de la Naturaleza de Aragón, 189 pp., Zaragoza.

Lana-Renault, N. \& Regüés, D., 2007. Bedload transport under different flow conditions in a human-disturbed catchment in the Central Spanish Pyrenees. Catena, 71 (1): 155-163. http://dx.doi.org/10.1016/j.catena.2006.04.029

Lana-Renault, N. \& Regüés, D., 2009. Seasonal patterns of suspended sediment transport in an abandoned farmland catchment in the Central Spanish Pyrenees. Earth Surface Processes and Landforms, 34 (9): 1291-1301. http://dx.doi. org/10.1002/esp. 1825

Lana-Renault, N., Alvera, B. \& García-Ruiz, J.M., 2010. The snowmelt period in a Mediterranean high mountain catchment: runoff and sediment transport. Cuadernos de Investigación Geográfica, 36 (2): 99-108.

Lana-Renault, N., Latron, J., Karssenberg, D., Serrano-Muela, P., Regüés, D., Bierkens, M.F.P., 2011a. Differences in stream flow in relation to changes in land cover: A comparative study in two sub-Mediterranean mountain catchments. Journal of Hydrology, 411 (3-4): 366-378. http://dx.doi. org/10.1016/j.jhydrol.2011.10.020

Lana-Renault, N., Alvera, B. \& García-Ruiz, J.M., 2011b. Runoff and sediment transport during the snowmelt period in a Mediterranean high mountain catchment. Arctic, Antarctic, and Alpine Research, 43 (2): 213-222. http://dx.doi. org/10.1657/1938-4246-43.2.213

Lana-Renault, N., Nadal-Romero, E., Serrano-Muela, M.P., Alvera, B., Sánchez-Navarrete, P., Sanjuán, Y. \& García-Ruiz, J.M., 2014a. Comparative analysis of the response of various land covers to an exceptional rainfall event in the central Spanish Pyrenees, October, 2012. Earth Surface Processes and Landforms, 39 (5): 581-594. http://dx.doi.org/10.1002/esp.3465

Lana-Renault, N., Regüés, D., Serrano, P. \& Latron, J., 2014b. Spatial and temporal variability of groundwater dynamics in a sub-Mediterranean mountain catchment. Hydrological Processes, 28 (8): 3288-3299. http://dx.doi.org/10.1002/ hyp. 9892

Lana-Renault, N., Regüés, D., Martí-Bono, C., Beguería, S., Latron, J., Nadal, E., Serrano, P. \& García-Ruiz, J.M., 2007a. Temporal variability in the relationships between precipitation, discharge and suspended sediment concentration in a Mediterranean mountain catchment. Nordic Hydrology, 38 (2): 139-150. http://dx.doi.org/10.2166/nh.2007.003

Lana-Renault, N., Latron, J. \& Regüés, D., 2007b. Streamflow response and water-table dynamics in a sub-Mediterranean research catchment (Central Pyrenees). Journal of Hydrology, 347 (3-4): 497-507. http://dx.doi.org/10.1016/j. jhydrol.2007.09.037

Lasanta, T., 1988. The process of desertion of cultivated areas in the Central Spanish Pyrenees. Pirineos, 132: 15-36.

Lasanta, T., 1989. Evolución reciente de la agricultura de montaña: el Pirineo aragonés. Geoforma Ediciones, 220 pp., Logroño.

Lasanta, T., 2014. El paisaje de campos abandonados en Cameros Viejo (sistema Ibérico, La Rioja). Instituto de Estudios Riojanos. Colección Ciencias de la Tierra, 32: 305 pp., Logroño.

Lasanta, T., Arnaéz, J., Oserin, M. \& Ortigosa, L., 2001. Marginal lands and erosion in terraced fields in the Mediterranean mountains: a case study in the Camero Viejo (Northwestern Iberian System, Spain). Mountain Research and Development, 21 (1): 69-76. http://dx.doi.org/10.1659/02764741(2001)021[0069:MLAEIT]2.0.CO;2

Lasanta, T., Beguería, S. \& García-Ruiz, J.M., 2006a. Geomorphic and hydrological effects of traditional shifting agriculture in a Mediterranean mountain area, Central Spanish Pyrenees. Mountain Research and Development, 26 (2): 146-152. http://dx.doi.org/10.1659/0276-4741(2006)26 [146:GAHEOT]2.0.CO;2

Lasanta, T., González-Hidalgo, J.C., Vicente-Serrano, S.M. \& Sferi, E., 2006b. Using landscape ecology to evaluate an alternative management scenario in abandoned Mediterranean mountainous areas. Landscape and Urban Planning, 78: 101-114. http://dx.doi.org/10.1016/j.landurbplan.2005.06. 003

Lasanta, T., Arnáez, J., Errea, M.P., Ortigosa, L. \& Ruiz-Flaño, P., 2009. Mountain pastures, environmental degradation, and landscape remediation: the example of a Mediterranean policy initiative. Applied Geography, 29 (3): 308-319. http://dx.doi.org/10.1016/j.apgeog.2008.09.006

Lasanta, T., Nadal-Romero, E., Serrano-Muela, P., Vicente-Serrano, S. \& García-Ruiz, J.M., 2010. Escorrentía y erosión tras el abandono de tierras de cultivo en montaña: resultados de la Estación Experimental «Valle de Aísa». Pirineos, 165: 115-133. http://dx.doi.org/10.3989/Pirineos.2010.165006

Lasanta, T., Errea, M.P., Bouzebboudja, M.R. \& Medrano, L.M., 2013. Pastoreo y desbroce de matorrales en Cameros Viejo. Instituto de Estudios Riojanos. Colección Ciencias de la Tierra, 30, 186 pp., Logroño.

Lasanta, T., Nadal-Romero, E., Errea, P. \& Arnáez, J., 2015. The effects of landscape conservation measures in changing landscape patterns: A case study in Mediterranean mountains. Land Degradation and Development. http://dx.doi. org/10.1002/ldr.2359.

Lasheras-Álvarez, L., Pérez-Sanz, A., Gil-Romera, G., González-Sampériz, P., Sevilla-Callejo, M. \& Valero-Garcés, B., 2013. Historia del fuego y la vegetación en una secuencia 
holocena del Pirineo central: La Basa de la Mora. Cuadernos de Investigación Geográfica, 39 (1): 77-95.

Leunda, M., 2013. Caracterización ambiental del Holoceno reciente en el ibón de Marboré, Huesca, Pirineo central. Primeros resultados del análisis palinológico. Trabajo Fin de Master, Universidad de Zaragoza, 56 pp., Zaragoza.

Lewis, C.J., McDonald, E.V., Sancho, C., Peña, J.L. \& Rhodes, E.J., 2009. Climatic implications of correlated Upper Pleistocene glacial and fluvial deposits on the Cinca and Gállego Rivers (NE Spain) base don OSL dating and soil stratigraphy. Global and Planetary Change, 67 (3-4): 141-152. http://dx.doi.org/10.1016/j.gloplacha.2009.01.001

Liébault, F. \& Piégay, H., 2001. Assessment of channel changes due to long-term bedload supply decrease, Roubion River, France. Geomorphology, 36 (3-4): 167-186. http://dx.doi. org/10.1016/S0169-555X(00)00044-1

Lockwood, J. G., 1985. World climatic systems. Edward Arnold, ed., 292 pp., London.

López-Moreno, J.I., 2000. Los glaciares del Alto Valle del Gállego (Pirineo Central) desde la Pequeña Edad del Hielo. Implicaciones en la evolución de la temperatura. Geoforma Ediciones, 77 pp., Logroño.

López-Moreno, J.I., 2005. Recent variations of snowpack depth in the Central Spanish Pyrenees. Arctic, Antarctic, and Alpine Research, 37 (2): 253-260. http://dx.doi.org/10.1657/ 1523-0430(2005)037[0253:RVOSDI]2.0.CO;2

López-Moreno, J.I. \& García-Ruiz, J.M., 2003. Influencia de los embalses sobre el régimen fluvial en los Pirineos centrales. Cuadernos de Investigación Geográfica, 29: 7-21.

López-Moreno, J.I. \& García-Ruiz, J.M., 2004. Influence of snow accumulation and snowmelt on streamflow in the central Spanish Pyrenees. Hydrological Sciences Journal, 49 (5): 787-802. http://dx.doi.org/10.1623/hysj.49.5.787.55135

López-Moreno, J.I., Beguería, S. \& García-Ruiz, J.M., 2000. El régimen del embalse de Yesa (cuenca alta del río Aragón, Pirineo Central) y su adaptación a la variabilidad del régimen fluvial. Cuadernos de Investigación Geográfica, 26: 131-145.

López-Moreno, J.I., Beguería, S. \& García-Ruiz, J.M., 2002. Influence of the Yesa reservoir on floods of the Aragón River, central Spanish Pyrenees. Hydrology and Earth System Sciences, 6 (4): 753-762. http://dx.doi.org/10.5194/hess-6753-2002

López-Moreno, J.I., Beguería, S. \& García-Ruiz, J.M., 2004. The management of a large Mediterranean reservoir: storage regimens of the Yesa reservoir, Upper Aragón River Basin, Central Spanish Pyrenees. Environmental Management, 34 (4): 508-515. http://dx.doi.org/10.1007/s00267-003-0249-1

López-Moreno, J.I., Beguería, S. \& García-Ruiz, J.M., 2006. Trends in high flows in the central Spanish Pyrenees: response to climatic factors or to land-use change? Hydrological Sciences Journal, 51 (6): 1039-1050. http://dx.doi.org/10.1623/ hysj.51.6.1039

López-Moreno, J.I., Goyette, S. \& Beniston, M., 2008a. Climate change prediction over complex areas: spatial variability of uncertainties and predictions over the Pyrenees from a set of regional climate models. International Journal of Climatology, 28 (11): 1535-1550. http://dx.doi.org/10.1002/joc.1645

López-Moreno, J.I., Goyette, S., Beniston, M. \& Alvera, B., 2008 b. Sensitivity of the snow energy balance to climatic changes: prediction of snowpack in the Pyrenees in the 21st century. Climate Research, 36 (3): 203-217. http://dx.doi. org/10.3354/cr00747

López-Moreno, J.I., Beniston, M. \& García-Ruiz, J.M., 2008c. Environmental change and water management in the Pyrenees: Facts and future perspectives for Mediterranean mountains. Global and Planetary Change, 61 (3-4): 300-312. http://dx.doi.org/10.1016/j.gloplacha.2007.10.004
López-Moreno, J.I., Goyette, S. \& Beniston, M., 2009. Impact of climate change on snowpack in the Pyrenees: Horizontal spatial variability and vertical gradients. Journal of Hydrology, 374 (3-4): 384-396. http://dx.doi.org/10.1016/j. jhydrol.2009.06.049

López-Moreno, J.I., Beguería, S., Valero-Garcés, B. \& GarcíaRuiz, J.M., 2003. Intensidad de las avenidas y aterramiento de embalses en el Pirineo Central español. Ería, 61: 159-168.

López-Moreno, J.I., Vicente-Serrano, S.M., Angulo-Martínez, S.M., Beguería, S. \& El Kenawy, A., 2010. Trends in daily precipitation on the northeastern Iberian Peninsula, 19552006. International Journal of Climatology, 30 (7): 10261041. http://dx.doi.org/10.1002/joc. 1945

López-Moreno, J.I., Vicente-Serrano, S.M., Morán-Tejeda, E., Lorenzo-Lacruz, J., El Kenawy, A. \& Beniston, M., 2011a. Effects of the North Atlantic Oscillation (NAO) on combined temperature and precipitation winter modes in the Mediterranean mountains: Observed relationships and projections for the 21st century. Global and Planetary Change, 77 (1-2): 62-76. http://dx.doi.org/10.1016/j.gloplacha.2011.03. 003

López-Moreno, J.I., Vicente-Serrano, S.M., Morán-Tejeda, E., Zabalza, J., Lorenzo-Lacruz, J. \& García-Ruiz, J.M., 2011b. Impact of climate evolution and land use changes on water yield in the Ebro basin. Hydrology and Earth System Sciences, 15 (1): 311-322. http://dx.doi.org/10.5194/hess-15-311-2011

López-Moreno, J.I., Revuelto, J., Gilaberte, M., Morán-Tejeda, E., Pons, M., Jover, E., Esteban, P., García, C. \& Pomeroy, J.W., 2013. The effect of slope aspect on the response of snowpack to climate warming in the Pyrenees. Theoretical and Applied Climatology, 117 (1-2): 207-219. http://dx.doi. org/10.1007/s00704-013-0991-0

López-Moreno, J.I., Zabalza, J., Vicente-Serrano, S.M., Revuelto, J., Gilaberte, M., Azorín-Molina, C., Morán-Tejeda, E., García-Ruiz, J.M. \& Tague, C., 2014. Impact of climate and land use change on water availability and reservoir management: Scenarios in the Upper Aragón River, Spanish Pyrenees. Science of the Total Environment, 493: 1222-1231. http://dx.doi.org/10.1016/j.scitotenv.2013.09.031

López-Vicente, M., Lana-Renault, N., García-Ruiz, J.M., Navas, A., 2011. Assessing the potential effect of different land cover management practices on sediment yield from an abandoned farmland catchment in the Spanish Pyrenees. Journal of Soils and Sediments, 11: 1440-1455. http:// dx.doi.org/10.1007/s11368-011-0428-2

Lorente, A., García-Ruiz, J.M., Beguería, S. \& Arnáez, J., 2002. Factors explaining the spatial distribution of hillslope debris flows. A case study in the Flysch Sector of the Central Spanish Pyrenees. Mountain Research and Development, 22 (1): 32-39. http://dx.doi.org/10.1659/0276-4741(2002)022[0032:FETSD $\mathrm{O}] 2.0 . \mathrm{CO} ; 2$

Lorente, A., Beguería, S., Bathurst, J.C. \& García-Ruiz, J.M., 2003. Debris flow characteristics and relationships in the Central Spanish Pyrenees. Natural Hazards and Earth System Sciences, 3 (6): 683-692.

Lugon, R., Delaloye, R., Serrano, E., Reynard, E., Lambiel, C. \& González-Trueba, J.J., 2004. Permafrost and Little Ice Age relationships, Posets Massif, Central Pyrenees, Spain. Permafrost and Periglacial Processes, 15 (3): 207-220. http://dx.doi.org/10.1002/ppp.494

Marshall, S.J., Tarasov, L., Clarke, G.K. \& Peltier, W.R., 2000. Glaciological reconstruction of the Laurentide Ice Sheet: physical processes and modelling challenges. Canadian Journal of Earth Sciences, 37 (5): 769-793. http://dx.doi. org/10.1139/e99-113

Martí Bono, C. \& Puigdefábregas, J., 1983. Consecuencias geomorfológicas de las lluvias de noviembre de 1982 en las 
cabeceras de algunos valles pirenaicos. Estudios Geográficos, 170-171: 275-290.

Martí, C., Valero, B \& García-Ruiz, J.M., 1997. Large, historical debris flows in the Central Spanish Pyrenees. Physics and Chemistry of the Earth, 22 (3-4): 381-385. http://dx.doi. org/10.1016/S0079-1946(97)00162-6

Martín Moreno, R., 2004. Comparación de dos glaciares: Longyearbreen (Spitsbergen) y Monte Perdido (Pirineos). Características y evolución desde la Pequeña Edad del Hielo. Ería, 63: 5-22.

Martínez de Pisón, E. \& Arenillas Parra, M., 1988. Los glaciares actuales del Pirineo español. En: La nieve en el Pirineo español. Ministerio de Obras Públicas, Madrid, pp. 29-98.

Martínez de Pisón, E. \& Serrano, E., 1997. Morfología glaciar del Valle de Tena (Pirineo aragonés). En: A. Gómez Ortiz \& A. Pérez Alberti (eds.), Las huellas glaciares de las montañas españolas. Universidade de Santiago de Compostela: 239-261 pp., Santiago de Compostela.

Martínez-Castroviejo, R. \& García-Ruiz, J.M., 1990. Coladas de piedras (debris flows) y dinámica fluvial en ríos torrenciales del Pirineo Central: el caso del río Ijuez. Cuadernos de Investigación Geográfica, 16: 55-72.

Martínez-Castroviejo, R., García-Ruiz, J.M., Díez, J.C. \& Alvera, B., 1991. Coarse sediment transport in an experimental high mountain catchment of Central Pyrenees, Spain. Zeitschrift für Geomorphologie, Suppl. Bd, 83: 105-114.

Martínez-Fernández, J., López-Bermúdez, F., Martínez-Fernández, J. \& Romero-Díaz, A., 1995. Land use and soil-vegetation relationships in a Mediterranean ecosystem. Catena, 25 (1): 153167. http://dx.doi.org/10.1016/0341-8162(95)00007-F

Miras, Y., Ejarque, A., Riera, S., Palet, J.M., Orengo, H. \& Euba, I., 2007. Dynamique holocène de la végétation et occupation des Pyrénées andorranes depuis le Néolithique ancien, d'après l'analyse pollinique de la tourbière de Bosc dels Estanyons (2180m Vall de Madriu, Andorre). Comptes Rendus Palevol., 6: 291-300. http://dx.doi.org/10.1016/j.crpv.2007.02.005

Montserrat, J., 1992. Evolución glaciar y postglaciar del clima y la vegetación en la vertiente sur del Pirineo: Estudio palinológico. Instituto Pirenaico de Ecología, 147 pp., Zaragoza.

Montserrat Recoder, P., 1964. Ecología del pasto. Publicaciones del Centro Pirenaico de Biología Experimental, 1 (2): 1-68.

Moore, P., Webb, J.A. \& Collinson, A., 1991. Pollen analysis. 2nd edition, Blackwell Scientific Publications, 216 pp., Oxford.

Morellón, M., Valero-Garcés, B., Vegas-Villarrúbia, T., González-Sampériz, P., Romero, O., Delgado-Huertas, A., Mata, P., Moreno, A., Rico, M. \& Corella, P., 2009. Lateglacial and Holocene palaeohydrology in the western Mediterranean región: The Lake Estanya record (NE Spain). Quaternary Science Reviews, 28: 2582-2599. http://dx.doi.org/ 10.1016/j.quascirev.2009.05.014

Morellón, M., Pérez-Sanz, A., Corella, J.P., Büntgen, U., Catalán, J., González-Sampériz, P., González-Trueba, J.J., López-Sáez, J.A., Moreno, A., Pla-Rabes, S., Saz-Sánchez, M.Á., Scussolini, P., Serrano, E., Steinhilber, F., Stefanova, V., Vegas-Villarrúbia, T. \& Valero-Garcés, B., 2012. A multiproxy perspective on millennium-long climate variability in the southerm Pyrenees. Climate of the Past, 8 (2): 683700. http://dx.doi.org/10.5194/cp-8-683-2012

Morellón, M., Valero-Garcés, B., González-Sampériz, P., Vegas-Villarrúbia, T., Rubio, E., Rieradevall, M., DelgadoHuertas, A., Mata, P., Romero, O., Engstrom, D.R., LópezVicente, M., Navas, A. \& Soto, J., 2011. Climate changes and human activities recorded in the sediments of Lake Estanya (NE Spain) during the Medieval Warm Period and Little Ice Age. Journal of Paleolimnology, 46 (3): 423-452. http://dx.doi.org/10.1007/s10933-009-9346-3
Moreno, A., Belmonte, A., Bartolomé, M., Sancho, C., Oliva, B., Stoll, H., Edwards, L.R., Cheng, H. \& Hellstrom, J., 2013. Formación de espeleotemas en el noreste peninsular y su relación con las condiciones climáticas durante los últimos ciclos glaciares. Cuadernos de Investigación Geográfi$c a, 39$ (1): 25-47.

Moreno, A., Pérez, A., Frigola, J., Nieto-Moreno, V., RodrigoGámiz, M., Martrat, B., González-Sampériz, P., Morellón, M., Martín-Puertas, C., Corella, J.P., Belmonte, A., Sancho, C., Cacho, I., Herrera, G., Canals, M., Grimalt, J.O., JiménezEspejo, F., Martínez-Ruiz, F., Vegas-Villarrúbia, T. \& ValeroGarcés, B.L., 2012. The Medieval Climate Anomaly in the Iberian Peninsula reconstructed from marine and lake records. Quaternary Science Reviews, 43: 16-32. http://dx.doi. org/10.1016/j.quascirev.2012.04.007

Nadal-Romero, E., 2011. Las áreas de cárcavas (badlands) como fuente de sedimento en cuencas de montaña: procesos de meteorización, erosión y transporte en margas del Pirineo Central. Publicaciones del Consejo de Protección de la Naturaleza de Aragón, 377 pp., Zaragoza.

Nadal-Romero, E. \& Regüés, D., 2010. Geomorphological dynamics of subhumid mountain badland areas - weathering, hydrological and suspended sediment transport processes: A case study in the Araguás catchment (Central Pyrenees) and implications for altered hydroclimatic regimes. Progress in Physical Geography, 34 (2): 123-150. http://dx.doi.org/ 10.1177/0309133309356624

Nadal-Romero, E., Latron, J., Lana-Renault, N., Serrano-Muela, P., Martí-Bono, C. \& Regüés, D., 2008a. Temporal variability in hydrological response within a small catchment with badland areas, central Pyrenees. Hydrological Sciences Journal, 53 (3): 629-639. http://dx.doi.org/10.1623/hysj.53.3.629

Nadal-Romero, E., Latron, J., Martí-Bono, C. \& Regüés, D., 2008b. Temporal distribution of suspended sediment transport in a humid Mediterranean badland area: The Araguás catchment, Central Pyrenees. Geomorphology, 97: 601-616. http://dx.doi.org/10.1016/j.geomorph.2007.09.009

Nadal-Romero, E., Lasanta, T. \& García-Ruiz, J.M., 2013. Runoff and sediment yield from land under various uses in a Mediterranean mountain area: long-term results from an experimental station. Earth Surface Processes and Landforms, 38 (13): 346-355. http://dx.doi.org/10.1002/esp.3281

Nadal-Romero, E., Lana-Renault, N., Serrano-Muela, P., Regüés, D., Alvera, B. \& García-Ruiz, J.M., 2012a. Sediment balance in four catchments with different land cover in the Central Spanish Pyrenees. Zeitschrift für Geomorphologie, 56 (Suppl. 3): 147-165. http://dx.doi.org/10.1127/0372-8854/2012/S-00109

Nadal-Romero, E., Lasanta, T., González-Hidalgo, J.C., de Luis, M. \& García-Ruiz, J.M., 2012b. The effect of intense rainstorm events on the suspended sediment response under various land uses: The Aísa Valley Experimental Station. Cuadernos de Investigación Geográfica, 38 (1): 27-47.

Nadal-Romero, E., Serrano-Muela, M.P., Regüés, D., Lana-Renault, N. \& Cammeraat, E. enviado a. Hydrological response of a small afforestation catchment in a Mediterranean mountain area. Hydrological Research.

Nadal-Romero, E., Revuelto, J., Errea, M.P. \& López-Moreno, J.I., enviado b. Erosion and deposition processes determined by terrestrial laser scanner and photogrammetry in humid badlands in Central Spanish Pyrenees. Soil.

Navas, A., Machín, J. \& Soto, J. 2005. Assessing soil erosion in a Pyrenean mountain catchment using GIS and fallout 137Cs. Agriculture, Ecosystems and Environment, 105 (3): 493-506. http://dx.doi.org/10.1016/j.agee.2004.07.005

Nieto-Moreno, V., Martínez-Ruiz, F., Giralt, S., Jiménez-Espejo, S., Gallego-Torres, D., Rodrigo-Gámiz, M., GarcíaOrellana, J., Ortega-Huertas, M., de Lange, G.J., 2011. Tracking climate variability in the Western Mediterranean 
during the Late Holocene: a multiproxy approach. Climate of the Past, 7 (4): 1395-1414. http://dx.doi.org/10.5194/ cp-7-1395-2011

Nogués-Bravo, D., Araujo, M.B., Errea, M.P. \& Martínez-Rica, J.P., 2007. Exposure of global mountain systems to climate warming during the 21 st century. Global Environmental Change, 17 (3-4): 420-428. http://dx.doi.org/10.1016/j. gloenvcha.2006.11.007

Oliva, M. \& Gómez Ortiz, A., 2011. Holocene slope dynamics in Sierra Nevada (south Spain). Sedimentological analysis of solifluction landforms and lake deposits. Geological Society, London, Special Publications, 354: 227-239. http://dx.doi. org/10.1144/SP354.15

Oliva-Urcia, B., Moreno, A., Valero-Garcés, B., Mata, P. \& Grupo Horda, 2013. Magnetismo y cambios ambientales en registros terrestres: El lago de Marboré, Parque Nacional de Ordesa y Monte Perdido (Huesca). Cuadernos de Investigación Geográfica, 39 (1): 117-140.

Ortigosa, L.M., 1991. Las repoblaciones forestales en La Rioja: resultados y efectos geomorfológicos. Geoforma Ediciones, 149 pp., Logroño.

Ortigosa, L. \& García-Ruiz, J.M., 1995. Geomorphological consequences of afforestation at a basin scale, an example from the Central Pyrenees. Physics and Chemistry of the Earth, 20 (34): 345-349. http://dx.doi.org/10.1016/0079-1946(95)00047-X

Ortigosa, L., García-Ruiz, J.M. \& Gil, E., 1990. Land reclamation by reforestation in the Central Pyrenees. Mountain Research and Development, 10 (3): 281-288.

Palacios, D., Andrés, N., López-Moreno, J.I. \& García-Ruiz, J.M., 2015. Late Pleistocene deglaciation in the Central Pyrenees: The Upper Gállego Valley. Quaternary Research. http://dx.doi.org/10.1016/j.yqres.2015.01.010.

Pallàs, R., Rodés, A., Braucher, R., Bourlès, D., Delmas, M., Calvet, M. \& Gurnell, Y., 2010. Small, isolated glacial catchments as priority targets for cosmogenic surface exposure dating of Pleistoicene climate fluctuations, southeastern Pyrenees. Geology, 38 (10): 891-894. http://dx.doi.org/ 10.1130/G31164.1

Pascua Echegaray, E., 2012. Señores del Paisaje. Ganadería y recursos naturales en Aragón, siglos XIII-XVII. Universidad de Valencia, 327 pp, Valencia.

Pellitero, R., Serrano, E. \& González Trueba, J.J., 2011. Glaciares rocosos del sector central de la montaña cantábrica: indicadores paleoambientales. Cuadernos de Investigación Geográfica, 37 (2): 119-144.

Peña, J.L., Sancho, C., Lewis, C., McDonald, E. \& Rhodes, E., 2003. Las morrenas terminales de los valles glaciares del Gállego y Cinca (Pirineo de Huesca). Datos cronológicos. Boletín Glaciológico Aragonés, 4: 91-109.

Pérez-Obiol, R., Bal, M.C., Pèlachs, A., Cunill, R. \& Soriano, J.M., 2012. Vegetation dynamics and anthropogenically forced changes in the Estanilles peat bog (southern Pyrenees) during the last seven millennia. Vegetation History and Archaeobotany, 21:385-396. http://dx.doi.org/10.1007/s00334012-0351-5

Pérez Sanz, A., González-Sampériz, P., Valero-Garcés, B., Moreno, A., Morellón, M., Sancho, C., Belmonte, A., Gil-Romera, G., Sevilla, M. \& Navas, A., 2011. Clima y actividades humanas en la dinámica de la vegetación durante los últimos 2000 años en el Pirineo Central: El registro palinológico de la Basa de la Mora (Macizo de Cotiella). Zubía, 23: 17-38.

Pérez-Sanz, A., González-Sampériz, P., Moreno, A., ValeroGarcés, B., Gil-Romera, G., Rieradevall, M., Tarrats, P., Lasheras-Álvarez, L., Morellón, M., Belmonte, A., Sancho, C., Sevilla-Callejo, M. \& Navas, A., 2013. Holocene climate variability, vegetation dynamics and fire regime in the central Pyrenees: The Basa de la Mora sequence (NE
Spain). Quaternary Science Reviews, 73: 149-169. http:// dx.doi.org/10.1016/j.quascirev.2013.05.010

Pérez-Sanz, A. 2014. Holocene climate, vegetation and human impact in the Western Mediterranean inferred from Pyrenean lake records and climate models. Tesis Doctoral inédita, Universidad de Zaragoza, 194 pp., Zaragoza.

Pla, S. \& Catalán, J., 2005. Chrysophyte cysts from lake sediments reveal the submillennial winter/spring climate variability in the northwestern Mediterranean region throughout the Holocene. Climate Dynamics, 24: 263-278. http:// dx.doi.org/10.1007/s00382-004-0482-1

Playán, E. \& Mateos, L., 2006. Modernization and optimization of irrigation systems to increase water productivity. Agricultural Water Management, 80: 100-116. http://dx.doi. org/10.1016/j.agwat.2005.07.007

Puigdefábregas, J., 1970. Características de la inversión térmica en el extremo oriental de la depresión interior altoaragonesa. Publicaciones del Centro Pirenaico de Biología Experimental, 7 (1): 23-34.

Puigdefábregas, J., 1978. El abedul en el Pirineo. Estudios Geográficos, 153: 563-566.

Puigdefábregas, J. \& Alvera, B., 1986. Particulate and dissolved matter in snowmelt runoff from small watersheds. Zeitschrift für Geomorphologie Suppl. Bd, 58: 69-80.

Puigdefábregas, J. \& García-Ruiz, J.M., 1984. Dynamique des versants au niveau supraforestier: Glissements massifs des sols anciens dans les Pyrénées Centrales. Documents d'Ecologie Pyrénéenne, 3-4: 449-454.

Rasmussen, S.O., Bigler, M., Blockley, S.P., Blunier, T., Buchardt, S.L., Clausen, H.B., Cvijanovic, I., Dahl-Jensen, D., Johnsen, S.J., Fischer, H., Gkinis, V., Guillevic, M., Hoek, W.Z., Lowe, J.J., Pedro, J.B., Popp, T., Seierstad, I.K., Steffensen, J.P.., Svensson, A.M., Vallelonga, P., Vinther, B.M., Walker, M.J.C., Wheatley, J.J. \& Winstrup, M., 2014. A stratigraphic framework for abrupt climatic changes during the Last Glacial period based on three synchronized Greenland ice-core records: refining and extending the INTIMATE event stratigraphy. Quaternary Science Reviews, 106: 14-28. http://dx.doi.org/10.1016/j.quascirev.2014.09.007

Redondo Vega, J.M., Gómez Villar, A., González Gutiérrez, R.B. \& Santos González, J., 2010. Los glaciares rocosos de la Cordillera Cantábrica. Secretariado de Publicaciones, Universidad de León, 171 pp., León.

Revuelto, J., López-Moreno, J.I., Azorín-Molina, C., Arguedas, G., Vicente-Serrano, S.M. \& Serreta, A., 2013. Utilización de técnicas de láser escáner terrestre en la monitorización de procesos geomorfológicos dinámicos: el manto de nieve y heleros en áreas de montaña. Cuadernos de Investigación Geográfica, 39 (2): 335-357.

Riera, S., Wansard, G. \& Julià, R., 2004. 2000-year environmental history of a karstic lake in the Mediterranean PrePyrenees: the Estanya lakes (Spain). Catena, 55 (3): 293324. http://dx.doi.org/10.1016/S0341-8162(03)00107-3

Rijckborst, H., 1967. Hydrology of the Upper Garone basin (Valle de Arán, Spain). Leidse Geologische Mededelingen, 40: $1-74$.

Rubio Fernández, V. \& Hernández Santón, C., 1990. La evolución reciente del cauce del río Ara. Cuadernos de Investigación Geográfica, 16 (1-2): 99-108.

Ruiz Flaño, P., 1993. Procesos de erosión en campos abandonados del Pirineo. Geoforma Ediciones, 191 pp., Logroño.

Ruiz-Flaño, P., García-Ruiz, J.M. \& Ortigosa, L., 1992. Geomorphological evolution of abandoned fields. A case study in the Central Pyrenees. Catena, 19 (3-4): 301-308. http://dx.doi.org/10.1016/0341-8162(92)90004-U

Ruiz Sinoga, J.D. \& Martínez Murillo, J.F., 2012. Respuesta ecohidrológica de los suelos en campos abandonados (sur de España). Cuadernos de Investigación Geográfica, 38 (2): 31-51. 
Rull, V., González-Sampériz, P., Corella, J.P., Morellón, M. \& Giralt, S., 2011. Vegetation changes in the southern Pyrenean flank during the last millennium in relation to climate and human activities: the Montcortés lacustrine record. Journal of Paleolimnology, 46 (3): 387-404. http://dx.doi. org/10.1007/s10933-010-9444-2

Sabio Alcutén, A., 2011. Mediano, el ojo del pasado. Diputación Provincial de Huesca, 297 pp., Huesca.

Sanchís-Ibor, C. \& Segura-Beltrán, F., 2014. Spatial variability of cannel changes in a Mediterranean ephemeral stream in the last six decades (1946-2006). Cuadernos de Investigación Geográfica, 40 (1): 89-118.

Sanjuán, Y., Gómez-Villar, A., Nadal-Romero, E., Álvarez Martínez, J., Arnáez, J., Serrano-Muela, M.P., Rubiales, J.M., González-Sampériz, P. \& García-Ruiz, J.M., 2014. Linking land cover changes in the sub-alpine and montane belts to changes in a torrential river. Land Degradation \& Development. http://dx.doi.org/10.1002/ldr.2294

Saz, M.Á. \& Creus, J., 2001. El clima del Pirineo centrooriental desde el siglo XV: estudio dendroclimático del observatorio de Capdella. Boletín Glaciológico Aragonés, 2: $37-79$.

Schnurrenberger, D. Russell, J. \& Kelts K., 2003. Classification of lacustrine sediments based on sedimentary components. Journal of Paleolimnology, 29: 141-154.

Serrano Cañadas, E., 1991. Glacial evolution of the Upper Gállego Valley (Panticosa Mountains and Ribera de Biescas, Aragonese Pyrenees, Spain). Pirineos, 138: 83-104.

Serrano-Muela, M.P., Lana-Renault, N., Nadal-Romero, E., Regüés, D., Latron, J., Martí-Bono, C. \& García-Ruiz, J.M., 2008. Forests and their hydrological effects in Mediterranean mountains. The case of the Central Spanish Pyrenees. Mountain Research and Development, 28 (3-4): 279-285. http://dx.doi.org/10.1659/mrd.0876

Serrano-Muela, M.P., Nadal-Romero, E., Lana-Renault, N., González-Hidalgo, J.C., López-Moreno, J.I., Beguería, S., Sanjuan, Y. \& García-Ruiz, J.M., 2013. An exceptional rainfall event in the Central Western Pyrenees: Spatial patterns in discharge and impact. Land Degradation \& Development. http://dx.doi.org/10.1002/ldr.2221.

Serrano Notivoli, R., Mora Mur, D., Ollero Ojeda, A., Sánchez Fabra, M. \& Saz Sánchez, M.Á., 2014. Respuesta hidrológica al evento de precipitación de junio de 2013 en el Pirineo Central. Investigaciones Geográficas, 62: 5-21. http://dx.doi.org/ 10.14198/INGEO2014.62.01

Soler, M. \& Puigdefábregas, C., 1972. Esquema litológico del Alto Aragón Occidental. Pirineos, 106: 5-15.

Steffen, W., Sanderson, A., Tyson, P., Jäger, J., Matson, P., Moore III, B., Oldfield, F., Richardson, K., Schnellnhuber, H., Turner II, B. \& Wasson, R., Editors, 2004. Global Change and the Earth System: a planet under pressure. Executive summary. The IGBP Global Change Series. Springer-Verlag, Berlin, Heidelburg, 44 pp., New York.

Surian, N. \& Cisotto, A., 2007. Channel adjustments, bedload transport and sediment sources in a gravel-bed river, Brenta River, Italy. Earth Surface Processes and Landforms, 32 (11): 1641-1656. http://dx.doi.org/10.1002/esp.1591

Trimble, S.W., 1999. Decreased rates of alluvial sediment storage in the Coon Creek Basin, Wisconsin, 1975-93. Science, 285 (5431): 1244-1246. http://dx.doi.org/10.1126/science.285. 5431.1244

Utrilla, P. \& Rodanés, J.M., 1997. La actuación del hombre sobre el paisaje durante la Prehistoria en el Valle Medio del Ebro. In: García-Ruiz, J.M., López García, P. (Eds.), Acción humana y desertificación en ambientes mediterráneos. Instituto Pirenaico de Ecología-CSIC, pp. 61-98, Zaragoza.

Valero-Garcés, B.L., Navas, A. \& Machín, J., 1996-97. Una aproximación sedimentológica al aterramiento de embalses y la erosión en cuencas de montaña: El embalse de Barasona y la Cuenca del Ésera-Isábena (Pirineos Centrales, Huesca). Cuadernos de Investigación Geográfica, 22-23: 7-31.

Valero-Garcés, B.L., Navas, A., Machín, J., Walling, D., 1999. Sediment sources and siltation in mountain reservoirs: a case study from the Central Spanish Pyrenees. Geomorphology, 28: 23-41. http://dx.doi.org/10.1016/S0169-555X(98)00096-8

Valero-Garcés, B.L. \& Moreno, A. 2011. Iberan lacustrine records: responses to past and present global changes in the Mediterranean region. Journal of Paleolimnology, 46: 319325. http://dx.doi.org/10.1007/s10933-011-9559-0

Valero-Garcés, B. Oliva-Urcia, B., Moreno, A., Rico, M., Mata, P., Salazar, A. Rieradevall, M., García-Ruiz, J.M., Chueca, J., González-Sampériz, P., Pérez, A., Salabarnada, A., Pardo, A., Sancho, C., Barreiro, F., Bartolomé, M., García-Prieto, E., Gil-Romera, G., López-Merino, L., Sevilla-Callejo, M. \& Tarrats, P., 2013. Dinámica glacial, clima y vegetación en el Parque Nacional de Ordesa y Monte Perdido durante el Holoceno. In: Proyectos de Investigación en Parques Parques Nacionales (2009-2012), L. Ramírez \& B. Asensio (eds.), Organismo Autónomo Parques Nacionales, Madrid, pp. 7-37.

Valero-Garcés, B., González-Sampériz, P., Moreno, A. \& Grupo PaleoIPE. 2014. Paisajes y climas del último ciclo glacial en el NE de la Península Ibérica: una visión desde la evolución de los glaciares, lagos y espeleotemas. In: Geoecología, cambio ambiental y paisaje: homenaje al profesor José María García-Ruiz (J. Arnáez, P. González-Sampériz, T. Lasanta \& B.L. Valero-Garcés, eds.), Instituto Pirenaico de Ecología y Universidad de La Rioja: 19-49 pp., Logroño.

Van Asch, T.W.J., Buma, J. \& Van Beek, L.P.H., 1999. A view on some hydrological triggering systems in landslides. Geomorphology, 30 (1-2): 25-32. http://dx.doi.org/10.1016/ S0169-555X(99)00042-2

Vannière, B., Galop, D., Rendu, C. \& Davasse, B., 2001. Feu et pratiques agro-pastorales dans les Pyrénées-Orientales: le cas de la montagne d'Enveitg (Cerdagne, Pyrénées-Orientales, France). Revue Géographique des Pyrénées et du SudOuest, 11: 29-42.

Vicente-Serrano, S.M. \& López-Moreno, J.I., 2008. The nonstationary influence of the North Atlantic Oscillation on European precipitation. Journal of Geophysical Research-Atmosphere, 113: D20120. http://dx.doi.org/10.1029/2008JD 010382

Vicente-Serrano, S.M., Lasanta, T. \& Romo, A., 2005. Analysis of the spatial and temporal evolution of vegetation cover in the Spanish Central Pyrenees: the role of human management. Environmental Management, 34 (6): 802-818. http://dx.doi.org/10.1007/s00267-003-0022-5

Vicente-Serrano, S.M., López-Moreno, J.I. \& Beguería, S., 2007. La precipitación en el Pirineo español: diversidad espacial de las tendencias y escenarios futuros. Pirineos, 162: 43-69. http://dx.doi.org/10.3989/pirineos.2007.v162

Vicente-Serrano, S.M., Beguería, S., López-Moreno, J.I., GarcíaVera, M.Á. \& Stepanek, P., 2010. A complete daily precipitation database for North-East Spain: reconstruction, quality control and homogeneity. International Journal of Climatology, 30: 1146-1163. http://dx.doi.org/10.1002/joc. 1850

Vitousek, P.M., Mooney, H.A., Lubxhenko, J. \& Melillo, J.M., 1997. Human domination of earth's ecosystems. Science, 277: 494-499. http://dx.doi.org/10.1126/science.277.5325.494

Viviroli, D., Weingartner, R. \& Messerli, B., 2003. Assessing the hydrological significance of the world's mountains. Mountain Research and Development, 23 (1): 32-40. Doi: http://dx.doi.org/10.1659/0276-4741(2003)023[0032:ATHS $\mathrm{OT}] 2.0 . \mathrm{CO} ; 2$ 
Viviroli, D., Archer, D.R., Buytaert, W., Fowler, H.J., Greenwood, G.B., Hamlet, A.F., Huang, Y., Koboltschnig, G., Litaor, M.I., López-Moreno, J.I., Lorentz, S., Schädler, B., Schreier, H., Schwaiger, K., Vuille, M. \& Woods, R., 2011. Climate change and mountain water resources: overview and recommendations for research, management and policy. Hydrology and Earth System Sciences, 15 (2): 471-504. http://dx.doi.org/10.5194/hess-15-471-2011

White, S., García-Ruiz, J.M., Martí, C., Valero, B., Errea, M.P. \& Gómez-Villar, A., 1997. The 1996 Biescas campsite disaster in the Central Spanish Pyrenees, and its temporal and spatial context. Hydrological Processes, 11 (14): 1797-1812. http://dx.doi.
org/10.1002/(SICI)1099-1085(199711)11:14<1797:: AID-HYP605>3.0.CO;2-7

Wolman, M.G., 1954. A method of sampling coarse river-bed material. Transactions of the American Geophysical Union, 35 (6): 951-956. http://dx.doi.org/10.1029/TR035i006p00951

Zampieri, M., Scoccimarro, E., Gualdi, S. \& Navarra, A., 2015. Observed shift towards earlier spring discharge in the main Alpine rivers. Science of the Total Environment, 503: 222232. http://dx.doi.org/10.1016/j.scitotenv.2014.06.036

Zavala, L.M., de Celis, R. \& Jordán, A., 2014. How wildfires affect soil properties. A brief review. Cuadernos de Investigación Geográfica, 40 (2): 311-331. 